\title{
Solid State Lighting Program
}

\author{
FINAL REPORT
}

Nov. 1, 2013

\section{Phosphors for near UV-Emitting LEDs for Efficacious Generation of White Light}

Work Performed Under Agreement:

DE -EE0002003

Submitted By:

University of California, San Diego

9500 Gilman Dr.

La Jolla, CA 92093-0411

Principal Investigator:

Joanna McKittrick

858-735-7064 (phone)

858-534-5698 (fax)

jmckittrick@ucsd.edu

\author{
Submitted To: \\ U. S. Department of Energy \\ National Energy Technology Laboratory \\ Project Officer: Dr. Brian Dotson \\ E-Mail: Brian.Dotson@NETL.DOE.GOV
}

\begin{abstract}
Disclaimer: "This report was prepared as an account of work sponsored by an agency of the United States Government. Neither the United States Government nor any agency thereof, nor any of their employees, makes any warranty, express or implied, or assumes any legal liability or responsibility for the accuracy, completeness, or usefulness of any information, apparatus, product, or process disclosed, or represents that its use would not infringe privately owned rights. Reference herein to any specific commercial product, process, or service by trade name, trademark, manufacturer, or otherwise does not necessarily constitute or imply its endorsement, recommendation, or favoring by the United States Government or any agency thereof. The views and opinions of authors expressed herein do not necessarily state or reflect those of the United States Government or any agency thereof."
\end{abstract}




\section{TABLE OF CONTENTS}

1. Executive Summary

2. Project Description

2.1 Objectives - overview of research plan

2.2 Identification of phosphor host/activator combinations

2.3 Nanocrystalline phosphors

2.4 Electrophoretic deposition of phosphors

2.5 Identification of phosphor blends

2.6 Fabrication of UV-LED light source

2.7 Comparison to existing technology and potential improvements

3. Project activities

3.1 Project partners and roles

3.2 Results and discussion

3.3 Concluding remarks

4. Milestones and success criteria

4.1 Comparison to MYPP plan

5. Deliverables

6. Publications and presentations resulting from this work 
1. EXECUTIVE SUMMARY

1) We studied phosphors for near-UV (nUV) LED application as an alternative to blue LEDs currently being used in SSL systems. We have shown that nUV light sources could be very efficient at high current and will have significantly less binning at both the chip and phosphor levels. We identified phosphor blends that could yield $4100 \mathrm{~K}$ lamps with a CRI of approximately 80 and $\mathrm{LPW}_{\mathrm{nUV}, \mathrm{opt}}$ equal to 179 for the best performing phosphor blend. Considering the fact that the lamps were not optimized for light coupling, the results are quite impressive. The main bottleneck is an optimum blue phosphor with a peak near $440 \mathrm{~nm}$ with a full width half maximum of about $25 \mathrm{~nm}$ and a quantum efficiency of $>95 \%$. Unfortunately, that may be a very difficult task when we want to excite a phosphor at $\sim 400 \mathrm{~nm}$ with a very small margin for Stokes shift. Another way is to have all the phosphors in the blend having the excitation peak at $400 \mathrm{~nm}$ or slightly shorter wavelength. This could lead to a white light source with no body color and optimum efficacy due to no self-absorption effects by phosphors in the blend. This is even harder than finding an ideal blue phosphor, but not necessarily impossible.

2) With the phosphor blends identified, light sources using nUV LEDs at high current could be designed with comparable efficacy to those using blue LEDs. It will allow us to design light sources with multiple wattages using the same chips and phosphor blends simply by varying the input current. In the case of blue LEDs, this is not currently possible because varying the current will lower the efficacy at high current and alter the color point. With improvement of phosphor blends, control over CRI could improve. Less binning at the chip level and also at the phosphor blend level could reduce the cost of SSL light sources.

3) This study provided a deeper understanding of phosphor characteristics needed for LEDs in general and nUV LEDs in particular. Two students received Ph.D. degrees and three undergraduates participated in this work. Two of the undergraduate students are now in graduate school. The results were widely disseminated -20 archival journal publications (published, accepted or in preparation) and three conference proceedings resulted. The students presented their work at 11 different national/international conferences (32 oral or poster presentations) and the PI's delivered 12 invited, keynote or plenary lectures. 


\section{PROJECT DESCRIPTION}

\subsection{OBJECTIVES - OVERVIEW OF RESEARCH PLAN}

Task list:

1. Identification and development of novel phosphors for near UV LED source excitation $\left(\lambda_{\mathrm{ex}}=\right.$ $370-410 \mathrm{~nm})$

a. Search for novel host lattice-sensitizer-activator combinations for efficient absorption and emission

b. Nano-size phosphors for reduced scattering

i. Optimized for strong absorption in near UV and negligible visible absorption and low scattering coefficient in both visible and UV range

c. Targeted quantum efficiency $\sim 95 \%$

2. Development of core/shell nanophosphors

3. Electrophoretic deposition of phosphors

a. Conformal distribution

b. "Remote phosphor" configuration

i. Extraction efficiency $\left(\eta_{\text {ext }}\right)$ ultimately $\sim 95 \%$

4. Identification of phosphor blends for optimal CRI and CCT

5. Fabricate LED white-emitting lamp

a. Efficacy near $140 \mathrm{LPW}$

\subsection{IDENTIFICATION OF HOST/ACTIVATOR COMBINATIONS}

Identification of host/activator combinations will be performed by theoretical and analytical calculations, mainly based on the method developed by Dorenbos ${ }^{1}$. In this method, the emission wavelength of a wide band gap phosphor composition is a function of the energy of the free ion activator $\left(E_{F}\right)$, the crystal field depression, $D(A)$ and the Stokes shift, $S(A)$. The main question is then to identify hosts in which the $4 f$-to- $5 d$ excitation energy will lie in the spectral range of 380$400 \mathrm{~nm}$. During the last few years, Dorenbos empirically studied this problem and observed that energy, $E_{a}\left(R E^{3+}, A\right)(\mathrm{RE}=$ rare earth element) required to excite a $4 f$ electron to the lowest $5 d$ level split by the crystalline field depends on the free ion energy, $E_{F}\left(R E^{3+}\right)$ and crystal field depression in host, $A$ given by $D(A)$ is:

$$
E_{a}\left(R E^{3+}\right)=E_{F}\left(R E^{3+}\right)-D(A)
$$

This interesting relationship shows that excitation energies depend on two parameters: one depending on the rare earth ion and other depending on the host lattice $A$. This equation provides a theoretical framework to explore $4 f$-to $5 d$ transitions for a rare earth ion in a given host, if the $5 d$-to- $4 f$ transition energy is available for one rare earth ion in that host. The emission energies, $E_{e}\left(R E^{3+}, A\right)$ also satisfy a similar relationship:

$$
E_{e}\left(R E^{3+}\right)=E_{F}\left(R E^{3+}\right)-D(A)-S(A) .
$$

$S(A)$ describes the Stokes shift in host $A$ and is independent of the rare earth ions. Similar relations have been found to be valid for divalent ions. The validity of these expressions has been established both empirically and by a priori calculations for rare earth ions in solids.

Both Eqs. 1 and 2 have been found to be valid within $\pm 500 \mathrm{~cm}^{-1}$. Values of $E_{F}\left(R E^{3+}\right)$ are available for most ions. An extensive list of $D(A)$ has been tabulated by Dorenbos for trivalent

\footnotetext{
${ }^{1}$ P. Dorenbos, "The $5 \mathrm{~d}$ level positions of the trivalent lanthanides in inorganic compounds," J. Lumin. 91, 155 (2000)
} 
rare earth ions and a somewhat smaller list for divalent ions. For $\mathrm{Ce}^{3+}, E_{a}\left(C e^{3+}, A\right)$ can be shown to be:

$$
E_{a}\left(C e^{3+}\right)=49340\left(\mathrm{~cm}^{-1}\right)-D(A)
$$

Thus, for excitation in the spectral range of $380-400 \mathrm{~nm}$, hosts with $D(A)$ ranging from $23025-24340 \mathrm{~cm}^{-1}$ are needed. These are rather high values of $D(A)$ and can be obtained in iodides, some oxides, oxy-halides, sulfides and oxy-nitrides. A quick inspection of the data reported by Dorenbos reveals about twenty-four host lattices, some of which are employed as hosts for phosphors for UV LEDs. For some of them, $S(A)$ is also available which can be used to predict the $5 d$-to- $4 f$ emission energies. A thorough search of literature together with some exploratory studies of $\mathrm{Ce}^{3+}$ ions in yet to be considered novel hosts based on crystal structure data (for example the Inorganic Crystal Structure Database, ICSD) could add potential candidates for $\mathrm{Ce}^{3+}$ activation.

\subsection{NANOCRYSTALLINE PHOSPHORS}

Nanophosphors can be fabricated by a variety of chemical synthesis methods: combustion, coprecipitation and sol gel processing. In a combustion reaction, metal nitrates and a fuel (carbohydrazide or urea) are combined and the reaction is initiated at low temperature. The reaction is highly exothermic, resulting in a flame with a temperature in excess of $1200^{\circ} \mathrm{C}$. The resulting powders are nanocrystalline and single phase. In co-precipitation, a basic solution is added to an acidic aqueous solution of atomically mixed elements, resulting in precipitation of hydrous oxides that are subsequently heated at low temperatures to drive off residual organics and water. The nanocrystalline powders typically need to be heated to high temperatures to fully crystallize the structure.

Core-shell formation at the nanoscale is broadly used to stabilize nanoparticles or nanowires to enhance their optical, catalytic and magnetic properties. It has been shown that coating with both organic and inorganic shells, particularly inorganic shells, significantly enhances the photoluminescence of nanoparticles, due to the effective passivation of surface states that cause the non-radiative recombination of electron and holes in semiconductor nanocrystals.

\subsection{ELECTROPHORETIC DEPOSITION OF PHOSPHORS}

Electrophoretic deposition (EPD) is a technique in which charged particles dispersed in a liquid are deposited onto a substrate under the force of an applied electric field. EPD has many advantages besides its benign processing conditions, such as a high uniformity, the possibility of producing deposits fast and continuously, and a low level of contamination. The EPD cell simply consists of two vertical, parallel electrodes held in polycarbonate plates separated by a fixed distance. The cathode typically is a removable conducting substrate on which a LED diode can be connected surrounded by a stainless steel ring to create a uniform electric field. The anode is platinum gauze. The apparatus is placed in a beaker containing the slurry and connected to a high voltage, potentiostatic power supply.

\subsection{IDENTIFICATION OF PHOSPHOR BLENDS}

Using the spectral power distribution (SPD) of red, green and blue phosphors selected on the basis of fluorescence measurement, phosphor blends will be formed to achieve the desired color coordinates and color temperatures compatible with high efficacy. Our main objective will be to develop a white light source at $4100 \mathrm{~K}$ CCT with CRI $>80$. Such blend modeling programs are routinely used within OS for phosphor application in fluorescent lamps. 


\subsection{FABRICATION OF UV-LED LIGHT SOURCE}

Device fabrication will primarily take place using the phosphor layers developed at UCSD, and UV-emitting LED sources from within the company or obtained from commercial vendors. Using internally developed UV-LEDs at OSRAM Opto-Semiconductors will facilitate earlier integration of the technology developed in this project to a product. Several configurations are possible. Chips may be mounted either in a chip-on-board manner onto a flat substrate or mounted into a commercial LED package. Phosphor will be applied either in a "remote phosphor" configuration being developed at OS or applied directly on the chip as mentioned earlier.

\subsection{COMPARISON TO EXISTING TECHNOLOGY}

Fig. 1 compares the existing white-emitting light source in (a) with the proposed design in (b). Several significant differences are notable. First is the use of a UV-emitting LED instead of a blue-emitting LED. Second, nanophosphors with a core/shell morphology are deposited in a 'remote phosphor' configuration, on top of a transparent substrate. Third, the color coordinates, $\mathrm{CRI}$ and CCT can be finely tuned through use of various phosphor blends.

Using red-, green- and blue-emitting phosphors it will be possible to improve the CRI and CCT over that of the YAG:Ce ${ }^{3+} /$ blue-emitting LED. The extraction efficacy will be improved through utilization of nanophosphors configured with a remote phosphor design. The near-UV LED has less binning, which result in less lamp-to-lamp variation and a smaller current droop. All of these contribute to an improved white-emitting light source. Additionally, there is accessibility to any color through color conversion.

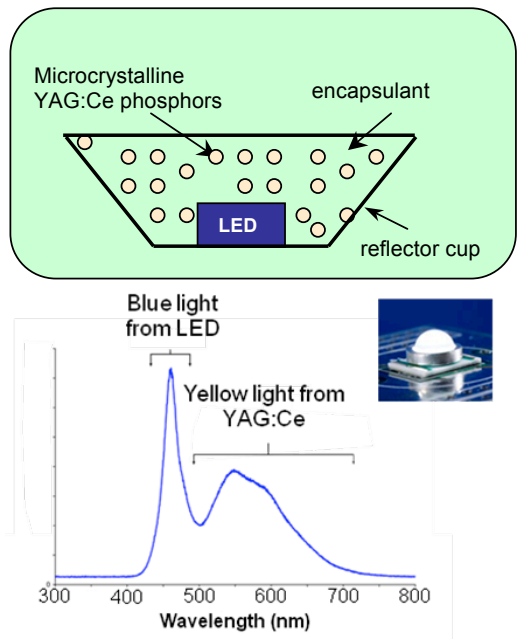

(a)

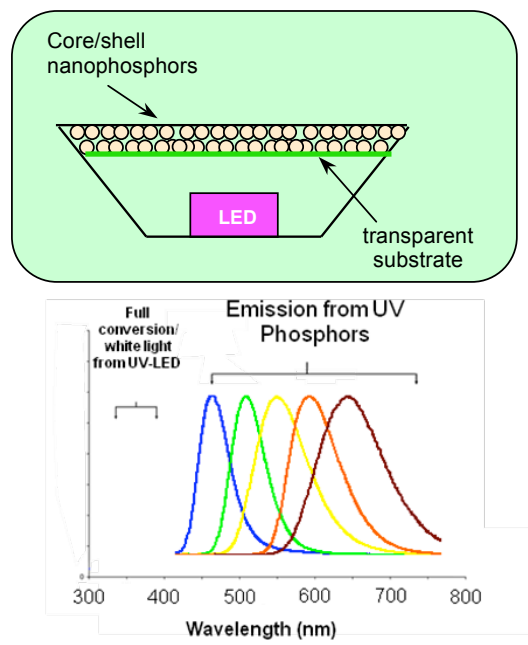

(b)

Fig. 1. Comparison of (a) current blue-emitting LED coupled with a yellow-emitting phosphor (YAG: $\mathrm{Ce}^{3+}$ ) and (b) proposed design with a UV-emitting LED with a blend of phosphors. 


\section{Project ACTIVIties}

The research results from Tasks 1-6 are discussed in this section.

1. Phase I

a. Task 1: Identification of phosphors for excitation in the spectral range of 370-410 $\mathrm{nm}(\mathrm{OS})$

b. Task 2: Synthesis and optimization of candidate phosphors for quantum efficiency

2. Phase II greater than $95 \%$ (OS, UCSD)

a. Task 3: Development of core/shell nanophosphors (UCSD)

b. Task 4: Successful development for integrating the phosphor with the LED by electrophoretic deposition (UCSD)

3. Phase III

a. Task 5: Development of phosphor blends for white light generation (OS)

b. Task 6: Fabrication of simple white light sources using candidate phosphor blends and LEDs with efficacy near $165 \mathrm{lpw}_{\mathrm{opt}}(\mathrm{OS})$

Note: This project was given a 6-mo. no-cost extension due to the delay in OS starting the project. The final agreement between UCSD and OS was not signed until 06/10, approximately nine months after UCSD started the project. However, we have caught up with our task progress. The project was also given a 6-mo. no-cost extension, from 03/28/13 to 09/30/13.

\subsection{PROJECT PARTNERS AND ROLES}

This is a collaborative work between UC San Diego (La Jolla, CA) and Osram Sylvania (Central Research, Beverly MA). The UCSD team consists of PI Prof. Joanna McKittrick, co-PI Prof. Jan Talbot, graduate students Jinkyu Han and Jae Ik Choi and undergraduate research students John Lee, Young Jin Kim and Juliette Micone. The UCSD team is responsible for synthesis and characterization of phosphors (McKittrick) and the electrophoretic deposition of phosphors (Talbot). The OS team consists of co-PI Dr. Kailash Mishra, and scientists Drs. Mark Hannah, Maria Anc, Dr. Miguel Galvez and Alan Piquette. The OS team is responsible for the identification of phosphor compositions (Mishra), quantum efficiency and thermal stability measurements (Hannah), development of phosphor blends and the fabrication of white-emitting light sources (Anc, Galvez, Piquette).

\subsection{RESULTS AND DISCUSSION}

Task 1 - Identification of phosphors for excitation in the spectral range of 370-410 $\mathrm{nm}$ We identified $20 \mathrm{Eu}^{2+}$ and $30 \mathrm{Ce}^{3+}$ activated phosphor compositions for near-UV excitation, as shown in Table I.

Table 1. Potential phosphor compositions identified for $\mathrm{Ce}^{3+}$ and $\mathrm{Eu}^{2+}$ activation Potential hosts for $\mathrm{Eu}^{2+}$ activation

\begin{tabular}{llcccccc}
\hline Host & $\begin{array}{c}\mathbf{D}(\mathbf{A}) \\
\mathbf{c m}^{-1}\end{array}$ & $\begin{array}{c}\mathbf{S}(\mathbf{A}) \\
\mathbf{c m}^{-1}\end{array}$ & $\begin{array}{c}\mathbf{E}_{\mathbf{a}} \\
\left(\mathbf{c m}^{-1}\right)\end{array}$ & $\begin{array}{c}\mathbf{E}_{\mathbf{a}} \\
(\mathbf{n m})\end{array}$ & $\begin{array}{c}\mathbf{E}_{\mathbf{e}} \\
\left(\mathbf{c m}^{-1}\right)\end{array}$ & $\begin{array}{c}\mathbf{E}_{\mathbf{e}} \\
(\mathbf{n m})\end{array}$ \\
\hline 1 & $\alpha-\mathrm{SrSiO}_{3}$ & 9610 & 1663 & 24390 & 410 & 22727 & 440 \\
2 & $\mathrm{Ba}_{2} \mathrm{Mg}_{\left(\mathrm{B}_{3} \mathrm{O}_{6}\right)_{2}}$ & 8359 & 2112 & 25641 & 390 & 23529 & 425 \\
\hline
\end{tabular}




\begin{tabular}{|c|c|c|c|c|c|c|c|}
\hline 3 & $\mathrm{Ba}_{2} \mathrm{SiO}_{4}$ & 10959 & 3240 & 23041 & 434 & 19801 & 505 \\
\hline 4 & $\mathrm{Ba}_{3} \mathrm{Mg}\left(\mathrm{SiO}_{4}\right)$ & 9610 & 1560 & 24390 & 410 & 22830 & 438 \\
\hline 5 & $\mathrm{BaAl}_{12} \mathrm{O}_{19}$ & 7684 & 3589 & 26316 & 380 & 22727 & 440 \\
\hline 6 & $\mathrm{BaMgAl}_{10} \mathrm{O}_{17}$ & 9490 & 2438 & 24510 & 408 & 22072 & 453 \\
\hline 7 & $\mathrm{Ca}_{2} \mathrm{~B}_{5} \mathrm{SiO}_{9}(\mathrm{OH})_{5}$ & 8359 & 3663 & 25641 & 390 & 21978 & 455 \\
\hline 8 & $\mathrm{Ca}_{3} \mathrm{Mg}\left(\mathrm{SiO}_{4}\right)_{2}$ & 9610 & 3159 & 24390 & 410 & 21231 & 471 \\
\hline 9 & $\mathrm{Ca} 3 \mathrm{Mg}_{3}\left(\mathrm{PO}_{4}\right)_{4}$ & 9610 & 1454 & 24390 & 410 & 22936 & 436 \\
\hline 10 & $\mathrm{CaB}(\mathrm{OH}) \mathrm{SiO}_{4}$ & 9068 & 1969 & 24932 & 401 & 22963 & 435 \\
\hline 11 & $\mathrm{CaMg}\left(\mathrm{SiO}_{4}\right)$ & 8529 & 2115 & 25471 & 393 & 23356 & 428 \\
\hline 12 & $\mathrm{CaMg}\left(\mathrm{SiO}_{4}\right)$ & 12495 & 3324 & 21505 & 465 & 18181 & 550 \\
\hline 13 & $\mathrm{LaMgAl}_{11} \mathrm{O}_{19}: \mathrm{Ce} 1$ & 8026 & 3752 & 25974 & 385 & 22222 & 450 \\
\hline 14 & $\mathrm{Sr}_{2} \mathrm{SiO}_{3} \mathrm{Cl}_{2}$ & 9610 & 3982 & 24390 & 410 & 20408 & 490 \\
\hline 15 & $\mathrm{Sr}_{2} \mathrm{SiO}_{4}$ & 8359 & 5233 & 25641 & 390 & 20408 & 490 \\
\hline 16 & $\mathrm{Sr}_{2} \mathrm{SiO}_{4}\left(2^{\text {nd }}\right.$ site $)$ & 3879 & 12263 & 30121 & 332 & 17858 & 560 \\
\hline 17 & $\mathrm{Sr}_{3} \mathrm{Mg}\left(\mathrm{SiO}_{4}\right)_{2}$ & 9610 & 2560 & 24390 & 410 & 21830 & 458 \\
\hline 18 & $\mathrm{SrAl}_{2} \mathrm{O} 4$ & 8747 & 2761 & 25253 & 396 & 22492 & 445 \\
\hline 19 & $\mathrm{SrAl}_{2} \mathrm{O} 4$ & 10636 & 4059 & 23364 & 428 & 19305 & 518 \\
\hline 20 & $\mathrm{SrMgAl}_{11} \mathrm{O}_{17}$ & 9309 & 3186 & 24691 & 405 & 21505 & 465 \\
\hline
\end{tabular}

Potential hosts for $\mathrm{Ce}^{3+}$ activation

\begin{tabular}{|c|c|c|c|c|c|c|c|}
\hline & Host & $\begin{array}{l}D(A) \\
\text { cm }^{-1}\end{array}$ & $\begin{array}{l}\text { S(A) } \\
\text { cm }^{-1}\end{array}$ & $\begin{array}{c}E_{a} \\
\left(\mathrm{~cm}^{-1}\right)\end{array}$ & $\begin{array}{c}E_{a} \\
(n m)\end{array}$ & $\begin{array}{c}E_{e} \\
\left(\mathrm{~cm}^{-1}\right)\end{array}$ & $\begin{array}{c}E_{e} \\
(n m)\end{array}$ \\
\hline 1 & $\mathrm{Ba}_{2} \mathrm{Lu}\left(\mathrm{BO}_{3}\right)_{2} \mathrm{Cl}$ & 22313 & 5568 & 27027 & 370 & 21459 & 466 \\
\hline 2 & $\mathrm{Ba}_{2} \mathrm{Y}\left(\mathrm{BO}_{3}\right)_{2} \mathrm{Cl}$ & 22313 & 5568 & 27027 & 370 & 21459 & 466 \\
\hline 3 & $\mathrm{BaAl}_{2} \mathrm{~S}_{4}$ & 23366 & 3452 & 25974 & 385 & 22522 & 444 \\
\hline 4 & $\mathrm{BaGa}_{2} \mathrm{~S}_{4}$ & 23230 & 3485 & 26110 & 383 & 22625 & 442 \\
\hline 5 & $\mathrm{CaAl}_{2} \mathrm{~S}_{4}$ & 24088 & 2525 & 25252 & 396 & 22727 & 440 \\
\hline 6 & $\mathrm{Ce}_{3}\left(\mathrm{SiS}_{4}\right)_{2} \mathrm{Br}$ & 23765 & 4253 & 25575 & 391 & 21322 & 469 \\
\hline 7 & $\mathrm{Ce}_{3}\left(\mathrm{SiS}_{4}\right)_{2} \mathrm{Cl}$ & 23567 & 4809 & 25773 & 388 & 20964 & 477 \\
\hline 8 & $\mathrm{Cs}_{3} \mathrm{Gd}_{2} \mathrm{I}_{9}$ & 23830 & 2146 & 25510 & 392 & 23364 & 428 \\
\hline 9 & $\mathrm{GeTaO}_{4}$ & 24038 & & 25302 & 395 & & \\
\hline 10 & LaOI & 23748 & 3083 & 25592 & 391 & 22509 & 444 \\
\hline 11 & $\mathrm{LiYGeO}_{4}$ & 23284 & & 26056 & 384 & & \\
\hline 12 & $\mathrm{LuOCl}$ & 24716 & & 24624 & 406 & & \\
\hline 13 & $\mathrm{Mg}_{3} \mathrm{~F}_{3} \mathrm{BO}_{3}$ & 24267 & 3980 & 25073 & 399 & 21093 & 474 \\
\hline 14 & $\mathrm{NaYGeO}_{4}$ & 23284 & & 26056 & 384 & & \\
\hline 15 & $\mathrm{SrAl}_{12} \mathrm{O}_{19}$ & 23816 & 2900 & 25524 & 392 & 22624 & 442 \\
\hline 16 & $\mathrm{SrAl}_{2} \mathrm{~S}_{4}$ & 24151 & 3544 & 25189 & 397 & 21645 & 462 \\
\hline 17 & $\mathrm{SrGa}_{2} \mathrm{~S}_{4}$ & 24950 & 2068 & 24390 & 410 & 22322 & 448 \\
\hline 18 & $\mathrm{SrLaAlO}_{4}$ & 24332 & & 25008 & 400 & & \\
\hline 19 & $\mathrm{SrY}_{2} \mathrm{O}_{4}$ & 24529 & 7332 & 24811 & 403 & 17479 & 572 \\
\hline 20 & $\mathrm{X} 1-\mathrm{Gd}_{2} \mathrm{SiO}_{5}$ & 20608 & 5511 & 28732 & 348 & 23221 & 431 \\
\hline
\end{tabular}




\begin{tabular}{llllllll}
\hline 21 & $\mathrm{X} 1-\mathrm{Gd}_{2} \mathrm{SiO}_{5}$ & 23298 & 4765 & 26042 & 384 & 21277 & 470 \\
22 & $\mathrm{X} 1-\mathrm{Y}_{2} \mathrm{SiO}_{5}$ & 22301 & 4141 & 27039 & 370 & 22898 & 437 \\
23 & $\mathrm{X} 2-\mathrm{Lu}_{2} \mathrm{SiO}_{5}$ & 21730 & 2625 & 27610 & 362 & 24985 & 400 \\
24 & $\mathrm{X} 2-\mathrm{Lu}_{2} \mathrm{SiO}_{5}$ & 22744 & 4951 & 26596 & 376 & 21645 & 462 \\
25 & $\mathrm{X}_{2}-\mathrm{Y}_{2} \mathrm{SiO}_{5}$ & 21484 & 3042 & 27856 & 359 & 24814 & 403 \\
26 & $\mathrm{X}_{2}-\mathrm{Y}_{2} \mathrm{SiO}_{5}$ & 23093 & 5413 & 26247 & 381 & 20834 & 480 \\
27 & $\mathrm{Y}_{2} \mathrm{Si}_{2} \mathrm{O}_{7} \mathrm{~N}_{2}$ & 23699 & 5232 & 25641 & 390 & 20409 & 490 \\
28 & $\mathrm{Y}_{3} \mathrm{AlGa}_{4} \mathrm{O}_{12}$ & 24480 & & 24860 & 402 & & \\
29 & $\mathrm{YOI}_{30}$ & 24815 & & 24525 & 408 & & \\
\hline
\end{tabular}

Non-radiative energy transfer

Since lanthanide line emitters have been so successfully used in fluorescent lamps and displays, it makes sense to consider them as candidates for nUV LED phosphors. The $4 f$ electrons of lanthanide ions in the $3+$ state $\left(\mathrm{Ln}^{3+}\right)$ are shielded from crystal fields due to the $5 \mathrm{~s}$ and $5 p$ electrons of the ligands; hence the crystal field effect is very small. Therefore, each $\mathrm{Ln}^{3+}$ is uniquely characterized by its multiplet structure arising from the $4 f^{\mathrm{n}}$ configuration, and the corresponding $f-f$ absorption/emission bands are narrow and relatively independent of the host materials. The $\mathrm{Ce}^{3+}$ ion is an exception and the broad band emission results from a $4 f \rightarrow 5 d$ transition. Among the divalent rare earth ions, $\mathrm{Sm}^{2+}$ is a line emitter due to transition within the $4 f^{n}$ manifold. Depending on the lanthanide ion, emission could cover the visible spectrum providing appropriate RGB phosphors for higher efficacy and improved color rendering. For example, $\mathrm{Tm}^{3+}$ is a known blue emitter, $\mathrm{Tb}^{3+}, \mathrm{Er}^{3+}$ and $\mathrm{Dy}^{3+}$ emit in the green-yellow region, and $\mathrm{Pr}^{3+}, \mathrm{Sm}^{3+}$ and $\mathrm{Eu}^{3+}$ emit in the orange-red region. However, since there are no line-emitting $\mathrm{Ln}$ ions except for $\mathrm{Tm}^{3+}$ that emit preferentially in the blue, and in most hosts, a significant portion of the $\mathrm{Tm}^{3+}$ emission is lost to the infrared, a line-emitting blue component using a $\mathrm{Ln}^{3+}$ ion as an activator is not a very practical option.

Many of the green and red line emitting phosphors such as $\mathrm{Y}_{2} \mathrm{O}_{3}: \mathrm{Eu}^{3+}$ and $\mathrm{LaPO}_{4}: \mathrm{Ce}^{3+}$, $\mathrm{Tb}^{3+}$ have high quantum efficiencies $(>90 \%)$ when excited by $254 \mathrm{~nm}$ radiation. In the case of $\mathrm{Eu}^{3+}$ in $\mathrm{Y}_{2} \mathrm{O}_{3}$, the excitation is through the charge transfer band and in $\mathrm{LaPO}_{4}: \mathrm{Ce}^{3+}, \mathrm{Tb}^{3+}, \mathrm{Tb}^{3+}$ is excited through energy transfer from $\mathrm{Ce}^{3+}$ that absorbs the $254 \mathrm{~nm}$ radiation. The direct excitation of the rare earth ions, in spite of the richness of energy levels in the spectral region of interest, is very weak when compared to $4 f \rightarrow 5 d$ transitions. The general strategy for fluorescent lamps was to excite $\mathrm{Ln}^{3+}$ through the charge transfer transition or $4 f \rightarrow 5 d$ transitions. Unfortunately, the charge transfer bands of $\mathrm{Eu}^{3+}$ in most oxides are located at energies significantly higher than the photon energies from nUV LEDs. For all other lanthanides for which the charge transfer bands have been observed, they occur at higher energies than $\mathrm{Eu}^{3+}$. Therefore, a narrow band phosphor based on a charge transfer band is very unlikely to be found among oxide hosts. Earlier, it was noted that direct excitation through $4 f \rightarrow 5 d$ bands is almost impossible in oxide hosts other than for $\mathrm{Ce}^{3+}$ and $\mathrm{Eu}^{2+}$. Therefore, designing a narrow band

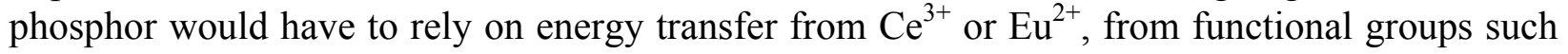
as molybdates or tungstates, or from direct excitation of the host material.

One approach to excite $\mathrm{Ln}^{3+}$ is through host excitation where an electron from the valence band is excited directly to the conduction band. Once in the conduction band, the energy can be transferred to a $\mathrm{Ln}$ ion. The excited $\mathrm{Ln}^{3+}$ then relaxes via an $f-f$ transition to generate the characteristic line emission. The exact mechanism is not well understood. It could be either 
capture of electron-hole pairs by the rare earth ion or Dexter-Förster energy transfer. $\mathrm{Dy}^{3+}$ is a classic example of a trivalent lanthanide that is often host-sensitized. The $\mathrm{Dy}^{3+}$ charge transfer state and $4 f \rightarrow 5 d$ energies are too large for $254 \mathrm{~nm}$ excitation, but in a host such as $\mathrm{Ga}_{2} \mathrm{O}_{3}$, there is bandgap absorption ( $260 \mathrm{~nm})$ and energy transfer leading to line emission. To use host excitation for a nUV approach the bandgap of the host would need to be in the $3.0 \mathrm{eV}-3.4 \mathrm{eV}$ range. Furthermore, to be efficient, the host would need to contain a trivalent cation to accommodate an $\mathrm{Ln}^{3+}$ activator. Gallium nitride fulfills those two requirements, but is not a good host for large ions due to the small size of $\mathrm{Ga}^{3+}$.

Similar to host excitation is excitation of $\mathrm{Ln}^{3+}$ by energy transfer from functional groups such as tungstates and molybdates. In this case, the exciting radiation is absorbed by a functional group within the host and then transferred to the $\mathrm{Ln}^{3+}$ activator. Typical tungstate and molybdate absorption bands are in the $250 \mathrm{~nm}-300 \mathrm{~nm}$ region, which again is not useful for a nUV LED lighting solution. However, there are examples of molybdates that absorb in the nUV, transfer that energy to $\mathrm{Eu}^{3+}$, and exhibit red emission (e.g. $\mathrm{Lu}_{6} \mathrm{MoO}_{12}: \mathrm{Eu}^{3+}$ ). Unfortunately, the QE values of such materials are typically very low.

The final type of sensitization is the use of other lanthanide ions. In this context, $\mathrm{Ce}^{3+}$ and $\mathrm{Eu}^{2+}$ are the most important sensitizer ions because their broadband $4 f-5 d$ transitions can be tuned to nUV energies. The idea is to find a suitable host that can be co-doped with either $\mathrm{Ce}^{3+}$ or $\mathrm{Eu}^{2+}$ and the $\mathrm{Ln}^{3+}$ line emitter(s) of choice. The $\mathrm{Ce}^{3+}$ or $\mathrm{Eu}^{2+}$ must absorb well in the $380 \mathrm{~nm}-$ $410 \mathrm{~nm}$ region and have an emission band that overlaps with at least one of the $f-f$ transitions in a given $\mathrm{Ln}^{3+}$ line emitter; preferably in the blue $(\sim 400 \mathrm{~nm}-500 \mathrm{~nm})$ range. Fig. 2 shows some of the possible energy levels for various $f-f$ transitions in the visible range for four different line emitters $\left(\mathrm{Pr}^{3+}, \mathrm{Sm}^{3+}, \mathrm{Eu}^{3+}\right.$ and $\left.\mathrm{Tb}^{3+}\right)$. All four of the selected narrowband emitters have at least one transition in the $400 \mathrm{~nm}-500 \mathrm{~nm}$ portion of the spectrum; most have several. If there is overlap between the emission of the $\mathrm{Ce}^{3+} / \mathrm{Eu}^{2+}$ and the $\mathrm{Ln}^{3+}$, there is the possibility of DexterFörster non-radiative energy transfer through a multipole-multipole interaction or a short range exchange interaction. These multipole-multipole and exchange interactions are allowed processes and can be quite efficient. An example of a well-known green-emitting fluorescent lamp phosphor that relies on $\mathrm{Ce}^{3+} \rightarrow \mathrm{Ln}^{3+}$ energy transfer is $\mathrm{LaPO}_{4}: \mathrm{Ce}^{3+}, \mathrm{Tb}^{3+}$. In terms of a red emitter, $\mathrm{Ce}^{3+}$ is typically not a good sensitizer for $\mathrm{Eu}^{3+}$ because of metal-to-metal charge transfer quenching, but it has been demonstrated that $\mathrm{Ce}^{3+}$ can sensitize $\mathrm{Eu}^{3+}$ indirectly through $\mathrm{Tb}^{3+}$, for example in $\mathrm{YBO}_{3}$. There have been experiments on $\mathrm{Ce}^{3+} \rightarrow \operatorname{Pr}^{3+}$ energy transfer in $\mathrm{Y}_{3} \mathrm{Al}_{5} \mathrm{O}_{12}: \mathrm{Ce}^{3+}, \mathrm{Pr}^{3+}$, but the $\mathrm{Pr}^{3+} \rightarrow \mathrm{Ce}^{3+}$ transfer efficiency was found to be higher than for $\mathrm{Ce}^{3+} \rightarrow \mathrm{Pr}^{3+}$. Similar studies were also done on $\mathrm{Ce}^{3+} \rightarrow \mathrm{Sm}^{3+}$ in a $\mathrm{Y}_{3} \mathrm{Al}_{5} \mathrm{O}_{12}$ host, but again, the transfer was not efficient. Even though there are a few instances of $\mathrm{Eu}^{2+} \rightarrow \mathrm{Ln}^{3+}$ such as in $\mathrm{Ca}_{10} \mathrm{~K}\left(\mathrm{PO}_{4}\right)_{7}: \mathrm{Eu}^{2+}, \mathrm{Tb}^{3+}, \mathrm{LiSrPO}_{4}: \mathrm{Eu}^{2+}, \mathrm{Tb}^{3+}$, and $\mathrm{NaSrPO}_{4}: \mathrm{Eu}^{2+}, \mathrm{Tb}^{3+}$ there are not many examples of $\mathrm{Eu}^{2+}$ sensitizing $\mathrm{Ln}^{3+}$ ions for narrowband green or, particularly, red emission. Part of the difficulty in using $\mathrm{Eu}^{2+}$ as a sensitizer is that the host must be able to accommodate both divalent and trivalent cations simultaneously or there is a charge imbalance. In the specific case of $\mathrm{Eu}^{2+} \rightarrow \mathrm{Eu}^{3+}$ transfer, it is also challenging to get $\mathrm{Eu}^{2+}$ and $\mathrm{Eu}^{3+}$ to simultaneously exist in the same host.

We investigated the possibility of designing a line emitting phosphor using $\mathrm{Y}_{3} \mathrm{Al}_{5} \mathrm{O}_{12}$ as host co-doped with $\mathrm{Sm}^{3+}$ and $\mathrm{Ce}^{3+}$. This system was chosen to generate a red emitting phosphor with energy transfer from the $\mathrm{Ce}^{3+}$ ions to $\mathrm{Sm}^{3+}$ ion. Unfortunately, while we did observe signature emission from the $\mathrm{Sm}^{3+}$ ions, it was primarily a result of directly exciting one of the $f-f$ transitions and not based on energy transfer from the $\mathrm{Ce}^{3+}$ ions. We did not further explore this 
system of phosphors for a variety of reasons. First, our main concern was with respect to saturation of the excited state of the rare earth ions due to their long radiative lifetime in the ms range. This could lead to saturation of emission from the trivalent ions at higher excitation energies, and therefore a color shift of the light source. Second, with spectral range of nUV radiation being limited to $380 \mathrm{~nm}-420 \mathrm{~nm}$, emission and absorption of radiation from both the sensitizer and activator ions being limited to the spectral region from $450 \mathrm{~nm}-650 \mathrm{~nm}$, it does not allow a large interval on the energy scale to accommodate a Stokes shift of the broad band emitter, and at the same time to meet the requirement of overlap of the emission spectrum of the sensitizer and the absorption spectrum of the activator ions to bring about a successful energy transfer. This problem is somewhat similar to

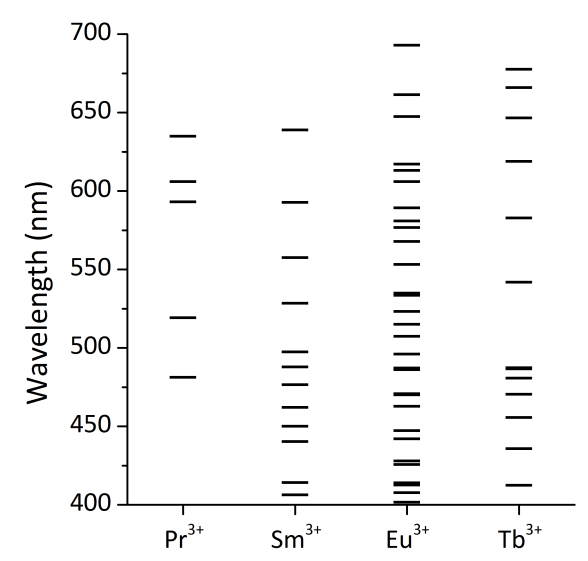

Fig. 2. Energy level diagrams for $\mathrm{Pr}^{3+}, \mathrm{Sm}^{3+}, \mathrm{Eu}^{3+}$ and $\mathrm{Tb}^{3+}$ ions based on $\mathrm{LaF}: \mathrm{Ln}^{3+}$. For convenience, the transition energies have been converted to the wavelength domain. designing a blue emitting phosphor upon excitation by nUV radiation. Finally, the constraint on available time to do a thorough job in this area was not available within the scope of this project. It is a challenging area for phosphor design. Unlike blue emitting LEDs, the nUV sources promise a better chance to design such a phosphor. This calls for long term basic research activities at universities or national labs.

\section{Task 2 - Synthesis and optimization of candidate phosphors for quantum efficiency greater}

\section{than 95\%}

We have synthesized numerous compositions including silicate, phosphate, oxyfluoride, and oxychloride phosphors activated with $\mathrm{Eu}^{2+}$. Tables 2-4 list some of the blue, green-yellow, and red emitting phosphors that we have synthesized and some of their luminescent characteristics. We have varied the activator concentration and the amounts of alkaline earth elements to optimize both the QE and thermal stability.

Table 2. Luminescence properties of candidate blue emitting phosphors for near UV-LEDs application.

\begin{tabular}{|c|c|c|c|c|c|c|}
\hline Group & Family & Activator & Composition & $\begin{array}{l}\text { Excitation } \\
\text { peak }(\mathrm{nm})\end{array}$ & $\begin{array}{c}\text { Excitation at } \\
380-400 \mathrm{~nm} \\
(\%)^{*}\end{array}$ & $\begin{array}{c}\text { Emission } \\
\text { peak } \\
(\mathrm{nm}) \\
\end{array}$ \\
\hline \multirow{11}{*}{ Phosphate } & \multirow{7}{*}{$\mathrm{ABPO}_{4}$} & \multirow{7}{*}{$\mathrm{Eu}^{2+}$} & $\mathrm{LiCaPO}_{4}$ & 400 & 100 & 475 \\
\hline & & & $\mathrm{LiSrPO}_{4}$ & 350 & 75 & 450 \\
\hline & & & $\mathrm{LiBaPO}_{4}$ & 350 & 80 & 480 \\
\hline & & & $\mathrm{NaBaPO}_{4}$ & 280 & 75 & 442 \\
\hline & & & $\mathrm{KCaPO}_{4}$ & 292 & 80 & 473 \\
\hline & & & $\mathrm{KSrPO}_{4}$ & 325 & 80 & 425 \\
\hline & & & $\mathrm{KBaPO}_{4}$ & 320 & 80 & 435 \\
\hline & \multirow{2}{*}{$\mathrm{AB}_{2}\left(\mathrm{PO}_{4}\right)_{2}$} & \multirow{2}{*}{$\mathrm{Eu}^{2+}$} & $\mathrm{SrMg}_{2}\left(\mathrm{PO}_{4}\right)_{2}$ & 375 & 90 & 420 \\
\hline & & & $\mathrm{SrZn}_{2}\left(\mathrm{PO}_{4}\right)_{2}$ & 365 & 85 & 416 \\
\hline & $\mathrm{A}_{3} \mathrm{~B}_{3}\left(\mathrm{PO}_{4}\right)_{4}$ & $\mathrm{Eu}^{2+}$ & $\mathrm{Ca}_{3} \mathrm{Mg}_{3}\left(\mathrm{PO}_{4}\right)_{4}$ & 300 & 70 & 450 \\
\hline & $\mathrm{A}_{2} \mathrm{P}_{2} \mathrm{O}_{7}$ & $\mathrm{Eu}^{2+}$ & $\mathrm{Ca}_{2} \mathrm{P}_{2} \mathrm{O}_{7}$ & 330 & 70 & 416 \\
\hline
\end{tabular}




\begin{tabular}{|c|c|c|c|c|c|c|}
\hline & & & $\mathrm{Sr}_{2} \mathrm{P}_{2} \mathrm{O}_{7}$ & 300 & 75 & 420 \\
\hline & $\mathrm{A}_{9} \mathrm{~B}\left(\mathrm{PO}_{4}\right)_{7}$ & $\mathrm{Eu}^{2+}$ & $(\mathrm{Ca}, \mathrm{Mg}, \mathrm{Sr})_{9} \mathrm{Y}\left(\mathrm{PO}_{4}\right)_{7}$ & $280-360$ & $65-85$ & $435-490$ \\
\hline \multirow{6}{*}{$\begin{array}{c}\text { Halo- } \\
\text { phosphate } \\
\text { and } \\
\text { silicate }\end{array}$} & $\mathrm{A}_{2} \mathrm{PO}_{4} \mathrm{Cl}$ & $\mathrm{Eu}^{2+}$ & $\mathrm{Ca}_{2} \mathrm{PO}_{4} \mathrm{Cl}$ & 360 & 85 & 454 \\
\hline & \multirow{3}{*}{$\mathrm{A}_{5}\left(\mathrm{PO}_{4}\right)_{3} \mathrm{Cl}$} & \multirow{3}{*}{$\mathrm{Eu}^{2+}$} & $\mathrm{Sr}_{5}\left(\mathrm{PO}_{4}\right)_{3} \mathrm{Cl}$ & 345 & 90 & 445 \\
\hline & & & $\mathrm{Ca}_{4.47} \mathrm{Mg}_{0.7}\left(\mathrm{PO}_{4}\right)_{3} \mathrm{Cl}_{9}$ & - & - & 453 \\
\hline & & & $\mathrm{Ca}_{5}\left(\mathrm{PO}_{4}\right)_{3} \mathrm{Cl}$ & 375 & 90 & 459 \\
\hline & $\mathrm{A}_{3} \mathrm{AlO}_{4} \mathrm{~F}$ & $\mathrm{Ce}^{3+}(<0.5 \%)$ & $(\mathrm{Sr}, \mathrm{Ba})_{3} \mathrm{AlO}_{4} \mathrm{~F}$ & 400 & 100 & 472 \\
\hline & $\mathrm{A}_{5} \mathrm{SiO}_{4} \mathrm{Cl}_{6}$ & $\mathrm{Eu}^{2+}$ & $\mathrm{Ba}_{5} \mathrm{SiO}_{4} \mathrm{Cl}_{6}$ & 380 & 100 & 440 \\
\hline \multirow{8}{*}{ Silicate } & \multirow{3}{*}{$\mathrm{A}_{3} \mathrm{MgSi}_{2} \mathrm{O}_{8}$} & \multirow{3}{*}{$\mathrm{Eu}^{2+}$} & $\mathrm{Ba}_{3} \mathrm{MgSi}_{2} \mathrm{O}_{8}$ & 330 & 70 & 440 \\
\hline & & & $\mathrm{Sr}_{3} \mathrm{MgSi}_{2} \mathrm{O}_{8}$ & 330 & 55 & 465 \\
\hline & & & $\mathrm{Ca}_{3} \mathrm{MgSi}_{2} \mathrm{O}_{8}$ & 375 & 95 & 475 \\
\hline & $\mathrm{A}_{2} \mathrm{MgSi}_{2} \mathrm{O}_{7}$ & $\mathrm{Eu}^{2+}$ & $\mathrm{Sr}_{2} \mathrm{MgSi}_{2} \mathrm{O}_{7}$ & 365 & 65 & 476 \\
\hline & $\mathrm{AMgSi}_{2} \mathrm{O}_{6}$ & $\mathrm{Eu}^{2+}$ & $\mathrm{CaMgSi}_{2} \mathrm{O}_{6}$ & 365 & 75 & 450 \\
\hline & \multirow{2}{*}{$\mathrm{A}_{2} \mathrm{BSiO}_{4}$} & $\mathrm{Eu}^{2+}$ & $\mathrm{Li}_{2} \mathrm{CaSiO}_{4}$ & 380 & 100 & 480 \\
\hline & & & $\mathrm{Li}_{2} \mathrm{BaSiO}_{4}$ & 350 & 60 & 490 \\
\hline & $\mathrm{AB}_{2} \mathrm{Si}_{3} \mathrm{O}_{10}$ & $\mathrm{Ce}^{3+}$ & $\mathrm{BaY}_{2} \mathrm{Si}_{3} \mathrm{O}_{10}$ & 334 & 30 & 404 \\
\hline
\end{tabular}

Table 3. Luminescence properties of candidate green-yellow emitting phosphors for near UV-LEDs application.

\begin{tabular}{|c|c|c|c|c|c|c|}
\hline Group & Family & Activator & Composition & $\begin{array}{l}\text { Excitation } \\
\text { peak }(\mathrm{nm})\end{array}$ & $\begin{array}{c}\text { Excitation at } \\
380-400 \mathrm{~nm} \\
(\%)^{*} \\
\end{array}$ & $\begin{array}{c}\text { Emission } \\
\text { peak }(\mathrm{nm})\end{array}$ \\
\hline Phosphate & $\mathrm{ABPO}_{4}$ & $\mathrm{Eu}^{2+}$ & $\mathrm{NaCaPO}_{4}$ & 395 & 100 & 505 \\
\hline \multirow{5}{*}{$\begin{array}{l}\text { Halo- } \\
\text { silicate } \\
\text { and } \\
\text { aluminate }\end{array}$} & $\mathrm{A}_{3}\left(\mathrm{SiO}_{4}\right) \mathrm{Cl}_{2}$ & $\mathrm{Eu}^{2+}$ & $\mathrm{Ca}_{3} \mathrm{SiO}_{4} \mathrm{Cl}_{2}$ & 368 & 90 & 505 \\
\hline & \multirow{2}{*}{$\mathrm{A}_{3} \mathrm{AlO}_{4} \mathrm{~F}$} & \multirow{2}{*}{$\mathrm{Ce}^{3+}(>0.5 \%)$} & $(\mathrm{Sr}, \mathrm{Ba})_{3} \mathrm{AlO}_{4} \mathrm{~F}$ & 400 & 100 & 502 \\
\hline & & & $(\mathrm{Sr}, \mathrm{Ca})_{3}(\mathrm{Al}, \mathrm{Si}) \mathrm{O}_{4+\mathrm{z}} \mathrm{F}_{1-\mathrm{z}}$ & 405 & 95 & 540 \\
\hline & \multirow{2}{*}{$\mathrm{A}_{8} \mathrm{~B}_{2}\left(\mathrm{SiO}_{4}\right)_{4} \mathrm{Cl}_{2}$} & \multirow{2}{*}{$\mathrm{Eu}^{2+}$} & $\mathrm{Ca}_{8} \mathrm{Mg}\left(\mathrm{SiO}_{4}\right)_{4} \mathrm{Cl}_{2}$ & 365 & 85 & 510 \\
\hline & & & $\mathrm{Ca}_{8} \mathrm{Zn}\left(\mathrm{SiO}_{4}\right)_{4} \mathrm{Cl}_{2}$ & 450 & 80 & 505 \\
\hline \multirow{8}{*}{ Silicate } & \multirow{3}{*}{$\mathrm{A}_{2} \mathrm{SiO}_{4}$} & \multirow{3}{*}{$\mathrm{Eu}^{2+}$} & $\mathrm{Ba}_{2} \mathrm{SiO}_{4}$ & 360 & 95 & 510 \\
\hline & & & $\mathrm{Sr}_{2} \mathrm{SiO}_{4}$ & $330-380$ & $80-100$ & $545-570$ \\
\hline & & & $(\mathrm{Ba}, \mathrm{Sr})_{2} \mathrm{SiO}_{4}$ & $510-570$ & $80-100$ & $510-570$ \\
\hline & \multirow{3}{*}{$\mathrm{A}_{2} \mathrm{BSi}_{2} \mathrm{O}_{7}$} & \multirow{3}{*}{$\mathrm{Eu}^{2+}$} & $\mathrm{Ba}_{2} \mathrm{MgSi}_{2} \mathrm{O}_{7}$ & 380 & 100 & 505 \\
\hline & & & $\mathrm{Ba}_{2} \mathrm{ZnSi}_{2} \mathrm{O}_{7}$ & 353 & 90 & 500 \\
\hline & & & $\mathrm{Ca}_{2} \mathrm{MgSi}_{2} \mathrm{O}_{7}$ & 395 & 100 & 541 \\
\hline & $\mathrm{A}_{2} \mathrm{BSiO}_{4}$ & $\mathrm{Eu}^{2+}$ & $\mathrm{Li} 2 \mathrm{SrSiO} 4$ & 310 & 90 & 565 \\
\hline & $\mathrm{A}_{3} \mathrm{SiO}_{5}$ & $\mathrm{Ce}^{3+}$ & $\mathrm{Sr}_{3} \mathrm{SiO}_{5}$ & 405 & 95 & 520 \\
\hline \multirow{3}{*}{ Aluminate } & \multirow{2}{*}{$\mathrm{AAl}_{2} \mathrm{O}_{4}$} & \multirow{2}{*}{$\mathrm{Eu}^{2+}$} & $\mathrm{SrAl}_{2} \mathrm{O}_{4}$ & 310 & 80 & 517 \\
\hline & & & $\mathrm{BaAl}_{2} \mathrm{O}_{4}$ & 350 & 75 & 498 \\
\hline & $\mathrm{A}_{4} \mathrm{Al}_{12} \mathrm{O}_{25}$ & $\mathrm{Eu}^{2+}$ & $\mathrm{Sr}_{4} \mathrm{Al}_{12} \mathrm{O}_{25}$ & 360 & 95 & 495 \\
\hline Borate & $\mathrm{A}_{3} \mathrm{~B}_{2} \mathrm{O}_{6}$ & $\mathrm{Eu}^{2+}$ & $\mathrm{Sr}_{3} \mathrm{~B}_{2} \mathrm{O}_{6}$ & 360 & 75 & 578 \\
\hline \multirow{8}{*}{$\begin{array}{c}\text { Nitride } \\
\text { and } \\
\text { oxynitride }\end{array}$} & b-SiAlON & $\mathrm{Eu}^{2+}$ & $\mathrm{Si}_{6-\mathrm{z}} \mathrm{Al}_{\mathrm{z}} \mathrm{O}_{\mathrm{z}} \mathrm{N}_{8-\mathrm{z}}$ & 300 & 80 & 535 \\
\hline & \multirow{5}{*}{$\mathrm{ASi}_{2} \mathrm{O}_{2} \mathrm{~N}_{2}$} & \multirow{5}{*}{$\mathrm{Eu}^{2+}$} & $\mathrm{SrSi}_{2} \mathrm{O}_{2} \mathrm{~N}_{2}$ & 390 & 100 & 570 \\
\hline & & & $\mathrm{CaSi}_{2} \mathrm{O}_{2} \mathrm{~N}_{2}$ & 350 & 95 & 560 \\
\hline & & & $\mathrm{BaSi}_{2} \mathrm{O}_{2} \mathrm{~N}_{2}$ & 300 & 80 & 500 \\
\hline & & & $(\mathrm{Sr}, \mathrm{Ca}) \mathrm{Si}_{2} \mathrm{O}_{2} \mathrm{~N}_{2}$ & $350-390$ & $80-100$ & $538-555$ \\
\hline & & & $(\mathrm{Sr}, \mathrm{Ba}) \mathrm{Si}_{2} \mathrm{O}_{2} \mathrm{~N}_{2}$ & $300-390$ & $80-100$ & $495-564$ \\
\hline & $\mathrm{A}_{3} \mathrm{Si}_{6} \mathrm{O}_{12} \mathrm{~N}_{2}$ & \multirow{2}{*}{$\mathrm{Ce}^{3+}$} & $\mathrm{Ba}_{3} \mathrm{Si}_{6} \mathrm{O}_{12} \mathrm{~N}_{2}$ & 420 & 90 & 527 \\
\hline & $\mathrm{A}_{4} \mathrm{Si}_{2} \mathrm{O}_{7} \mathrm{~N}_{2}$ & & $\mathrm{Y}_{4} \mathrm{Si}_{2} \mathrm{O}_{7} \mathrm{~N}_{2}$ & 390 & 100 & 500 \\
\hline
\end{tabular}




\begin{tabular}{|l|l|l|l|l|l|l|}
\hline & $\mathrm{A}_{2} \mathrm{Si}_{3} \mathrm{O}_{3} \mathrm{~N}_{4}$ & & $\mathrm{Y}_{2} \mathrm{Si}_{3} \mathrm{O}_{3} \mathrm{~N}_{4}$ & 390 & 100 & 500 \\
\hline
\end{tabular}

Table 4. Luminescence properties of candidate orange-red emitting phosphors for near UV-LEDs application.

\begin{tabular}{|c|c|c|c|c|c|c|}
\hline Group & Family & Activator & Composition & $\begin{array}{l}\text { Excitation } \\
\text { peak }(\mathrm{nm})\end{array}$ & $\begin{array}{c}\text { Excitation at } \\
380-400 \mathrm{~nm} \\
(\%)\end{array}$ & $\begin{array}{l}\text { Emission } \\
\text { peak }(\mathrm{nm})\end{array}$ \\
\hline \multirow{8}{*}{ Phosphate } & \multirow{2}{*}{$\mathrm{AB}_{2}\left(\mathrm{PO}_{4}\right)_{2}$} & \multirow{2}{*}{$\mathrm{Eu}^{2+}-\mathrm{Mn}^{2+}$} & $\mathrm{SrMg}_{2}\left(\mathrm{PO}_{4}\right)_{2}$ & 375 & 90 & 675 \\
\hline & & & $\mathrm{SrZn}_{2}\left(\mathrm{PO}_{4}\right)_{2}$ & 365 & 85 & 613 \\
\hline & $\mathrm{A}_{3} \mathrm{~B}_{3}\left(\mathrm{PO}_{4}\right)_{4}$ & $\mathrm{Eu}^{2+}-\mathrm{Mn}^{2+}$ & $\mathrm{Ca}_{3} \mathrm{Mg}_{3}\left(\mathrm{PO}_{4}\right)_{4}$ & 300 & 70 & 625 \\
\hline & \multirow{2}{*}{$\mathrm{A}_{2} \mathrm{P}_{2} \mathrm{O}_{7}$} & \multirow{2}{*}{$\mathrm{Eu}^{2+}-\mathrm{Mn}^{2+}$} & $\mathrm{Ca}_{2} \mathrm{P}_{2} \mathrm{O}_{7}$ & 330 & 70 & 600 \\
\hline & & & $\mathrm{Sr}_{2} \mathrm{P}_{2} \mathrm{O}_{7}$ & 300 & 75 & 585 \\
\hline & \multirow{3}{*}{$\mathrm{A}_{9} \mathrm{~B}\left(\mathrm{PO}_{4}\right)_{7}$} & \multirow{3}{*}{$\mathrm{Eu}^{2+}-\mathrm{Mn}^{2+}$} & $(\mathrm{Ca}, \mathrm{Mg}, \mathrm{Sr})_{9} \mathrm{Y}\left(\mathrm{PO}_{4}\right)_{7}$ & $280-360$ & $65-85$ & 632 \\
\hline & & & $\mathrm{Ca}_{9} \mathrm{La}\left(\mathrm{PO}_{4}\right)_{7}$ & 340 & 80 & 635 \\
\hline & & & $\mathrm{Ca}_{9} \mathrm{Lu}\left(\mathrm{PO}_{4}\right)_{7}$ & 290 & 50 & 645 \\
\hline $\begin{array}{c}\text { Halo- } \\
\text { phosphate }\end{array}$ & $\mathrm{A}_{5}\left(\mathrm{PO}_{4}\right)_{3} \mathrm{Cl}$ & $\mathrm{Eu}^{2+}-\mathrm{Mn}^{2+}$ & $\mathrm{Ca}_{5}\left(\mathrm{PO}_{4}\right)_{3} \mathrm{Cl}$ & 375 & 90 & 585 \\
\hline \multirow{6}{*}{ Silicate } & \multirow{2}{*}{$\mathrm{A}_{3} \mathrm{MgSi}_{2} \mathrm{O}_{8}$} & \multirow{2}{*}{$\mathrm{Eu}^{2+}-\mathrm{Mn}^{2+}$} & $\mathrm{Ba}_{3} \mathrm{MgSi}_{2} \mathrm{O}_{8}$ & 330 & 70 & 620 \\
\hline & & & $\mathrm{Sr}_{3} \mathrm{MgSi}_{2} \mathrm{O}_{8}$ & 330 & 55 & 685 \\
\hline & $\mathrm{AMgSi}_{2} \mathrm{O}_{6}$ & $\mathrm{Eu}^{2+}-\mathrm{Mn}^{2+}$ & $\mathrm{CaMgSi}_{2} \mathrm{O}_{6}$ & 365 & 75 & 580,680 \\
\hline & \multirow{2}{*}{$\mathrm{A}_{3} \mathrm{SiO}_{5}$} & \multirow{2}{*}{$\mathrm{Eu}^{2+}$} & $\mathrm{Sr}_{3} \mathrm{SiO}_{5}$ & 400 & 100 & 580 \\
\hline & & & $(\mathrm{Sr}, \mathrm{Ba})_{3} \mathrm{SiO}_{5}$ & 400 & 100 & $580-610$ \\
\hline & $\mathrm{A}_{2} \mathrm{SiO}_{4}$ & $\mathrm{Eu}^{2+}$ & $(\mathrm{Sr}, \mathrm{Ca})_{2} \mathrm{SiO}_{4}$ & 400 & 100 & 600 \\
\hline \multirow{3}{*}{ Nitride } & \multirow{3}{*}{$\mathrm{A}_{2} \mathrm{Si}_{5} \mathrm{~N}_{8}$} & \multirow{3}{*}{$\mathrm{Eu}^{2+}$} & $\mathrm{Sr}_{2} \mathrm{Si}_{5} \mathrm{~N}_{8}$ & 400 & 100 & $610-680$ \\
\hline & & & $\mathrm{Ca}_{2} \mathrm{Si}_{5} \mathrm{~N}_{8}$ & 395 & 100 & 610 \\
\hline & & & $\mathrm{Ba}_{2} \mathrm{Si}_{5} \mathrm{~N}_{8}$ & 400 & 100 & $570-680$ \\
\hline
\end{tabular}

Blue-emitting phosphors $\left(\lambda_{\text {em }}=430-490 \mathrm{~nm}\right)$

$\mathrm{ABPO}_{4}(\mathrm{~A}=\mathrm{Li}, \mathrm{Na}, \mathrm{K}, \mathrm{B}=\mathrm{Ca}, \mathrm{Sr}, \mathrm{Ba})$ activated with $\mathrm{Eu}^{2+}$ families were studied. $\mathrm{LiCaPO}_{4}: \mathrm{Eu}^{2+}$ was found to have superior luminescence properties for near UV-LED application among the $\mathrm{ABPO}_{4}: \mathrm{Eu}^{2+}$ family as shown in Fig. 3. The QE of $\mathrm{LiCaPO}_{4}: \mathrm{Eu}^{2+}$ is $88 \%$ under $400 \mathrm{~nm}$ excitation. In addition, $\mathrm{LiCaPO}_{4}: \mathrm{Eu}^{2+}$ phosphor has an excellent excitation profile in the near UV range. However, when $\mathrm{LiCaPO}_{4}$ is prepared by solid state reaction appreciable amounts of $\mathrm{Li}_{3} \mathrm{PO}_{4}$ and $\mathrm{Ca}_{3}\left(\mathrm{PO}_{4}\right)_{2}$ are present as secondary phases. In order to improve the phase purity and synthesize sub-micron sized powders, a sol-gel method with a re-annealing step at $800^{\circ} \mathrm{C}$ was employed.

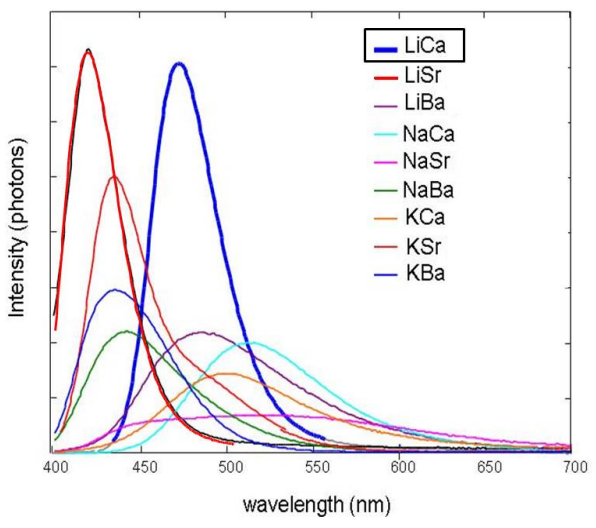

Fig. 3. PL emission spectra of $\mathrm{ABPO}_{4}: \mathrm{Eu}^{2+}(\mathrm{A}=\mathrm{Li}, \mathrm{Na}, \mathrm{K}, \mathrm{B}=\mathrm{Ca}, \mathrm{Sr}$, $\mathrm{Ba})$ phosphors.

The PL emission spectra of both samples excited at $400 \mathrm{~nm}$ are shown in Fig 4 . The PL spectra consist of a strong, broad, blue band centered around $470 \mathrm{~nm}$ attributed to the allowed $4 \mathrm{f}^{6} 5 \mathrm{~d} \rightarrow 4 \mathrm{f}^{7}$ transition of $\mathrm{Eu}^{2+}$. The emission intensity of the submicron sized re-annealed powder is higher than that of the powder annealed only at $1150^{\circ} \mathrm{C}$. The $\mathrm{QE}$ of the re-annealed powder increased from $62 \%$ to $\sim 80 \%$. It is obvious that the phase purity of $\mathrm{Li}\left(\mathrm{Ca}_{1-\mathrm{x}} \mathrm{Eu}_{\mathrm{x}}\right) \mathrm{PO}_{4}$ plays a crucial role in improving its luminescence properties. 
However, we have found $\left(\mathrm{Sr}_{1-\mathrm{x}} \mathrm{Ca}_{\mathrm{x}}\right)_{5}\left(\mathrm{PO}_{4}\right)_{3} \mathrm{Cl}_{1-}$ ${ }_{\mathrm{y}} \mathrm{F}_{\mathrm{y}}: \mathrm{Eu}^{2+}$ (SCAP) to be the optimal blue-emitting phosphor, which has a peak emission around 450 (Fig. 5). This phosphor is much better suited for these blends as it has much better excitation from $380 \mathrm{~nm}$ to $410 \mathrm{~nm}$ than our previous blues, and because of its emission peak, SCAP is better for color steering.

Green-yellow-emitting phosphors $\left(\lambda_{e m}=500-580\right.$ nm)

$\left(\mathrm{Ba}_{1-\mathrm{x}} \mathrm{Sr}_{\mathrm{x}}\right) \mathrm{SiO}_{4}: \mathrm{Eu}^{2+}(0 \leq \mathrm{x} \leq 1)$ phosphors have excellent thermal stability and a strong greenyellow emission centered around 510-570 nm depending on $\mathrm{x}$. The best composition is for $\left[\mathrm{Eu}^{2+}\right]$ $=3 \%-$ a substantial decrease in emission intensity occurs for $\left[\mathrm{Eu}^{2+}\right]<3 \%$. Fig. 6(a) shows the effect of $x$ on the emission spectra - the peak is red-

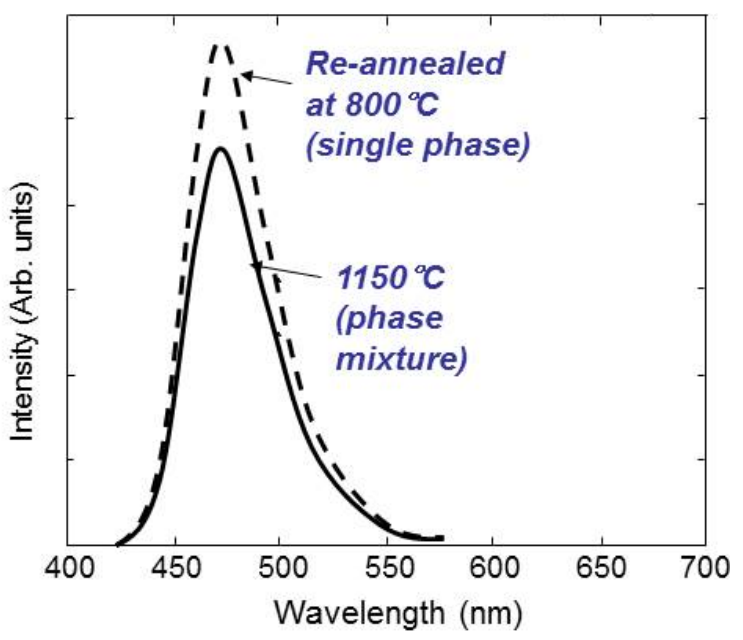

Fig. 4. PL emission spectra of $\mathrm{Li}\left(\mathrm{Ca}_{0.99} \mathrm{Eu}_{0.01}\right) \mathrm{PO}_{4}$ annealed at $1150^{\circ} \mathrm{C}$ and re-annealed at $800^{\circ} \mathrm{C}$. shifted as the amount of Sr increases. For these compounds, two the PL spectra is composed of emission from Eu from two different sites. One site (Site 1) is coordinated by 10 oxygen ions and another site (Site 2) is surrounded by 9 oxygen ions. The dominant contribution is ascribed to the emission by Site 1 . The peak intensity has a maximum for $\mathrm{x}=0.25$. QE measurements were taken on the three samples and the sample with $x=0$ has the highest at $94 \%$. This is a significant result as we have shown that nanophosphors with $\mathrm{QE} \sim 95 \%$ has been achieved, one of our milestones for this project. Fig $6 \mathrm{~b}$ shows QE values for solid-state reacted powders as a function of $\mathrm{x}$. As shown, the highest $\mathrm{QE}$ values are for the yellow-emitting composition at $\mathrm{x}=1$ and the green-emitting powder for $\mathrm{x}=0.25$. The difference between the $\mathrm{QE}$ values for the nano and micron-sized powders could be due to slight differences in the stoichiometries, due to the two processing conditions.

However, these nanophosphors prepared by sol-gel/Pechni method are severely agglomerated and non-spherical, which may not increase the light extraction efficiency significantly. A novel co-precipitation method using a nonaqueous solvent $\mathrm{N}, \mathrm{N}$-dimethylformamide (DMF) has been

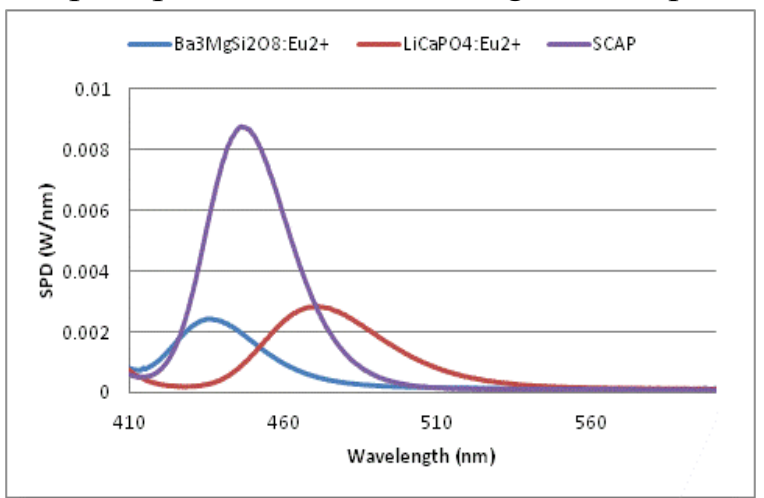

Fig. 5. Emission profile of the new SCAP blue phosphor compared to $\mathrm{Ba}_{3} \mathrm{MgSi}_{2} \mathrm{O}_{8}: \mathrm{Eu}^{2+}$ and $\mathrm{LiCaPO}_{4}: \mathrm{Eu}^{2+}$, other blue-emitting phosphors. developed to produce $\left(\mathrm{Ba}_{1-\mathrm{x}} \mathrm{Sr}_{\mathrm{x}}\right)_{2} \mathrm{SiO}_{4}: \mathrm{Eu}^{2+}$ phosphors with near-spherical, nano/submicron size particles with a narrow size distribution and high quantum efficiency. Fig. 7(a)-(d) shows the SEM micrographs of $\left(\mathrm{Ba}_{1-\mathrm{x}} \mathrm{Sr}_{\mathrm{x}} \mathrm{Eu}_{0.03}\right)_{2} \mathrm{SiO}_{4}(x=0$, $0.25,0.75,1)$ post-annealed at $1100^{\circ} \mathrm{C}$. These powders are near-spherical with diameters ranging from $100 \mathrm{~nm}$ - $300 \mathrm{~nm}$ and are uniformly distributed. The emission peak position as a function of $x$ is shown in Fig. 6(e). The peak position red-shifts as $x$ increases, which is attributed to the crystal field effect. The quantum efficiencies of powders are $82-90 \%$ under $400 \mathrm{~nm}$ excitation, which is slightly less than for our micron-sized powders (QE 95\%), but it is similar 

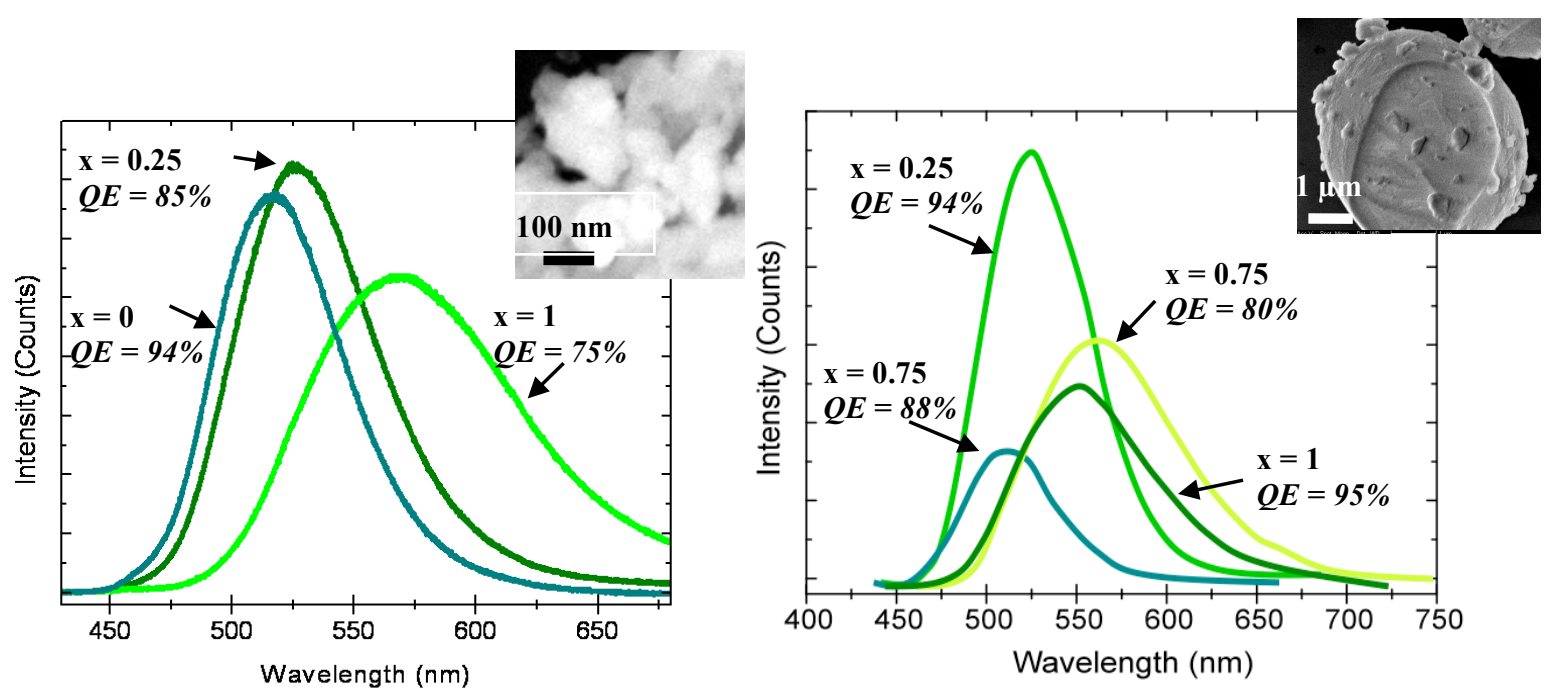

Fig. 6. PL emission intensity of $\left(\mathrm{Ba}_{1-\mathrm{x}} \mathrm{Sr}_{\mathrm{x}}\right) \mathrm{SiO}_{4}: \mathrm{Eu}^{2+}$ as a function of $\mathrm{x}$. (a) Sol gel/Pechini chemical synthesis of nanophosphors. Inset shows a particle size of 100-200 nm. $\lambda_{\text {ex }}=380 \mathrm{~nm}$. (b) solid state reacted powders.

to commercialized $\mathrm{Y}_{3} \mathrm{Al}_{5} \mathrm{O}_{12}: \mathrm{Ce}^{3+}$ phosphors $(\mathrm{QE} \sim 85 \%)$. These high quantum efficiencies indicate that nano/submicron sized $\mathrm{Ba}_{2} \mathrm{SiO}_{4}: \mathrm{Eu}^{2+}$ phosphors are very promising green emitters for application in white-emitting near-UV LEDs.
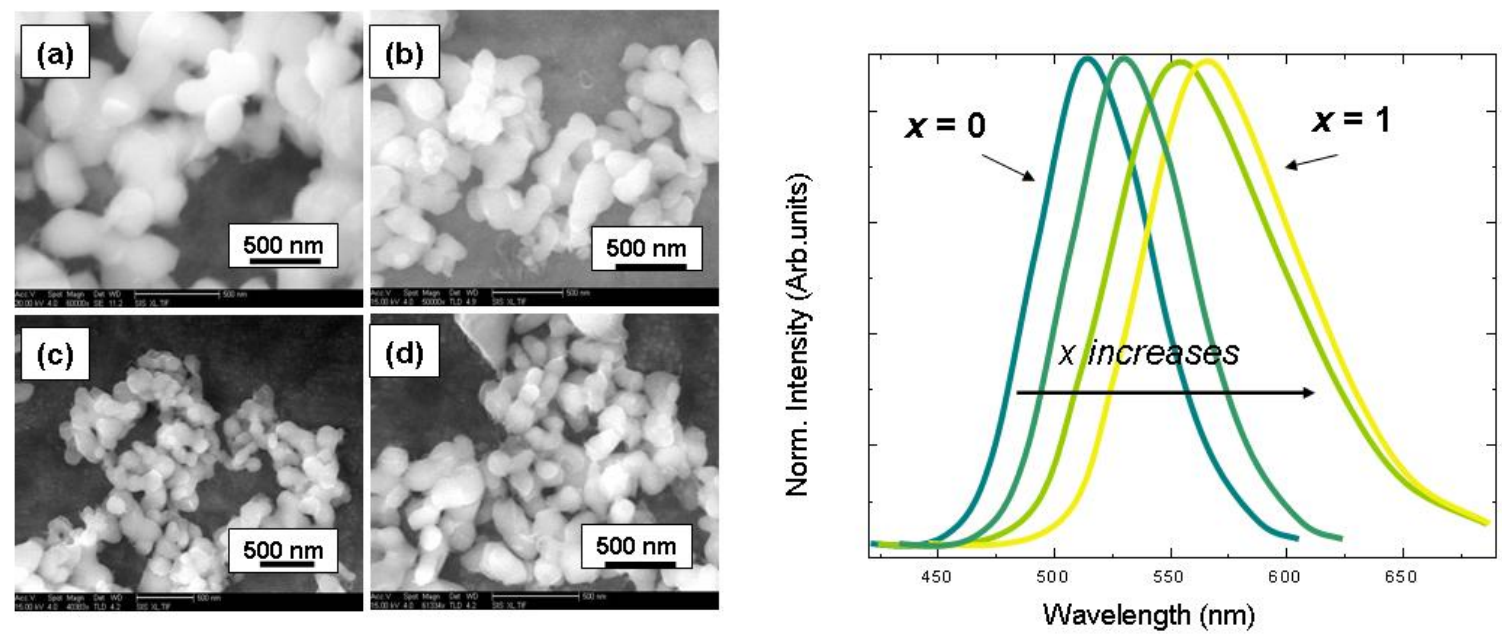

Fig. 7. SEM micrographs of $\left(\mathrm{Ba}_{1-\mathrm{x}} \mathrm{Sr}_{\mathrm{x}} \mathrm{Eu}_{0.03}\right)_{2} \mathrm{SiO}_{4}$ for (a) $x=0$, (b) $x=0.25$, (c) $x=0.75$, and (d) $x=1$ and (e) PL emission spectra of $\left(\mathrm{Ba}_{1-\mathrm{x}} \mathrm{Sr}_{\mathrm{x}} \mathrm{Eu}_{0.03}\right)_{2} \mathrm{SiO}_{4}(\mathrm{x}=0,0.25,0.75$, and 1)

The particle morphology of these phosphors is significantly dependent on the synthetic method. Fig. 8 (a)-(e) shows the SEM micrograph of $\left(\mathrm{Ba}_{1-\mathrm{x}} \mathrm{Sr}_{\mathrm{x}}\right) \mathrm{SiO}_{4}: \mathrm{Eu}^{2+}$ at $\mathrm{x}=1$ prepared by hydrothermal, solid-state reaction, combustion, co-precipitation and sol-gel method, respectively. The particle sizes prepared by hydrothermal and co-precipitation are $300-500 \mathrm{~nm}$ with nearly spherical shape. However, the morphology prepared by sol-gel and combustion method is needlelike and the length of the both particles is near $1 \mu \mathrm{m}$ and width is $50 \mathrm{~nm}$. Furthermore, the particles prepared by combustion method are agglomerated. The particles prepared by solid-state reaction are large and very agglomerated: the size is $\sim 5 \mu \mathrm{m}$. This demonstrates that the 
synthetic method plays an important role in determining particle size and morphology. In addition, the quantum efficiencies of theses powders range from $\sim 80-95 \%$ depending on the synthetic method.
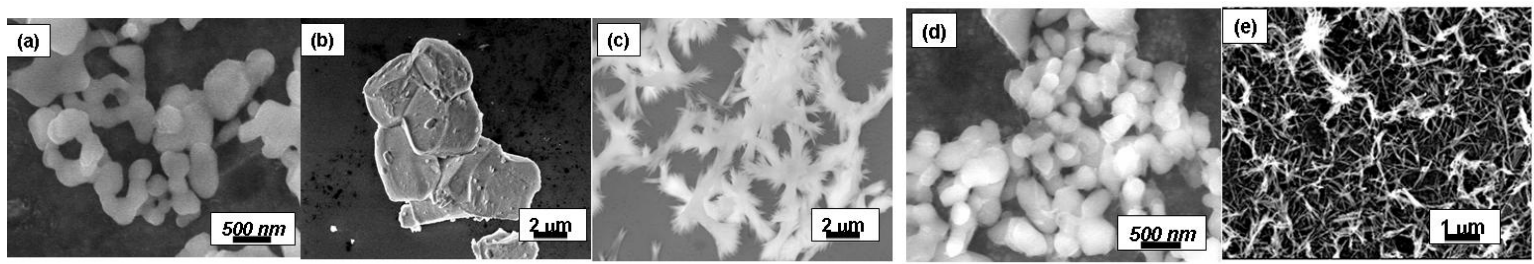

Fig. 8. SEM micrographs of $\mathrm{Sr}_{2} \mathrm{SiO}_{4}: \mathrm{Eu}^{2+}$ prepared by (a) hydrothermal, (b) solid-state reaction (c) combustion, (d) co-precipitation, and (e) sol-gel method.

Thermal stability is of great importance, since most phosphors degrade when operating at high temperature. Although the estimated temperature of phosphors in a commercially available white-emitting LED is between $150-200^{\circ} \mathrm{C}$, this is still enough thermal energy to reduce the QE. We have made thermal stability measurements, as shown in Fig. 9. Samples of $\left(\mathrm{Ba}_{1-\mathrm{x}} \mathrm{Sr}_{\mathrm{x}}\right)_{2} \mathrm{SiO}_{4}: \mathrm{Eu}^{2+}$ and $\mathrm{LiCaPO}_{4}: \mathrm{Eu}^{2+}$ were cooled to $80 \mathrm{~K}$ and then warmed to $500 \mathrm{~K}$ while monitoring the lifetime. At $450 \mathrm{~K}$ the lifetime of both phosphors retains $>95 \%$ of the lifetime at $80 \mathrm{~K}$, indicating that these compositions have excellent thermal stability.

When white light is generated from a two or three phosphor blend there will be significant chances for reabsorption of the higher energy photons. This will cause heat to build up in the phosphors and reduce the quantum efficiency. By using multiple activator ions, researchers have tried to avoid this problem with multiple emissions from single phase phosphors.

We can tune the emission of a phosphor by

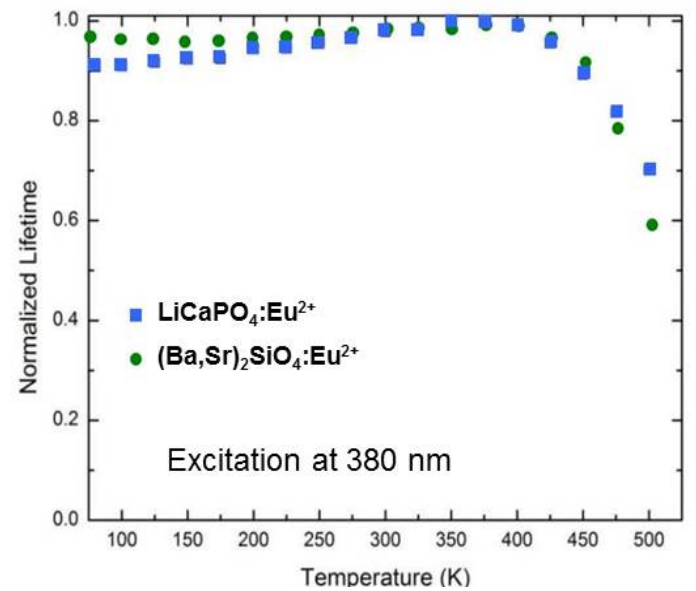

Fig. 9. Lifetime of $\mathrm{LiCaPO}_{4}: \mathrm{Eu}^{2+}$ and $(\mathrm{Ba}, \mathrm{Sr})_{2} \mathrm{SiO}_{4}: \mathrm{Eu}^{2+}$ phosphors as a function on temperature. producing solid solutions of compatible host crystals.

Fig. 10(a) and (b) show the emission spectra of $\mathrm{Eu}^{2+}$ activated $\left(\mathrm{KSrPO}_{4}\right)_{1-\mathrm{x}}\left(\mathrm{Ba}_{2} \mathrm{SiO}_{4}\right)_{\mathrm{x}}(\mathrm{KBPSO})$ and $\left(\mathrm{KSrPO}_{4}\right)_{1-\mathrm{x}}\left(\mathrm{Sr}_{2} \mathrm{SiO}_{4}\right)_{\mathrm{x}}(\mathrm{KSPSO})$ solid solutions, respectively. As $x$ increases, the ratio of the PL intensity at $490 \mathrm{~nm}$ to $430 \mathrm{~nm}$ increases. There are two sites in each compound. One site (site 1 ) is surrounded by 10 oxygen ions and another site (site 2) is surrounded by 9 oxygen ions. In the solid solution, $\mathrm{K}$ atoms (site 1) in $\mathrm{KSrPO}_{4}$ (weak emission) are replaced by $\mathrm{Ba}$ or $\mathrm{Sr}$ atoms from site 1 (strong emission) in $(\mathrm{Ba}, \mathrm{Sr})_{2} \mathrm{SiO}_{4}$; and $\mathrm{Sr}$ atoms (site 2) in $\mathrm{KSrPO}_{4}$ (strong emission) are replaced by $\mathrm{Ba}$ or $\mathrm{Sr}$ atoms from site 2 (weak emission) in $(\mathrm{Ba}, \mathrm{Sr})_{2} \mathrm{SiO}_{4}$ and thus the intensity at $490 \mathrm{~nm}$ increases and intensity at $430 \mathrm{~nm}$ decreases with increasing $x$.

The emission spectra $\left(\lambda_{\mathrm{ex}}=380 \mathrm{~nm}\right)$ of KBPSO and KSPSO at $x=0.1$, which showed the highest emission intensity compared to blue-emitting, sub-micron, $\mathrm{LiCaPO}_{4}$ : $\mathrm{Eu}^{2+}$ phosphor $(\mathrm{QE}$ $\sim 80 \%$ ). While the QE values for KBPSO and KSPSO were not measured, the fluorescence intensities of KBPSO and KSPSO are comparable to that of $\mathrm{LiCaPO}_{4}: \mathrm{Eu}^{2+}$. 


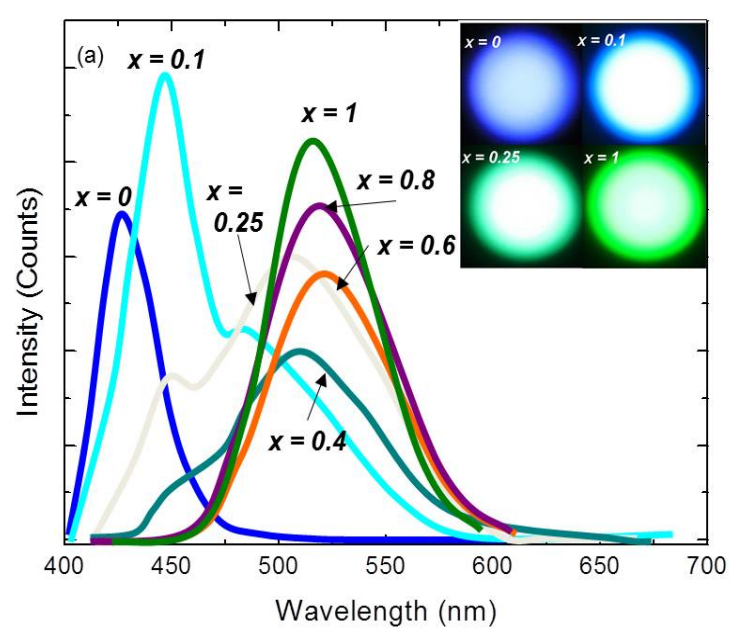

(a)

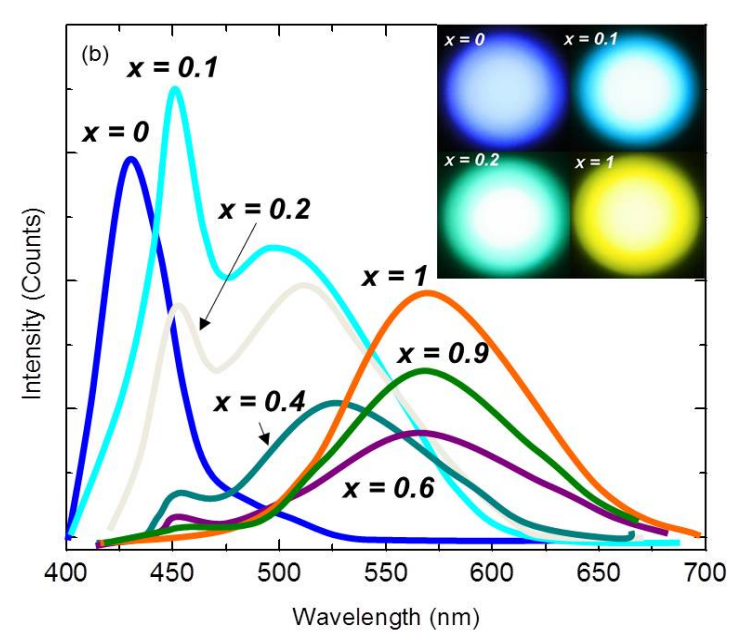

(D)

Fig. 10. PL emission spectra of $\mathrm{Eu}^{2+}$-activated (a) $\left(\mathrm{KSrPO}_{4}\right)_{1-\mathrm{x}} \cdot\left(\mathrm{Ba}_{2} \mathrm{SiO}_{4}\right)_{\mathrm{x}}$ and (b) $\left(\mathrm{KSrPO}_{4}\right)_{1-\mathrm{x}} \cdot\left(\mathrm{Sr}_{2} \mathrm{SiO}_{4}\right)_{\mathrm{x}}$ at various $x$ under $380 \mathrm{~nm}$ excitation. The insets are photos showing colors of the corresponding samples, which were taken with a $380 \mathrm{~nm}$ emitting UV-LED.

\section{Orange-emitting phosphors $\left(\lambda_{\text {em }}=580-610 \mathrm{~nm}\right)$}

Another promising silicate phosphor was investigated: $\left(\mathrm{Sr}_{1-\mathrm{x}} \mathrm{Ba}_{\mathrm{x}}\right)_{3} \mathrm{SiO}_{5}$, Fig. 11(a) is the excitation spectra for various values of $x$, showing that the phosphor is efficiently excited from $370 \mathrm{~nm}-412 \mathrm{~nm}$. Additionally the spectra are flat in that region, indicating that small variations in the emission wavelength of the UV LED will not affect the intensity of the emission. The emission spectra (Fig. 11(b)) illustrate the peaks ranges from 580 to $612 \mathrm{~nm}$ depending on $\mathrm{x}$. The QE of these phosphors are 85-95\% at $0 \leq x \leq 0.5,25-55 \%$ at $0.5 \leq x \leq 1$.
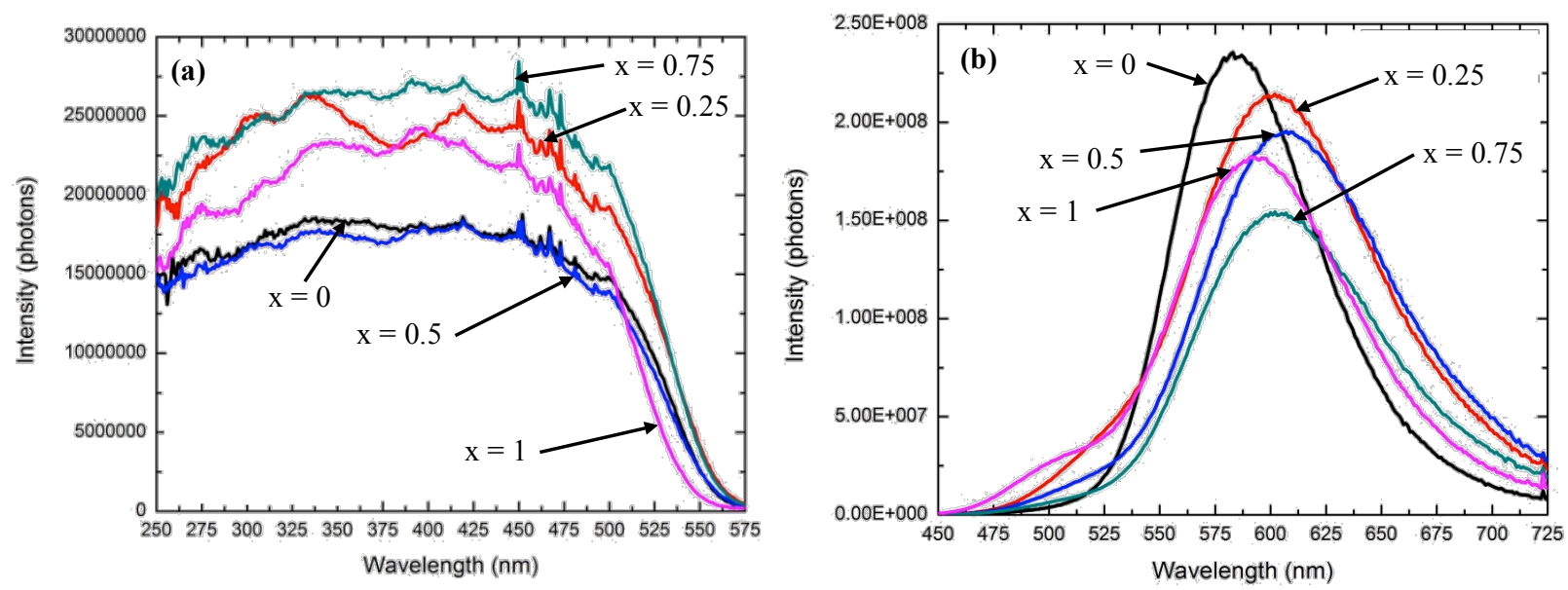

Fig. 11. $\left(\mathrm{Sr}_{1-\mathrm{x}} \mathrm{Ba}_{\mathrm{x}}\right)_{3} \mathrm{SiO}_{5}$ : $\mathrm{Eu}$ (a) excitation spectra for various values of $x$ and (b) emission spectra for various values of $x\left(\lambda_{\mathrm{ex}}=380 \mathrm{~nm}\right)$. 
Red-emitting phosphors $\left(\lambda_{e m}=610-650 \mathrm{~nm}\right)$

Seven different red-emitting $\left(\mathrm{Sr}_{2-\mathrm{x}} \mathrm{Eu}_{\mathrm{x}}\right) \mathrm{Si}_{5} \mathrm{~N}_{8}$ samples were produced with varying concentration of europium $(0.0075 \leq \mathrm{x} \leq 1.00)$. Fig. 12 shows the excitation, reflection and emission spectra of $\left(\mathrm{Sr}_{2-\mathrm{x}} \mathrm{Eu}_{\mathrm{x}}\right) \mathrm{Si}_{5} \mathrm{~N}_{8}$ at $\mathrm{x}=$ 0.005 . The intensity of the excitation spectrum at $\sim 400 \mathrm{~nm}$ is excellent and the emission peak is broad and centered around $613 \mathrm{~nm}$, when excited by $380 \mathrm{~nm}$. The QE of these samples was measured at $400 \mathrm{~nm}$ excitation, and then plotted. The peak location was also recorded and a plot of peak height was produced (Fig. 13(a)) as well as a plot of QE as a function of Eu concentration (Fig. 13(b)). The highest QE for this phosphor occurs at very low Eu levels. This, however, places the emission peak in the orange range of the spectrum, and limits the usefulness of the powder. To move the

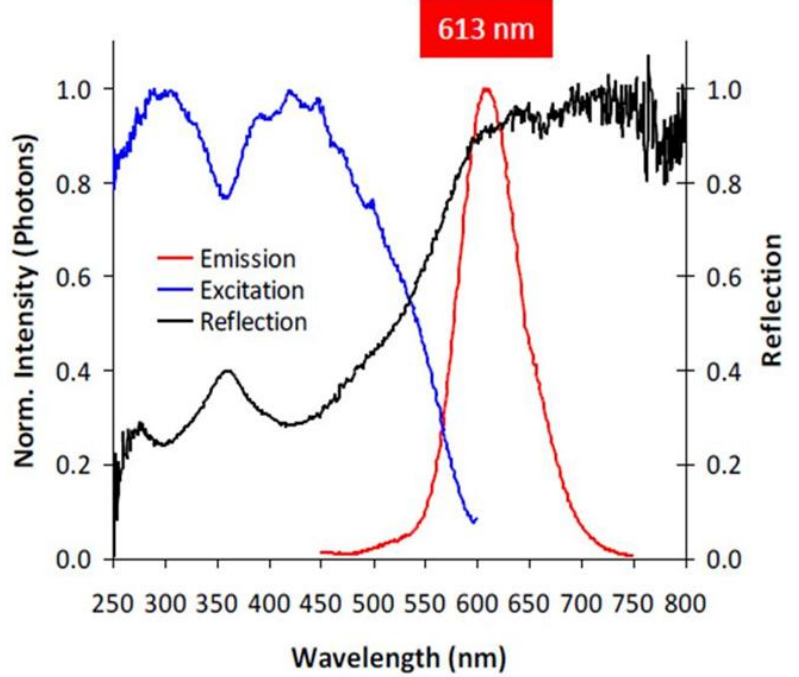

Fig. 12. Measurements on $\left(\mathrm{Sr}_{2-\mathrm{x}} \mathrm{Eu}_{\mathrm{x}}\right) \mathrm{Si}_{5} \mathrm{~N}_{8}$ : excitation, reflection and emission spectra. emission peak of the phosphor to a more red wavelength, a concentration of europium of around $\mathrm{x}=0.15-0.20$ is needed, which lowers the quantum efficiency to $\sim 75 \%$. Thus, a different red phosphor is desirable.

$\mathrm{Ba}_{3-\mathrm{x}} \mathrm{Eu}_{\mathrm{x}} \mathrm{Mg}_{1-\mathrm{y}} \mathrm{Mn}_{\mathrm{y}} \mathrm{Si}_{2} \mathrm{O}_{8}$ was synthesized and examined as a possible alternative. This phosphor produces red light through an energy transfer from $\mathrm{Eu}^{2+}$ to $\mathrm{Mn}^{2+}$. This process will prevent the phosphor from absorbing in the green to yellow-orange region of the spectrum and thus will not interfere with the emission of the other phosphors in a blend. Also, as this is a silicate phosphor, no special synthesis techniques are required. Fig. 14(a) shows the excitation, reflection and emission spectra of $\mathrm{Ba}_{3-\mathrm{x}} \mathrm{Eu}_{\mathrm{x}} \mathrm{Mg}_{1-\mathrm{y}} \mathrm{Mn}_{\mathrm{y}} \mathrm{Si}_{2} \mathrm{O}_{8}$. The peak intensity of the excitation spectrum at 270-300 nm does not meet the requirements for our project and the emission peak is broad and centered around 440,510, $620 \mathrm{~nm}$, when excited by $380 \mathrm{~nm}$. The quantum efficiencies
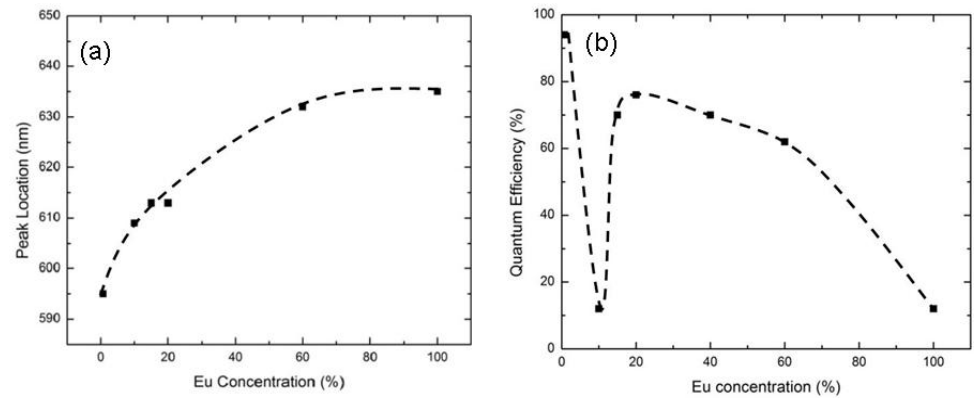

Fig. 13. (a) The relationship between the percent of europium and the emission peak location and (b) plot showing the relationship between the $\mathrm{QE}$ and the $\mathrm{Eu}$ concentration for $\left(\mathrm{Sr}_{2-\mathrm{x}} \mathrm{Eu}_{\mathrm{x}}\right) \mathrm{Si}_{5} \mathrm{~N}_{8}$. of these samples are $73 \%$ for the samples without $\mathrm{Mn}^{2+}$ and $54 \%$ with $\mathrm{Mn}^{2+}$. The decrease in $\mathrm{QE}$ is attributed to the longer lifetime of the $\mathrm{Mn}^{2+}$. As temperature increases, the red-emission $\left(\mathrm{Mn}^{2+}\right)$ decreases significantly and the lifetime at $400 \mathrm{~K}$ is just $50 \%$ of that at $80 \mathrm{~K}$ as shown in Fig. 14(b). Furthermore, the QE of other red-emitting phosphors with $\mathrm{Mn}^{2+}$ or $\mathrm{Eu}^{3+}$ activation are reported to be very low (below 5\%), thus we have stopped investigating $\mathrm{Eu}^{3+}$ and $\mathrm{Mn}^{2+}$ phosphor systems. 

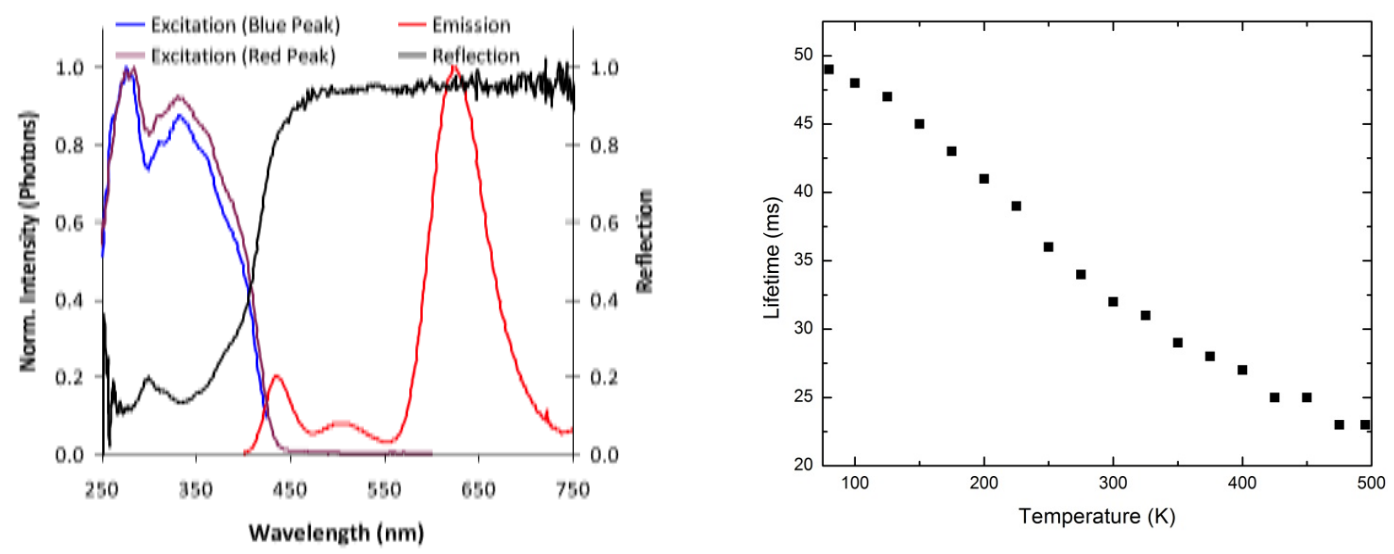

Fig. 14. (a) Measurements on $\mathrm{Ba}_{3-\mathrm{x}} \mathrm{Eu}_{\mathrm{x}} \mathrm{Mg}_{1-\mathrm{y}} \mathrm{Mn}_{\mathrm{y}} \mathrm{Si}_{2} \mathrm{O}_{8}$ : (a) excitation, reflection and emission spectra and (b) the lifetime of red-emission as a function of temperature.

\section{Task 3 - Development of core/shell nanophosphors}

\section{Development of luminescence output}

We began with $\mathrm{Y}_{2} \mathrm{SiO}_{5}: \mathrm{Ce}^{3+}, \mathrm{Tb}^{3+}$, a white-emitting phosphor, as a model phosphor core and deposited $\mathrm{SiO}_{2}$ shells directly on the cores. The phosphor cores were synthesized by a sol gel and modified Pechini method and the shells were deposited by a sol gel method. Fig. 15(a) shows the emission spectra for the core particles along with core/shell particles. The emission intensity increases with the presence of the shells. For a one hour $\mathrm{SiO}_{2}$ deposition time that resulted in a shell thickness of $15-30 \mathrm{~nm}$, the emission intensity increased by $70 \%$ over the bare core particles. Thicker shells $(40-60 \mathrm{~nm})$ decrease the emission intensity. SEM micrographs are shown in Fig. 15(b) and (c), where the thin amorphous $\mathrm{SiO}_{2}$ layer can be observed. This demonstrates two concepts: one is that an inert shell mitigates the surface defects effects, thereby improving the emission intensity and two, there is a critical shell thickness, beyond which the emission intensity decreases (although still better than the bare cores). This result is significant in that we have proven that nanophosphors have the potential to be used in a LED device.

We have shown that $\mathrm{Sr}_{2} \mathrm{SiO}_{4}: \mathrm{Eu}^{2+}$ is an excellent green-emitting phosphor that has the $\mathrm{QE}$ of 90-100\%. We investigated the effect of $\mathrm{SiO}_{2}$ shells on the nanophosphor cores. The emission intensity of the core and core/shell particles is shown in Fig. 15(d). The core particles appear agglomerated (Fig. 14(e)) but the deposition of $\sim 40 \mathrm{~nm}$ thick $\mathrm{SiO}_{2}$ shells de-agglomerates the particles (Fig. 14(f)), although there are multiple cores within one particle. However, the core/shell particles are $\sim 200 \mathrm{~nm}$ in diameter, still small enough to reduce scattering.

\section{Development of chemical and moisture stability}

As far as device application is concerned, halides and alkali earth elements in phosphor compositions detrimentally affect the moisture resistance (chemical stability) Fig 16 (a) and (b) shows the comparison of PL spectra of fresh $\mathrm{Ca}_{3} \mathrm{SiO}_{4} \mathrm{Cl}_{2}: \mathrm{Eu}^{2+}$ and $\mathrm{Ca}_{2} \mathrm{PO}_{4} \mathrm{Cl}_{\text {: }} \mathrm{Eu}^{2+}$ phosphors and the phosphors after soaking in water for $24 \mathrm{~h}$. The emission spectra consist of a single broad band near $520 \mathrm{~nm}$ for $\mathrm{Ca}_{3} \mathrm{SiO}_{4} \mathrm{Cl}_{2}: \mathrm{Eu}^{2+}$ and $455 \mathrm{~nm}$ for $\mathrm{Ca}_{2} \mathrm{PO}_{4} \mathrm{Cl}: \mathrm{Eu}^{2+}$. The PL intensity of both phosphors is significantly decreases after water exposure for $24 \mathrm{~h}$. After $24 \mathrm{~h}$ water exposure, the intensity of $\mathrm{Ca}_{3} \mathrm{SiO}_{4} \mathrm{Cl}_{2}: \mathrm{Eu}^{2+}$ is $20 \%$ and that of $\mathrm{Ca}_{2} \mathrm{PO}_{4} \mathrm{Cl}: \mathrm{Eu}^{2+}$ is $70 \%$ of that of fresh ones 
indicating luminescence properties of both phosphors are easily quenched by the moisture. However, poor moisture stability of these phosphors can be mitigated by $\mathrm{SiO}_{2}$ shells as shown in Fig 17 (a) and (b). Fig 17 (a) and (b) shows the SEM images and PL spectra of $\mathrm{SiO}_{2}$ coated on $\mathrm{Ca}_{3} \mathrm{SiO}_{4} \mathrm{Cl}_{2}: \mathrm{Eu}^{2+}$ and $\mathrm{Ca}_{2} \mathrm{PO}_{4} \mathrm{Cl}: \mathrm{Eu}^{2+}$ phosphors. The particle size is over $3 \mu \mathrm{m}$ for $\mathrm{Ca}_{3} \mathrm{SiO}_{4} \mathrm{Cl}_{2}: \mathrm{Eu}^{2+}$ and $300 \mathrm{~nm}$ for $\mathrm{Ca}_{2} \mathrm{PO}_{4} \mathrm{Cl}: \mathrm{Eu}^{2+}$ and the particles are coated with $15-25 \mathrm{~nm}$ $\mathrm{SiO}_{2}$. Compared to bare core particles, the PL intensity of the core/shell particles after $24 \mathrm{~h}$ water exposure is comparable to that of fresh ones indicating the moisture stability of these phosphors can be significantly improved by $\mathrm{SiO}_{2}$ shells.
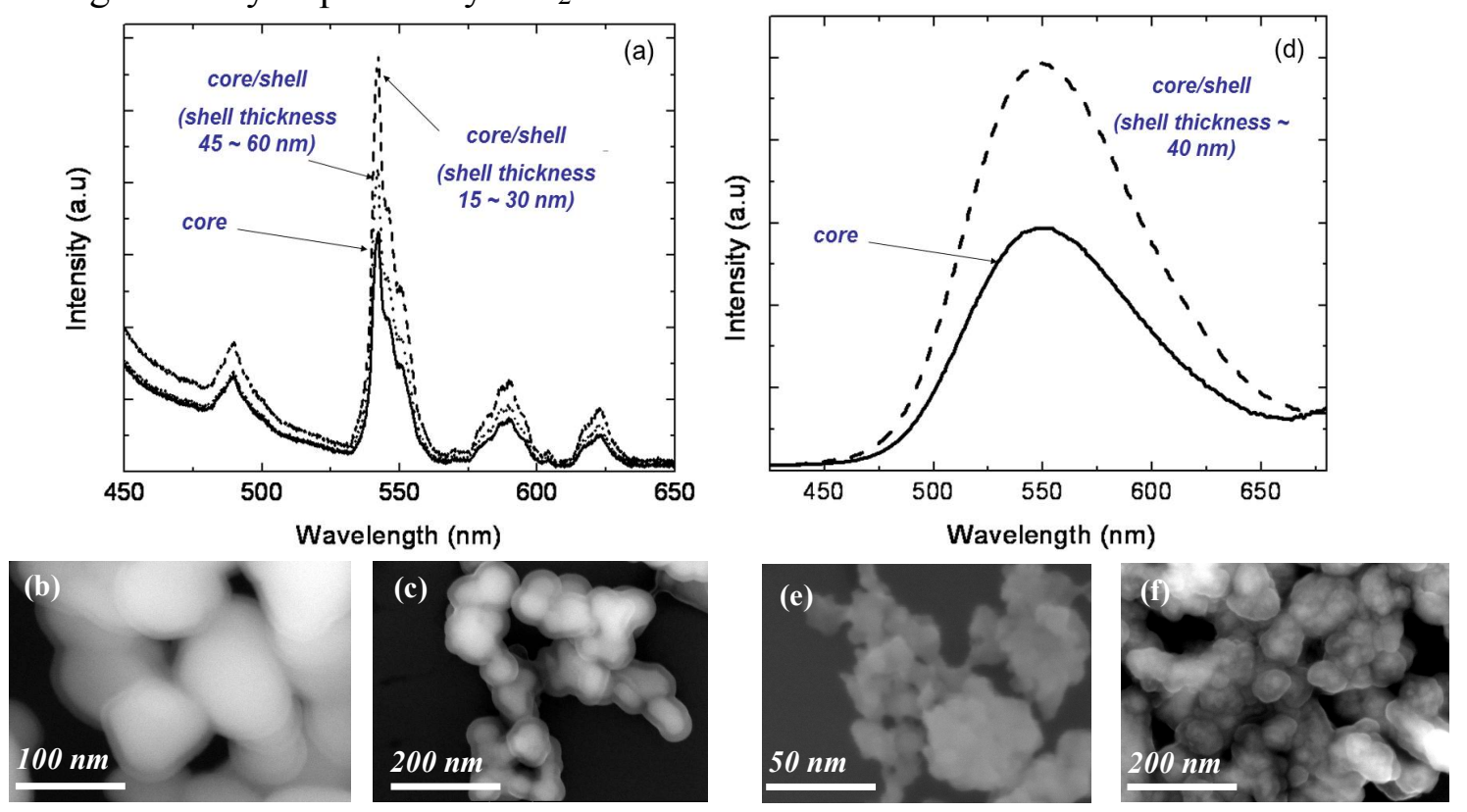

Fig. 15. Core/shell nanophosphors: $\mathrm{Y}_{2} \mathrm{SiO}_{5}: \mathrm{Ce}^{3+}, \mathrm{Tb}^{3+} / \mathrm{SiO}_{2}$; (a) emission spectra $\left(\lambda_{\text {ex }}=380 \mathrm{~nm}\right)$. SEM micrographs showing the amorphous $\mathrm{SiO}_{2}$ shell around the core particles for shell deposition times of $(\mathrm{b})$ $1 \mathrm{hr}$ and (c) $3 \mathrm{hr}$. $\mathrm{Sr}_{2} \mathrm{SiO}_{4}: \mathrm{Eu}^{2+} / \mathrm{SiO}_{2}$; (d) emission spectra $\left(\lambda_{\text {ex }}=380 \mathrm{~nm}\right)$ and SEM images (e) the bare cores and (f) core/shell nanophosphors for a $\mathrm{SiO}_{2}$ deposition time of $2 \mathrm{hr}$.

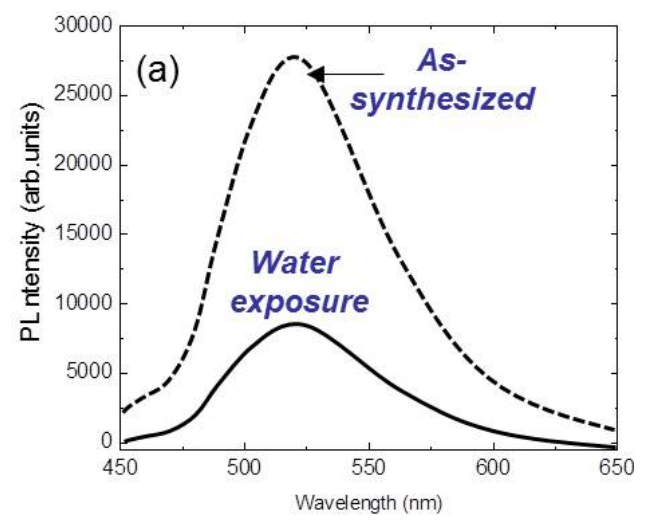

(a)

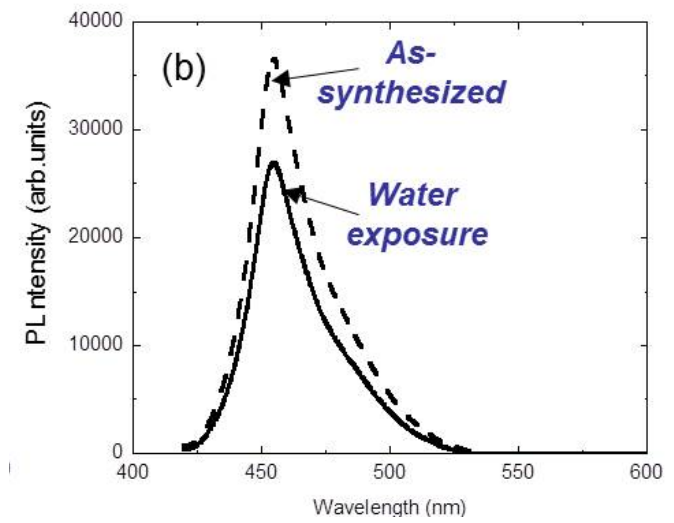

(b)

Fig 16. The comparison of PL spectra of (a) fresh $\mathrm{Ca}_{3} \mathrm{SiO}_{4} \mathrm{Cl}_{2}: \mathrm{Eu}^{2+}$ and after soaking in water for $24 \mathrm{~h}$ (b) fresh $\mathrm{Ca}_{2} \mathrm{PO}_{4} \mathrm{Cl}: \mathrm{Eu}^{2+}$ phosphors and after soaking in water for $24 \mathrm{~h}$. 

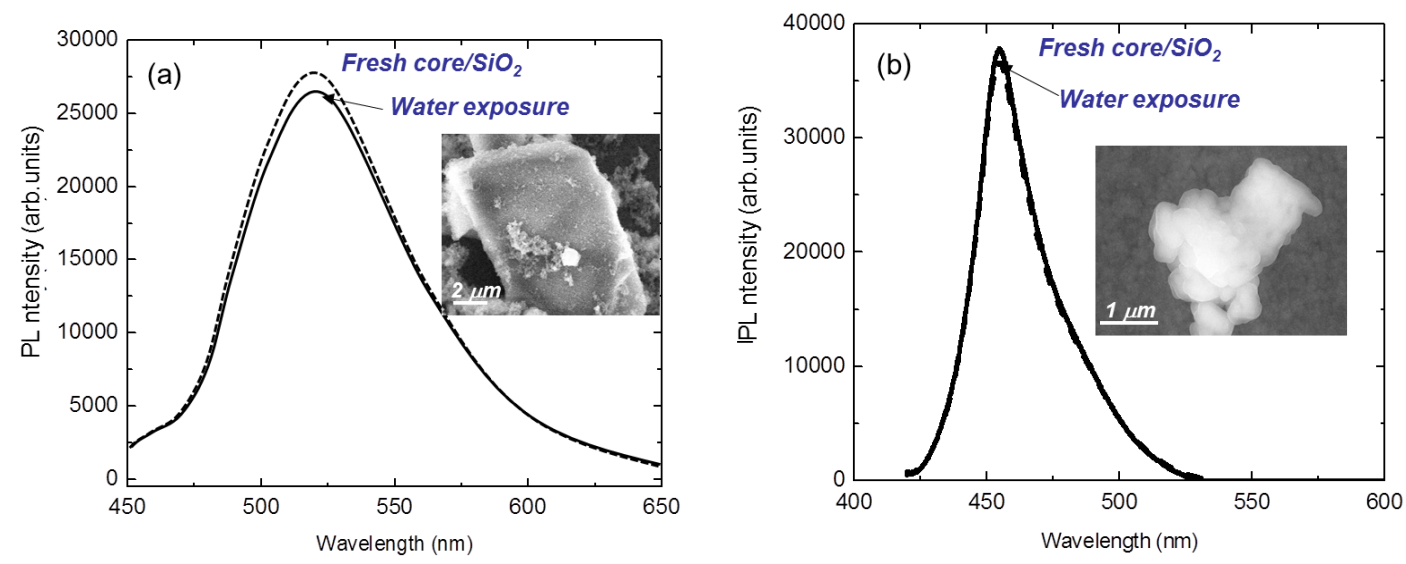

Fig 17. The $\mathrm{PL}$ spectra of fresh $\mathrm{Ca}_{3} \mathrm{SiO}_{4} \mathrm{Cl}_{2}: \mathrm{Eu}^{2+}$ and $\mathrm{Ca}_{3} \mathrm{SiO}_{4} \mathrm{Cl}_{2}: \mathrm{Eu}^{2+} / \mathrm{SiO}_{2}$ phosphors (b) fresh $\mathrm{Ca}_{2} \mathrm{PO}_{4} \mathrm{Cl}: \mathrm{Eu}^{2+}$ and $\mathrm{Ca}_{2} \mathrm{PO}_{4} \mathrm{Cl}: \mathrm{Eu}^{2+} / \mathrm{SiO}_{2}$ phosphors. The core/shell phosphors are measured after soaking in water for $24 \mathrm{~h}$.

\section{Task 4 - Electrophoretic deposition of phosphors}

Electrophoretic deposition (EPD) is widely used in the processing of materials and coatings. This technique is suitable for depositing charged particles dispersed in a liquid on a substrate under the force of an applied electric field; a schematic diagram is shown in Fig. 18. There are many factors related to the suspension and the process that affect EPD such as the dissociation of nitrate salts in IPA, the zeta potential of charged particles, the formation of the adhesive agents, and the factors which affect the adhesion strength of the deposited particles.

Our novel high efficiency phosphors were selected for EPD studies: $\left(\mathrm{SrCa}_{2} \mathrm{Si}_{5} \mathrm{~N}_{8}\right.$ (red), $\mathrm{Ba}_{2} \mathrm{SiO}_{4}$ (green), $\mathrm{LiCaPO}_{4}$ (blue), $\mathrm{Sr}_{0.75} \mathrm{Ba}_{0,25} \mathrm{SiO}_{4}$ (yellow) and $\left(\mathrm{Sr}_{0.75} \mathrm{Ba}_{0.25}\right)_{3} \mathrm{SiO}_{5}$ (orange) were deposited on ITO-coated substrates, as shown in Fig. 19. Most phosphor coverage is excellent, demonstrating that EPD is a viable method to produce phosphor layers for the 'remote phosphor' design.

For the EPD of individual phosphors, the deposit weight as a function of time is shown in Fig. 20(a) and was converted to thickness as a function of time using the theoretical density of the composition and assuming a packing density of $56 \%$ in Fig. 20(b). The deposition rate was $\sim 1 \mu \mathrm{m} / \mathrm{min}$ for green-, yellow-, and orange-emitting phosphors and $\sim 5 \mu \mathrm{m} / \mathrm{min}$ for red-emitting phosphor, estimated from the thickness of the films. To minimize the settling of $\sim 5-10 \mu \mathrm{m}$ phosphor particles, the deposition time was limited to $8 \mathrm{~min}$. After $8 \mathrm{~min}$, stratification of the particles in the bath was clearly observed.

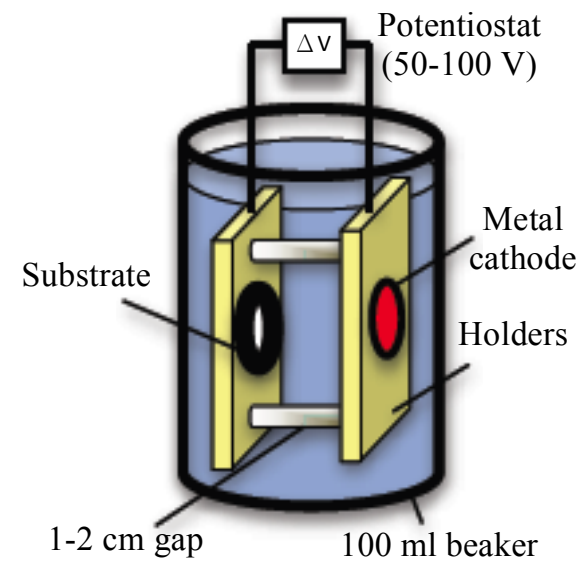

Fig. 18. Schematic diagram of the electrophoretic deposition bath. 


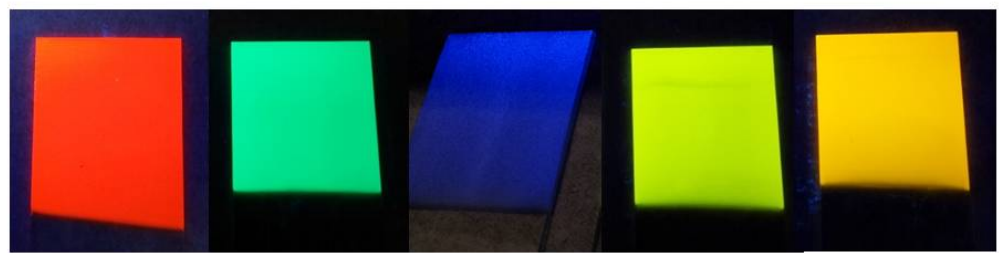

Fig. 19. Photograph of individual phosphor EPD deposits $(2.5 \times 2.5 \mathrm{~cm})$, Eu-activated $\mathrm{Sr}_{2-\mathrm{x}} \mathrm{Ca}_{\mathrm{x}} \mathrm{Si}_{5} \mathrm{~N}_{8}(\mathrm{red})$, $\mathrm{Ba}_{2} \mathrm{SiO}_{4}$ (green), $\mathrm{LiCaPO}_{4}$ (blue), $\left(\mathrm{Sr}_{0.75} \mathrm{Ba}_{0.25}\right)_{2} \mathrm{SiO}_{4}$ (yellow) and $\left(\mathrm{Sr}_{0.5} \mathrm{Ba}_{0.5}\right)_{3} \mathrm{SiO}_{5}$ (orange).

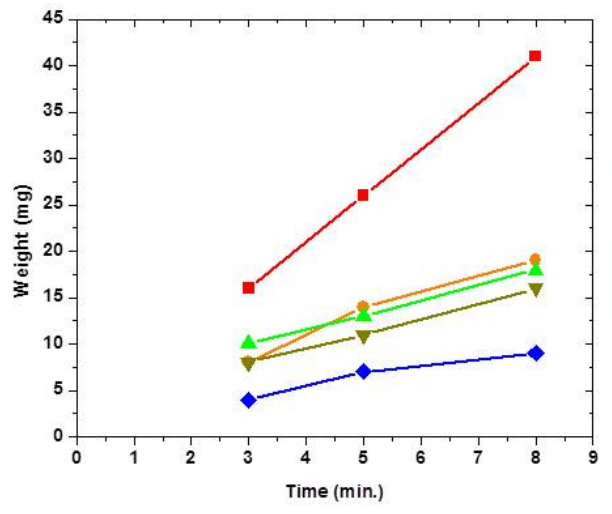

(a)

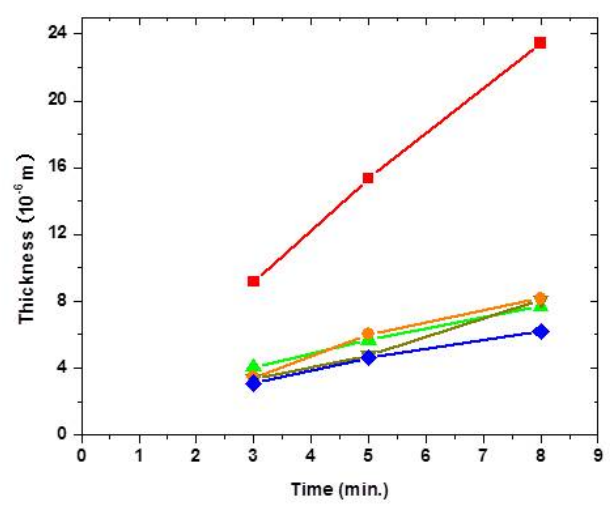

(b)

Fig. 20. (a) Deposit weight (per $6.45 \mathrm{~cm}^{2}$ ) and (b) thickness of individual phosphors as a function of time. $\mathrm{Eu}^{2+}$-activated $\mathrm{Sr}_{2-\mathrm{x}} \mathrm{Ca}_{\mathrm{x}} \mathrm{Si}_{5} \mathrm{~N}_{8}$ (red - squares), $\mathrm{Ba}_{2} \mathrm{SiO}_{4}$ (green - triangles), $\mathrm{LiCaPO}_{4}$ (blue - diamonds), $\left(\mathrm{Sr}_{0.75} \mathrm{Ba}_{0.25}\right)_{2} \mathrm{SiO}_{4}$ (dark yellow - inverted triangles) and $\left(\mathrm{Sr}_{0.5} \mathrm{Ba}_{0.5}\right)_{3} \mathrm{SiO}_{5}$ (orange - circles).

EPD was used to deposit phosphor layers either as a blend or as a sequential deposition, with the goal of obtaining white light with a CCT of $\sim 3000 \mathrm{~K}$ and a high CRI $(>80)$. Generally, the deposition rate is linear initially, as shown in Fig. 20(a), but as deposition time increased over 8 min, the rate decreased due to the settling of the particles and the decrease of the electric field on the electrode due to the resistance of the film. Specifically, this effect is severe during the deposition of the second layer, since the first layer reduces the electric field strength. Therefore, the range of deposition time was kept between 1 min to $8 \mathrm{~min}$. With OS's suggested phosphor blend compositions, two different blends were deposited on ITO-coated substrates.

Fig. 21 shows the emission results on a CIE chromaticity diagram calculated from PL spectra of a film deposited with two different phosphor blends. Fig. 21(a) shows the results of a three phosphor blend (blue-, yellow- and orange-emitting) with a CCT of $3202 \mathrm{~K}$ and CRI of 75. Fig. 21(b) shows the results of a four phosphor blend (blue-, green-, orange- and red-emitting) with a CCT of $3346 \mathrm{~K}$ and CRI of 94 . The insets show photographs of the generated white light emitted by $365 \mathrm{~nm}$ excitation. Both white-emissions are well-situated near the black body locus in the chromaticity diagram. A higher CRI was attained by blending four phosphors as expected, because of the addition of a red-emitting phosphor. 


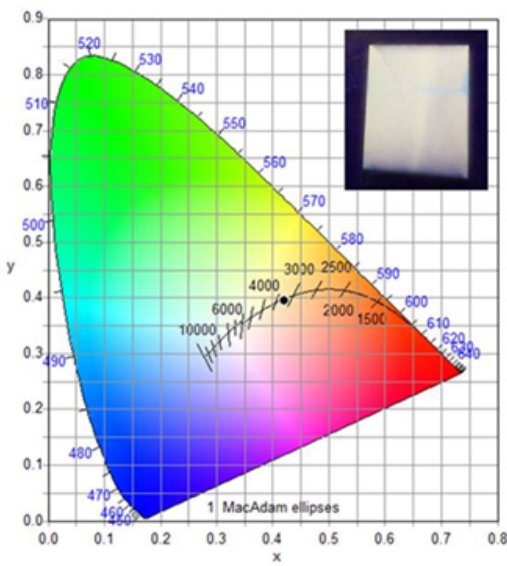

(a)

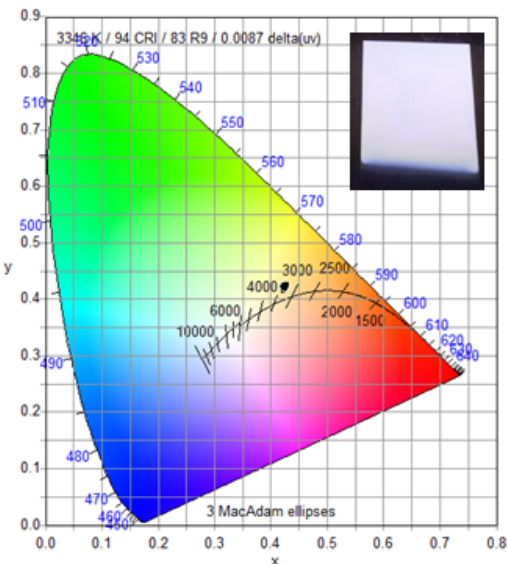

(b)

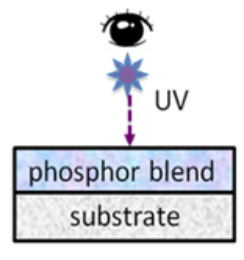

(c)

Fig. 21. CIE coordinates and photographs of electrophoretically deposited phosphor blend films $\left(\lambda_{\text {ex }}=\right.$ $380 \mathrm{~nm}$ ). (a) Three phosphor blend: mixture contains blue, 63 wt.\%, yellow, 15 wt.\% and orange, 22 wt. $\%$. CCT $=3202 \mathrm{~K}, \mathrm{CRI}=75$. (b) Four phosphor blend: mixture contains blue, 70 wt.\%, green, 13 wt. $\%$, orange, 5 wt. $\%$ and red, 12 wt. $\% . C C T=3346 \mathrm{~K}, \mathrm{CRI}=94$. (c) The insets show photographs of the generated white light emitted by $\lambda_{\text {ex }}=365 \mathrm{~nm}$.

These results demonstrate that EPD may be used to fabricate white-emitting phosphor blends with potential application for SSL. Furthermore, the properties of phosphor deposits, correlated color temperature and color rendering index can be manipulated using different phosphor blend compositions.

However, reabsorption of emission colors may occur among the phosphors. Therefore, layered films were investigated and compared to the blended films. Phosphor films were prepared by sequential deposition of red/orange and green/blue compositions to generate white light. The layered films were flipped over and illuminated in this orientation, which showed approximately the same luminescence characteristics. No change in the ratio of the reabsorption of green/blue emission by the red/orange phosphor was found regardless of the deposited order of the layered films. However, the blend deposition was better method due to easier emission color tuning.

Fig. 22(a) shows the results of a red/orange mixture (1 min deposition time) as the first layer and a green/blue mixture ( 8 min deposition time) as the second layer made by sequential deposition on a CIE chromaticity diagram with a CCT of $3156 \mathrm{~K}$ and CRI of 90 . The layered film was flipped over and illuminated, which showed approximately the same luminescence characteristics (Fig. 22(b): CCT of $3159 \mathrm{~K}$ and CRI of 90). A film with the opposite order, green/blue as the first layer $(3 \mathrm{~min})$ and a red/orange as the second layer $(5 \mathrm{~min})$, was also fabricated by sequential deposition. The CIE chromaticity diagram in Fig. 23(a) shows a CCT of $2721 \mathrm{~K}$ and CRI of 90 . The layered film was flipped over and illuminated and was found to have the same luminescence characteristics (Fig. 23(b): CCT of $2719 \mathrm{~K}$ and CRI of 90). Thus, two different orders of sequential deposition generated white light. 

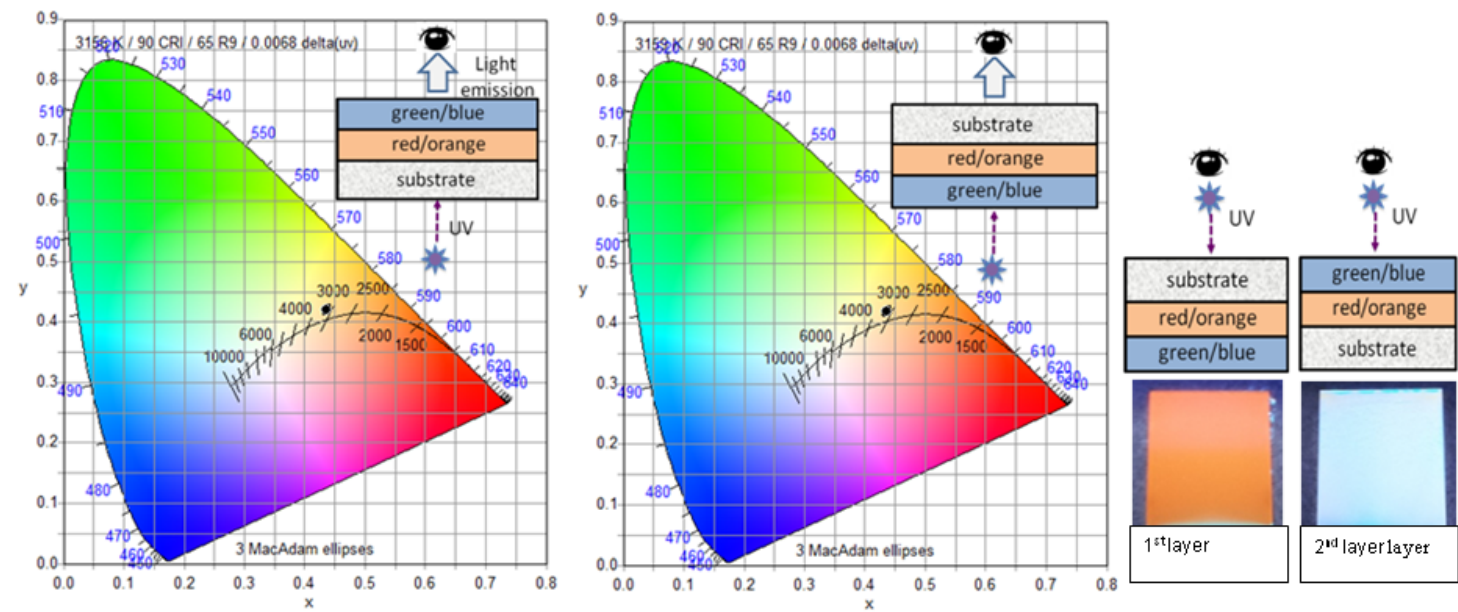

Fig. 22. Four phosphor blend deposited by sequential electrophoretic deposition. First layer contains $\mathrm{red} /$ orange (1:1 wt. ratio), second layer contain green/blue (2:3 wt. ratio). (a) CCT $=3156 \mathrm{~K}, \mathrm{CRI}=90$. (b) $\mathrm{CCT}=3159 \mathrm{~K}, \mathrm{CRI}=90\left(\lambda_{\mathrm{ex}}=380 \mathrm{~nm}\right)$. (c) $1^{\text {st }}$ layer photograph (looking through the substrate) and $2^{\text {nd }}$ layer photograph (looking on top of the phosphor) at $\lambda_{\mathrm{ex}}=365 \mathrm{~nm}$.

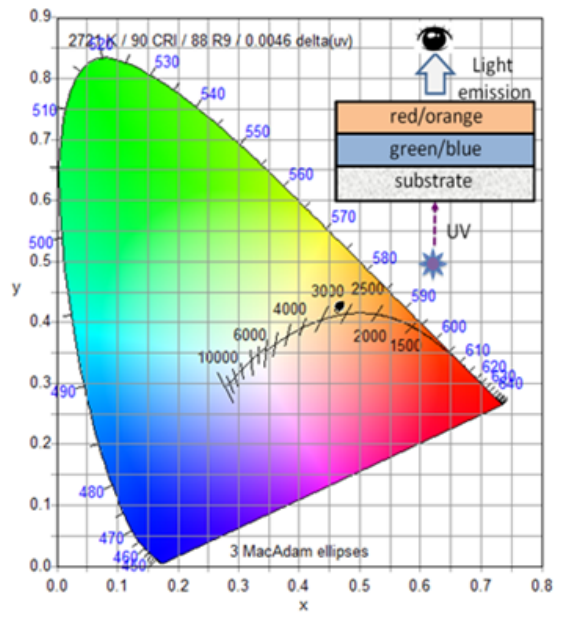

(a)

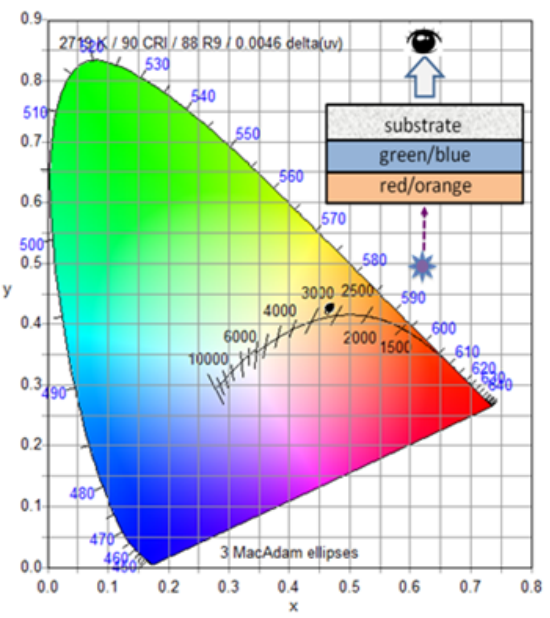

(b)

Fig. 23. Four phosphor blend deposited by sequential electrophoretic deposition. First layer contains green/blue (2:3 wt. ratio), second layer contain red/orange (1:1 wt. ratio). (a) CCT $=2721 \mathrm{~K}, \mathrm{CRI}=90$. (b) $\mathrm{CCT}=2719 \mathrm{~K}, \mathrm{CRI}=90\left(\lambda_{\mathrm{ex}}=380 \mathrm{~nm}\right)$.

For our goal of remote phosphor configuration with highly efficient phosphors, new blends were deposited by EPD. $\mathrm{LiCaPO}_{4}$ blue phosphor was replaced with another promising phosphor, $\operatorname{SCAP}\left(\left(\mathrm{Sr}_{1-\mathrm{x}} \mathrm{Ca}_{\mathrm{x}}\right)_{5}\left(\mathrm{PO}_{4}\right)_{3} \mathrm{Cl}_{1-\mathrm{y}} \mathrm{F}_{\mathrm{y}}: \mathrm{Eu}^{2+}\right)$ and $\mathrm{Ba}_{3} \mathrm{MgSi}_{2} \mathrm{O}_{8}: \mathrm{Eu}^{2+}$. The other phosphors, yellow $\left(\mathrm{Sr}_{0.75} \mathrm{Ba}_{0.25}\right)_{2} \mathrm{SiO}_{4}: \mathrm{Eu}^{2+}$, green $\mathrm{Ca}_{8} \mathrm{Mg}\left(\mathrm{SiO}_{4}\right)_{4} \mathrm{Cl}_{2}: \mathrm{Eu}^{2+}$ and red $\left(\mathrm{Ca}_{\mathrm{x}} \mathrm{Sr}_{1-\mathrm{x}-\mathrm{y}} \mathrm{Ba}_{\mathrm{y}}\right)_{2} \mathrm{Si}_{5} \mathrm{~N}_{8}: \mathrm{Eu}^{2+}$ have been added in EPD bath to meet black body locus in CIE diagram.

Two different blends were deposited onto ITO-coated substrates depending on blue phosphor. Fig. 24(a) shows a white converter using four phosphor compositions (blue -, yellow-, green and red-emitting) with CCT of $3259 \mathrm{~K}$ and CRI of 75 in the case of blue, $\mathrm{Ba}_{3} \mathrm{MgSi}_{2} \mathrm{O}_{8}$. Fig. 24(b) shows a white converter using four phosphor compositions (blue-, yellow-, green and redemitting) with CCT of $2997 \mathrm{~K}$ and CRI of 71 in the case of blue, SCAP. The white colors are well situated on the black body locus and white region of the CIE diagram. 


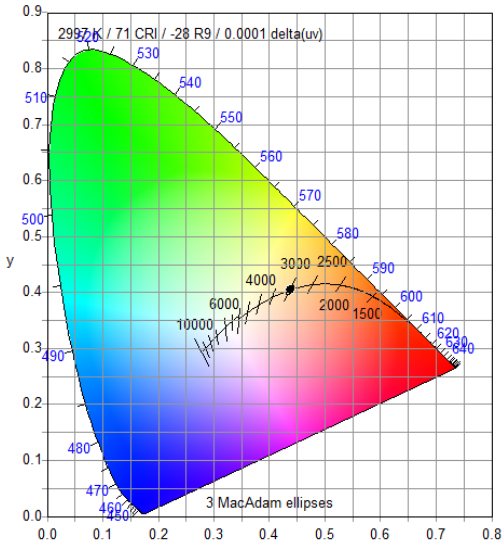

(a)

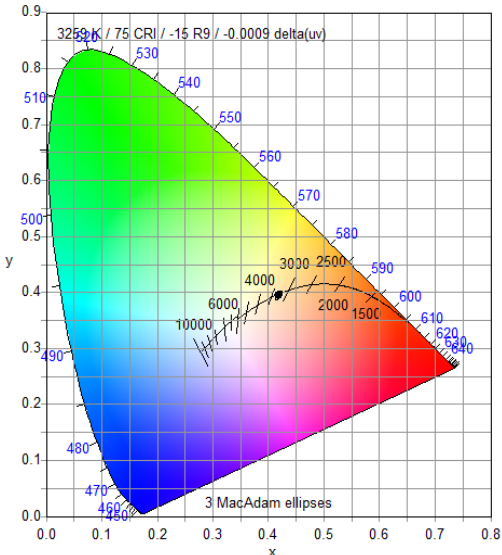

(b)

Fig. 24. CIE coordinates of 4 phosphors blend EPD (a) 4 phosphors blend with blue, $\mathrm{Ba}_{3} \mathrm{MgSi}_{2} \mathrm{O}_{8}$ : $\mathrm{B}$ (81\%), Y (11\%), G (3\%) and R (5\%), CRI: 75, CCT: $3259 \mathrm{~K}$ (b) 4 phosphors blend with blue, SCAP: B (63\%), Y (24\%), G (6\%) and R (7\%), CRI: 71, CCT: $2997 \mathrm{~K}$ (OS's solid state reacted powders were used. $\mathrm{Ba}_{3} \mathrm{MgSi}_{2} \mathrm{O}_{8},\left(\mathrm{Sr}_{1-\mathrm{x}} \mathrm{Ca}_{\mathrm{x}}\right)_{5}\left(\mathrm{PO}_{4}\right)_{3} \mathrm{Cl}_{1-\mathrm{y}} \mathrm{F}_{\mathrm{y}},\left(\mathrm{Sr}_{0.75} \mathrm{Ba}_{0.25}\right)_{2} \mathrm{SiO}_{4}, \mathrm{Ca}_{8} \mathrm{Mg}\left(\mathrm{SiO}_{4}\right)_{4} \mathrm{Cl}_{2}$ and $\left(\mathrm{Ca}_{\mathrm{x}} \mathrm{Sr}_{1-\mathrm{x}-\mathrm{y}} \mathrm{Ba}_{\mathrm{y}}\right)_{2} \mathrm{Si}_{5} \mathrm{~N}_{8}$ : blue, blue, yellow, green and red)

There have been few direct comparisons of EPD of nano- and micron-sized particles of the same material. Therefore, EPD of nano-, nano core $/ \mathrm{SiO}_{2}$ shell and micron-sized $\left(\mathrm{Ba}_{0.97} \mathrm{Eu}_{0.03}\right)_{2} \mathrm{SiO}_{4}$ phosphor particles for application in a near-UV LED-based light source was studied.

$\left(\mathrm{Ba}_{0.97} \mathrm{Eu}_{0.03}\right)_{2} \mathrm{SiO}_{4}$ was prepared by both a solid state reaction and a co-precipitation method, yielding either micron- $(\sim 5 \mu \mathrm{m})$ or nano-sized $(\sim 320 \mathrm{~nm})$ particles, and nano core $/ \mathrm{SiO}_{2}$ shell particles was prepared by the Stöber process. EPD was performed in IPA or amyl alcohol baths. When a suspension of nano-sized particles in IPA bath was used, a non-uniform and porous film resulted, as shown in Fig. 25. The poor quality of the deposit is attributed to excessive hydrogen evolution during deposition. The increased surface area of nano-sized particle can adsorb a larger quantity of water than for micron-sized particles. With that additional water in the bath, more hydrogen evolution can occur at the cathode due to water electrolysis. Therefore, amyl alcohol, which has low water solubility, was used as the EPD suspension medium instead of IPA.

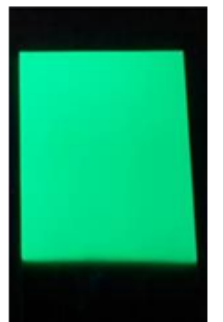

(a)

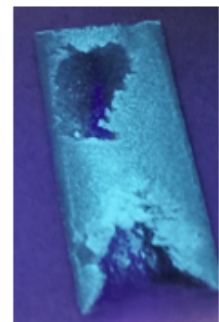

(b)

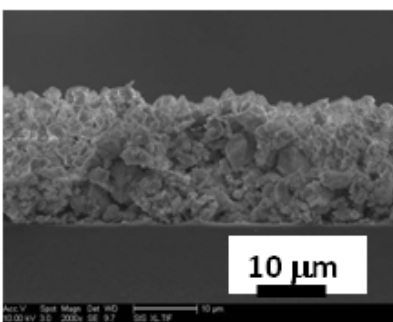

(c)

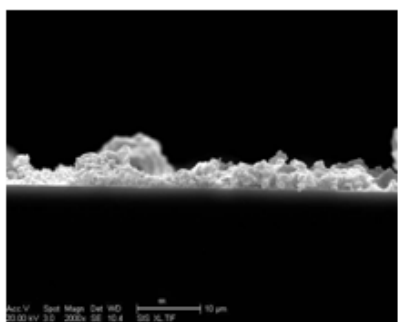

(d)

Fig. 25. A comparison of film quality of micron-sized and nano-sized powders deposited for $10 \mathrm{~min}$ from an IPA bath. Photographs of phosphor deposits $\left(2.5 \times 2.5 \mathrm{~cm}^{2}\right.$ excited by $\left.365 \mathrm{~nm}\right)$ of (a) micron- and (b) nano-sized particles. Cross-sectional SEM micrographs of (c) micron- (d) nano-sized particles.

The deposit weight and thickness deposits of nano- and micron-sized particles from a bath of amyl alcohol as a function of time are shown in Fig. 26. 


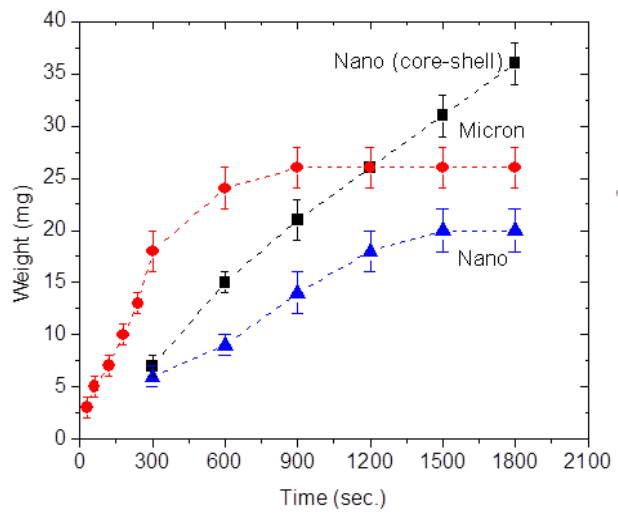

(a)

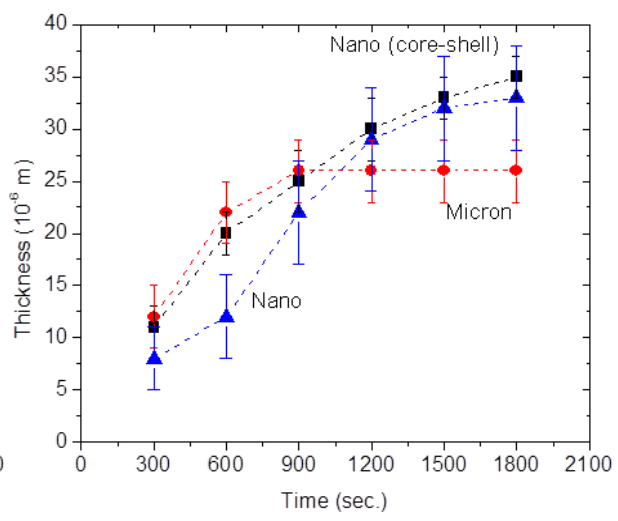

(b)

Fig. 26. (a) Deposit weight (per $6.25 \mathrm{~cm}^{2}$ ) and (b) thickness taken from SEM measurement of individual phosphors as a function of deposition time.

For short times $(<10 \mathrm{~min})$, the deposit weight and thickness increased linearly with time. The deposit thickness for the micron-sized particle leveled to $26 \mu \mathrm{m}$ at $15 \mathrm{~min}$, whereas the deposit thickness of nano-sized particle plateaued at $33 \mu \mathrm{m}$ at $\sim 30$ min. However, the thickness of core/shell nano-sized particles kept increasing to 30 min. Fig. 27 shows cross-sectional SEM micrographs of the deposits as a function of deposition time. Nano-, nano core/ $\mathrm{SiO}_{2}$ shell and micron-sized $\left(\mathrm{Ba}_{0.97} \mathrm{Eu}_{0.03}\right)_{2} \mathrm{SiO}_{4}$ phosphors were successfully deposited by electrophoretic deposition in an amyl alcohol bath.

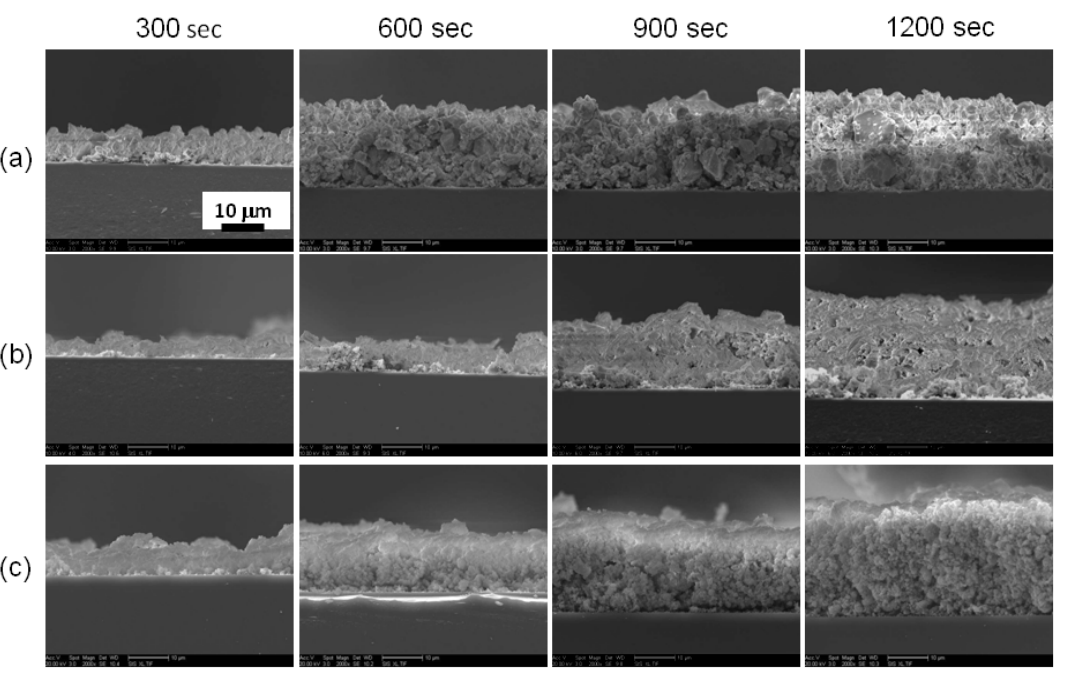

Fig. 27. Cross-sectional SEM micrographs showing the thickness as a function of deposition time: (a) micron-, (b) nano-sized and (c) core/shell nano-sized particles.

The deposited mass, $m$ can be estimated by the Hamaker equation, $m=C_{S} v_{e} A_{S} t$ where $C_{s}$ is the suspension concentration, $v_{e}$ is the electrophoretic velocity, $A_{s}$ is the deposition area, and $t$ is the deposition time. The electrophoretic velocity equals the product of the electrophoretic mobility, $\mu$, and the electric field, $E$. The Hamaker equation is valid only for short times when $C_{s}$ and the electric field are assumed to be constant. However, settling, particularly for micron-sized particles, can be significant. The settling velocity $v_{s}$, can be estimated by Stokes' law, $v_{s}=$ 
$\frac{2}{9} \frac{\left(\rho_{p}-\rho_{f}\right)}{\eta} g r^{2}$ where $\rho_{f}$ is the density of fluid, $g$ is the gravitational acceleration, and $r$ is the radius of a spherical particle. Therefore, a new equation was developed for predicting the deposited mass, considering the change in concentration of particles in the bath from both settling and deposition. The concentration in the suspension may change due to both deposition and settling. From a mass balance, the change in suspension concentration, $C_{s}$, due to settling and deposition can be written as $\frac{d C_{S}}{d t}=-C_{S} v_{S} \frac{A}{V}-\frac{1}{V} \frac{d m}{d t}$, where $A$ is the cross-section area of the bath and $V$ is the volume of the bath. However, the loss of concentration associated with the deposition can be considered minimal $(\sim 0.001 \mathrm{~g} / \mathrm{L})$ compared to the initial bath concentration $(5$ $\mathrm{g} / \mathrm{L})$ in our experiments, so the second term can be neglected. After integrating, the timedependent concentration is $C_{S}=C_{S, 0} \exp \left(-\frac{v_{S} A}{V} t\right)$, where $C_{S, 0}=$ initial bath concentration. By combining this Eqn. with the Hamaker Eqn., a new equation, $m(t)=\frac{C_{S, 0} A_{S} v_{e} V}{v_{S} A}\left[1-\exp \left(-\frac{v_{S} A}{V} t\right)\right]$ is obtained. The new equation predicted the deposited mass better. The experimental values for deposited mass as a function of time for nano- and core/shell nano-sized particles showed good agreement with this equation, however not for the micron-sized particles as shown in Fig. 28(a) and (b). This was attributed to vertical particle concentration gradients in the bath. To eliminate these possible gradients, the bath of micron-sized particles was stirred gently, which gave deposit weights in excellent agreement with the predicted ones from a new Eqn. verifying that instabilities occurred in the amyl alcohol bath. The deposited mass for micron-sized particles from an isopropyl alcohol bath that was not stirred showed good agreement with the theoretical values from a new equation as shown in Fig. 28(c), indicating that the concentration gradients did not develop in this bath.

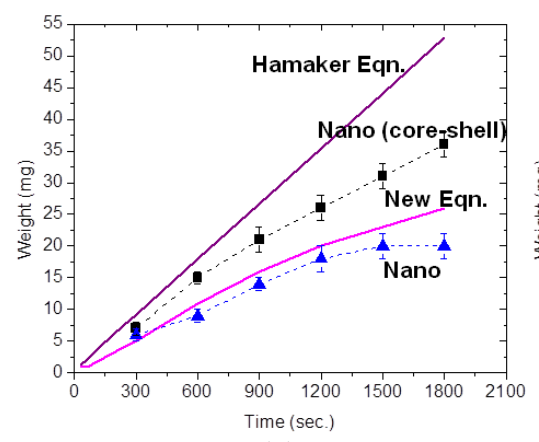

(a)

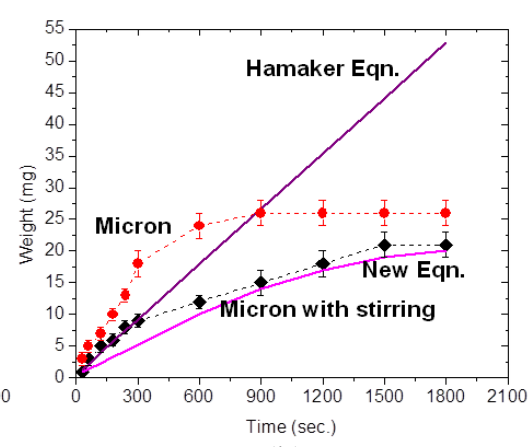

(b)

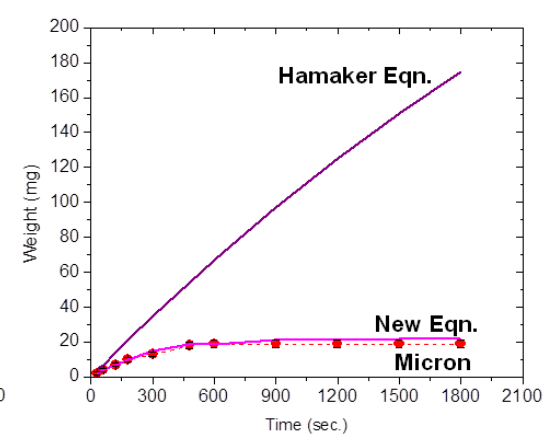

(c)

Fig. 28. Plot of experimental and predicted deposit weight as a function of deposition time. (a) nanosized particles in amyl alcohol bath, (b) micron-sized particles in amyl alcohol bath, (c) micron-sized particles in isopropyl alcohol bath.

\section{Task 5 - Identification of phosphor blends for optimal CRI and CCT}

The initial blend modeling began by considering five of the top performing individual phosphors, which ranged from blue to red (see Table 5 and Fig. 29(a)). Simulations were performed using the ColorCalculator software package from OSRAM SYLVANIA. At a given CCT, the simulations were designed to determine the maximum $\mathrm{LPW}_{\text {vis }}$ value and corresponding $\mathrm{CRI}$, or the maximum CRI and corresponding $\mathrm{LPW}_{\text {vis }}$ value. Besides providing information about efficacy and color rendering, one of the major outputs of the simulations was identifying how many different phosphors were actually needed to hit the targets. The first simulation was 
designed to estimate the maximum $\mathrm{LPW}_{\text {vis }}$ values versus CCT using the phosphors listed in Table 5. The following constraints were used for the simulation: CCT $=$ variable $(100 \mathrm{~K}$ increments with a $100 \mathrm{~K}$ window), CRI $\geq 80,|\Delta(\mathrm{uv})| \leq 0.004$, and between 3 and 5 of the phosphor must be used. The results are shown in Fig. 29(b). For each maximum efficacy value, the corresponding CRI was 80 (lowest allowable value from the simulation constraints), which is not unexpected. One of the important results from this simulation study was that the predicted maximum efficacy decreases with higher CCT values.

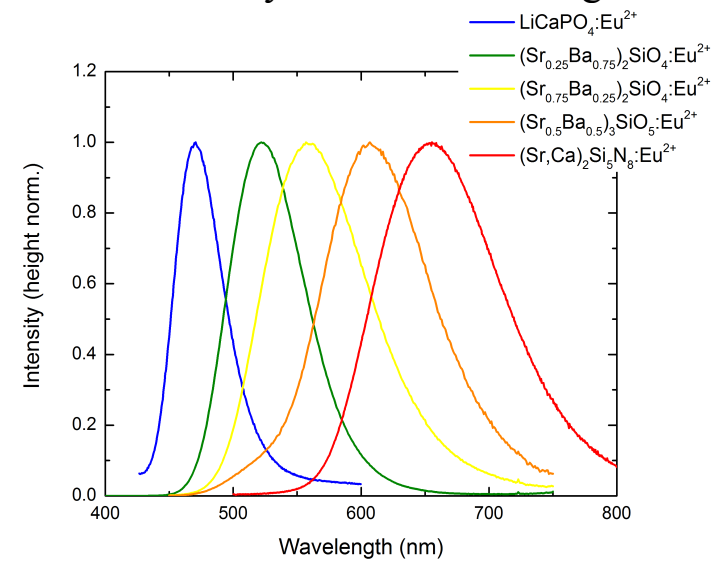

(a)

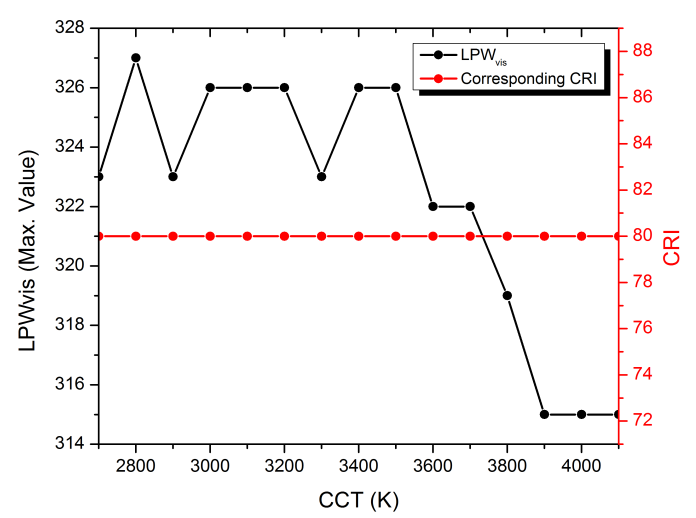

(b)

Fig. 29. (a) Normalized emission spectra of the individual phosphors used for the initial blend simulations. (b) Simulated maximum spectral efficacy versus CCT. The corresponding CRI is given for each point. Not unexpectedly, the CRI value is the lowest allowable based on the constraints.

Since not all of the phosphors were forced into the simulation, there were many blends that fulfilled the criteria that did not contain all five of the phosphors. An interesting result from this simulation is that the red phosphor was not included in any of the max-LPW vis blends. The broadband orange phosphor provided enough red to hit the minimum CRI target.

Based on this range of $\mathrm{LPW}_{\text {vis }}$ values, an LPW $_{\text {opt,nuv }}$ can be estimated. Assuming a Stokes efficiency of $67 \%$ (a representative value when going from $390 \mathrm{~nm}$ to the $\lambda_{\text {dom }}$ at each $\mathrm{CCT}$ ) and a conversion/extraction efficiency of $85 \%$, an $\mathrm{LPW}_{\text {vis }}$ of $\sim 320 \mathrm{~lm} / \mathrm{W}$ translates into an $\mathrm{LPW}_{\text {opt,nUV }}$ of $\sim 182 \mathrm{~lm} / \mathrm{W}$. The target efficacy $\left(\mathrm{LPW}_{\text {opt,nUV }}\right.$ at $390 \mathrm{~nm}$ ) set forth in the proposal was $175 \mathrm{~lm} / \mathrm{W}$. At the actual CCT target of

Table 5. Individual phosphors used for the initial blend simulations.

\begin{tabular}{|c|c|}
\hline Plue $-\mathrm{LiCaPO}_{4}: \mathrm{Eu}^{2+}$ & $\begin{array}{c}\text { Peak Emission } \\
\text { Wavelength (nm) }\end{array}$ \\
\hline Green - $\left(\mathrm{Sr}_{0.25} \mathrm{Ba}_{0.75}\right)_{2} \mathrm{SiO}_{4}: \mathrm{Eu}^{2+}$ & 471 \\
\hline Yellow $-\left(\mathrm{Sr}_{0.75} \mathrm{Ba}_{0.25}\right)_{2} \mathrm{SiO}_{4}: \mathrm{Eu}^{2+}$ & 521 \\
\hline Orange $-\left(\mathrm{Sr}_{0.5} \mathrm{Ba}_{0.5}\right)_{3} \mathrm{SiO}_{5}: \mathrm{Eu}^{2+}$ & 659 \\
\hline Red $-\left(\mathrm{Sr}_{2} \mathrm{Ca}_{2}\right)_{2} \mathrm{Si}_{5} \mathrm{~N}_{8}: \mathrm{Eu}^{2+}$ & 652 \\
\hline
\end{tabular}

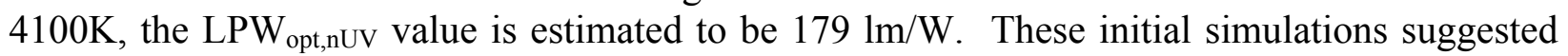
that the efficacy target of $175 \mathrm{LPW}_{\text {opt,nuv }}$ could be achieved

After making several initial blends and testing them, it became apparent that the particular group of phosphors listed in Table 5 has some drawbacks. The blue phosphor $\left(\mathrm{LiCaPO}_{4}: \mathrm{Eu}^{2+}\right)$, peaking at $471 \mathrm{~nm}$, was not blue enough, making it difficult to hit the black body line at CCTs near $4000 \mathrm{~K}$. The other leading candidates for blue phosphors were $\mathrm{Sr}_{5}\left(\mathrm{PO}_{4}\right)_{3} \mathrm{Cl}$ :Eu ${ }^{2+}(\mathrm{SCAP})$ with an emission peak at $450 \mathrm{~nm}$ and $\mathrm{Ba}_{3} \mathrm{MgSi}_{2} \mathrm{O}_{8}: \mathrm{Eu}^{2+}$ with a peak at $436 \mathrm{~nm}$. Based primarily on efficiency, but also efficacy, considerations, SCAP proved to be a better option. The green phosphor was slightly modified by increasing the Sr-to-Ba ratio to push the peak to $535 \mathrm{~nm}$. 
Shifting the blue phosphor to a lower wavelength and the green phosphor to a higher wavelength opened a gap in that part of the spectrum, which was filled by the introduction of a different phosphor, $\mathrm{Ca} 8 \mathrm{Mg}\left(\mathrm{SiO}_{4}\right)_{4} \mathrm{Cl}_{2}: \mathrm{Eu}^{2+}$ (emission peak at $508 \mathrm{~nm}$ ). The yellow phosphor performed very well and was not changed in the next iteration. The orange $\left(\left(\mathrm{Sr}_{0.5} \mathrm{Ba}_{0.5}\right)_{3} \mathrm{SiO}_{5}: \mathrm{Eu}^{2+}\right)$ and red $\left((\mathrm{Sr}, \mathrm{Ca})_{2} \mathrm{Si}_{5} \mathrm{~N}_{8}: \mathrm{Eu}^{2+}\right)$ phosphors were replaced by a single orange/red phosphor $\left((\mathrm{Sr}, \mathrm{Ba})_{2} \mathrm{Si}_{5} \mathrm{~N}_{8}: \mathrm{Eu}^{2+}\right)$ that had an emission peak located between the two $(615 \mathrm{~nm})$.

This new group of five phosphors (see Table 6 and Fig. 30(a)) was used in a second round of spectral simulations. The constraints of the second round of simulations were similar to the first round with the exception that a tighter $\Delta(\mathrm{uv})$ was required. Instead of allowing between \pm 0.004 , the acceptable $\Delta(\mathrm{uv})$ values were limited to \pm 0.003 . The results of the simulation are shown in Fig. 30(b). With this second set of five phosphors, the simulation predicts a higher maximum $\mathrm{LPW}_{\text {vis }}$ at each CCT than for the first set of values even with the smaller $\Delta$ (uv) window. Again, with the exception of the $4000 \mathrm{~K}$ point, the maximum LPW $_{\text {vis }}$ values occurred when the CRI was at the lowest allowable level. Using the same method as before, an estimation of the

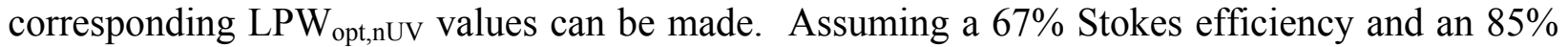
conversion/extraction efficiency, the $\mathrm{LPW}_{\text {opt,nuv }}$ at $4100 \mathrm{~K}$ is $187 \mathrm{~lm} / \mathrm{W}$. Again, this indicates that hitting our target of $175 \mathrm{~lm} / \mathrm{W}_{\text {opt,nUV }}$ at a Table 6. Individual phosphors used for the initial $\mathrm{CRI} \geq 80$ should be possible with this set of phosphors.

Numerous blends with the phosphors shown in Table 6 were made and tested. As we will show later, the blend that eventually hit our target came from this combination of five phosphors.

\begin{tabular}{|c|c|}
\hline blend simulations. & $\begin{array}{c}\text { Peak Emission } \\
\text { Wavelength (nm) }\end{array}$ \\
\hline Blue $-\mathrm{Sr}_{5}\left(\mathrm{PO}_{4}\right)_{3} \mathrm{Cl}_{2} \mathrm{Eu}^{2+}$ & 450 \\
\hline Green $1-\mathrm{Ca}_{8} \mathrm{Mg}_{(}\left(\mathrm{SiO}_{4}\right)_{4} \mathrm{Cl}_{2}: \mathrm{Eu}^{2+}$ & 508 \\
\hline Green $2-\left(\mathrm{Sr}_{0.4} \mathrm{Ba}_{0.6}\right)_{2} \mathrm{SiO}_{4}: \mathrm{Eu}^{2+}$ & 535 \\
\hline Yellow - $\left(\mathrm{Sr}_{0.75} \mathrm{Ba}_{0.25}\right)_{2} \mathrm{SiO}_{4}: \mathrm{Eu}^{2+}$ & 559 \\
\hline Orange/Red $-\left(\mathrm{Sr} B{ }_{2}\right)_{2} \mathrm{Si}_{5} \mathrm{~N}_{8}: \mathrm{Eu}^{2+}$ & 615 \\
\hline
\end{tabular}

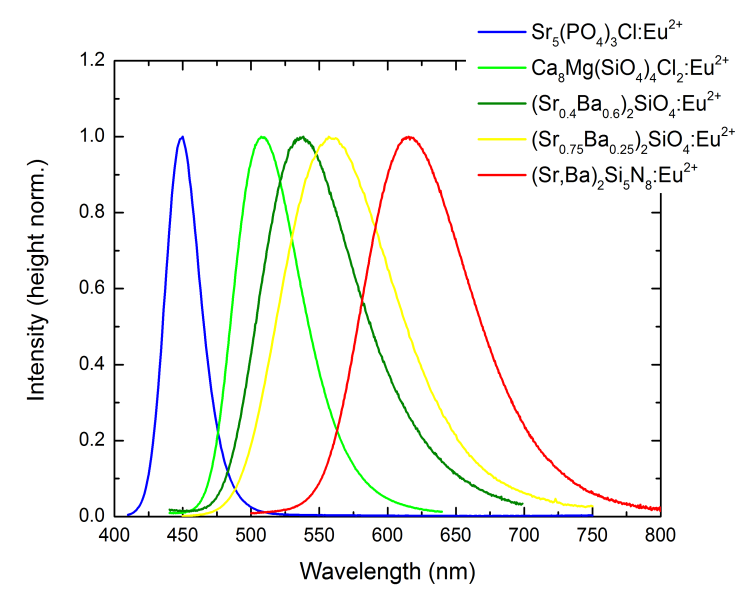

(a)

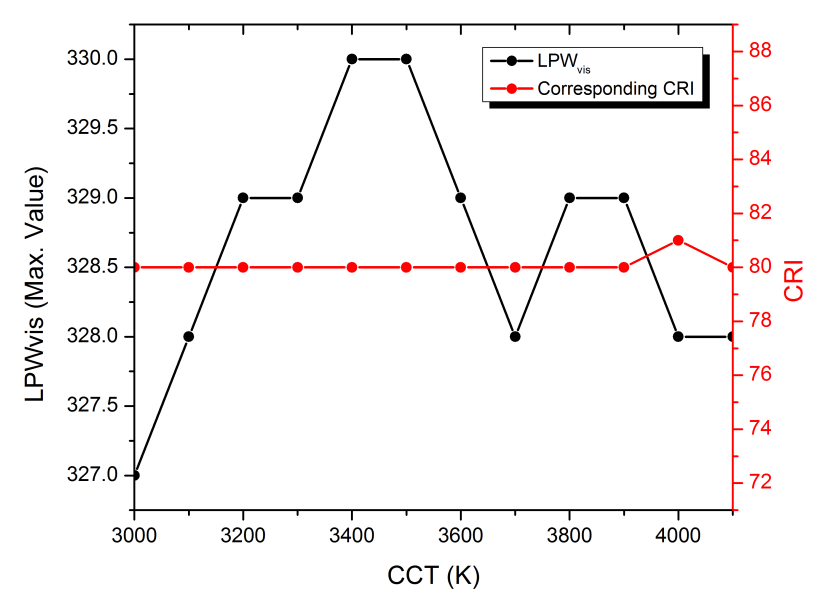

(b)

Fig. 30. (a) Normalized emission spectra of the individual phosphors used for the second round of blend simulations. (b) Simulated maximum spectral efficacy versus CCT using the second batch of five phosphors. The corresponding CRI is given for each point. 
From our earlier analysis of near-UV phosphors, we chose three candidate blue phosphors, LiCaPO4: $\mathrm{Eu}^{2+}, \mathrm{Ba}_{3} \mathrm{MgSi}_{2} \mathrm{O}_{8}: \mathrm{Eu}^{2+}(\mathrm{BAM})$, and $\mathrm{Sr}_{5}\left(\mathrm{PO}_{4}\right)_{3} \mathrm{Cl}: \mathrm{Eu}^{2+}$ (SCAP) for application in $\mathrm{nUV}$ LEDs. In order to determine the best among them for use in our white light blends they were tested for their conversion efficiency. Three remote phosphor hemispherical domes $2.54 \mathrm{~cm}$ in diameter and $1 \mathrm{~mm}$ thick were made with 4 weight percent of the phosphor powder mixed with silicone and cured. Once formed these domes were excited with a $380 \mathrm{~nm}$ light source using the same experimental settings, and the spectral power distribution for each phosphor was generated. The emission plots were analyzed and the conversion efficiency of each blue option was calculated. The results showed that SCAP has much higher conversion efficiency than the other two phosphors as shown in Fig. 31 and will be used in every white light blend. The peak emission of the phosphors and the FWHM are shown in Table 7 below.

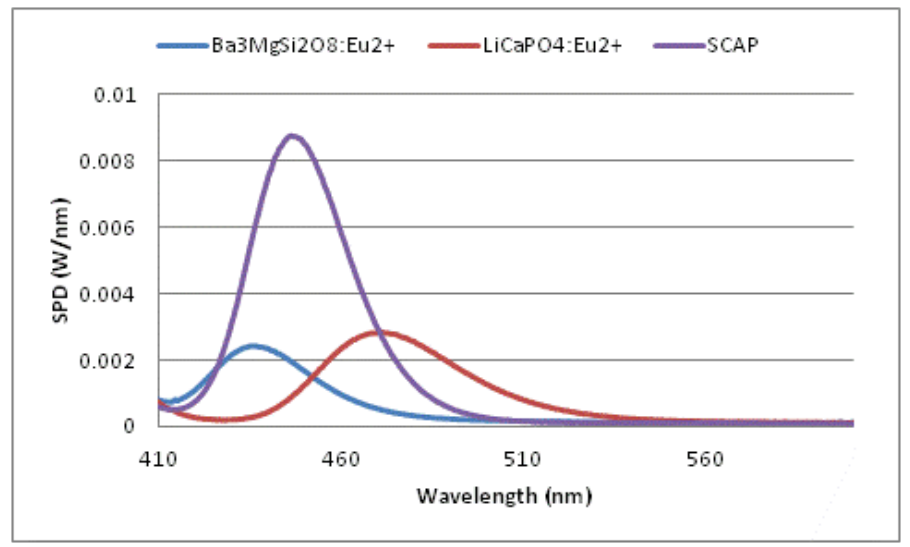

Fig. 31. Spectral power distribution of emitted blue light from UV phosphor conversion layer excited at $380 \mathrm{~nm}$ light source.

Table 7. Peak and FWHM emission of the three blue phosphors hemispherical shells excited with $380 \mathrm{~nm}$ light source.

\begin{tabular}{|l|c|c|c|}
\hline Phosphor & Peak Emission (nm) & FWHM (nm) & $\begin{array}{c}\text { Conversion } \\
\text { Efficiency }\end{array}$ \\
\hline $\mathrm{LiCaPO}_{4}: \mathrm{Eu}^{2}$ & 470 & 45.7 & $16 \%$ \\
\hline $\mathrm{Ba}_{3} \mathrm{MgSi}_{2} \mathrm{O}_{8}: \mathrm{Eu}^{2+}$ & 436 & 35.3 & $13 \%$ \\
\hline $\mathrm{Sr}_{5}\left(\mathrm{PO}_{4}\right)_{3} \mathrm{Cl}: \mathrm{Eu}^{2+}$ & 446 & 31.8 & $33 \%$ \\
\hline
\end{tabular}

The emission spectra from different green, yellow, orange and red phosphors were used to simulate the emission properties of white light blends. The simulations lead to a possible phosphor solution for a target lpw of 180 and CRI $>80$ for a CCT of $4200 \mathrm{~K}$. A dome is then formed using this phosphor blend and the emission profile of the sample is measured in a sphere. The CCT and the departure of the color point from the black body curve are measured. If the sample is observed to be within a three MacAdam ellipse we measure the lumen output of the phosphor converted light, and the total light output from the package to calculate the $\mathrm{lpw}_{\mathrm{opt}}$ for this configuration. If the sample is off of the black body curve, the blend composition is modified by interpolating the observed data, and new domes are made. This process was repeated until we achieved the desired color point.

We started with a three phosphor blend of SCAP for blue, a yellow phosphor $\mathrm{Lu}_{3} \mathrm{Al}_{5} \mathrm{O}_{12}: \mathrm{Ce}^{3+}$, and a red phosphor, $\mathrm{Sr}_{2} \mathrm{Si}_{5} \mathrm{~N}_{8}: \mathrm{Eu}^{2+}$. We could not achieve the proper color temperature with this blend. The CRI was sufficiently high, but the lumen output was below our stated goal of $175 \mathrm{lpw}_{\mathrm{opt}}$ (Table 8). In order to increase the lumen output, another green phosphor was added to the blend. In the first trials, $\mathrm{CaMg}\left(\mathrm{SiO}_{4}\right) \mathrm{Cl}$ : $\mathrm{Eu}$ was used for this purpose. 
Unfortunately, while the CRI improved with the addition of this phosphor, we did not see a significant increase in $\mathrm{lpw}_{\mathrm{opt}}$ (Table 9). Our next attempt to increase our lumen output was to add a fifth phosphor to the blend. We added a yellow emitting $\left(\mathrm{Sr}_{\mathrm{x}} \mathrm{Ba}_{1-\mathrm{x}}\right)_{2} \mathrm{SiO}_{4}: \mathrm{Eu}^{2+}$ to the blend. While the CRI of these blends still exceeds 80 , and CCTs from $3500 \mathrm{~K}$ all the way up to $4500 \mathrm{~K}$ could be achieved, we were still short of the target of $175 \mathrm{lpw}_{\mathrm{opt}}$ (Table 10).

We therefore dropped the green Lu-garnet phosphor from the mix, and tried to reach our targets with the remaining four phosphors: SCAP, $\left(\mathrm{Sr}_{\mathrm{x}} \mathrm{Ba}_{1-\mathrm{x}}\right)_{2} \mathrm{SiO}_{4}: \mathrm{Eu}^{2+}, \mathrm{CaMg}\left(\mathrm{SiO}_{4}\right) \mathrm{Cl}$ : Eu, and $\mathrm{Sr}_{2} \mathrm{Si}_{5} \mathrm{~N}_{8}: \mathrm{Eu}^{2+}$. However this still proved to be the wrong set of phosphors as the lpw values for these blends remained low. Table 11 shows the results of these blends. For our final set of experiments, only the 2-1-4 silicates were used as well as the 2-5-8 nitride for red. With these three phosphors we were able to create a blend with $180 \mathrm{lpw}_{\text {opt }}$ and a CRI of 78 (Table 12). Fig. 32 shows the emission spectra of this phosphor blend. While the CRI of this blend was just a little below our target, it achieved results closest to the goal, while the color point remained on the black body locus.

The goals stated in the plan have proven to be very difficult to achieve simultaneously. We can produce very high CRI light, but with limited lumen output (see Table 13). We can also achieve very high lumen output, but with low CRI (see Table 14). In the few cases where we were able to achieve both high lumens and high CRI we were not able to remain on the BBL. This is a problem with LED phosphors with broad emission and excitation bands. Self absorption of radiation, together with the absorption of the emission from short wavelength phosphors by the long wavelength phosphors, produces a very nonlinear process. This makes simulating the systems extremely difficult. A linear interpolation of the blend composition even in the neighborhood of a desired color point fails to produce a desired phosphor blend. This is true for both near-UV and blue LED solid state lighting systems.

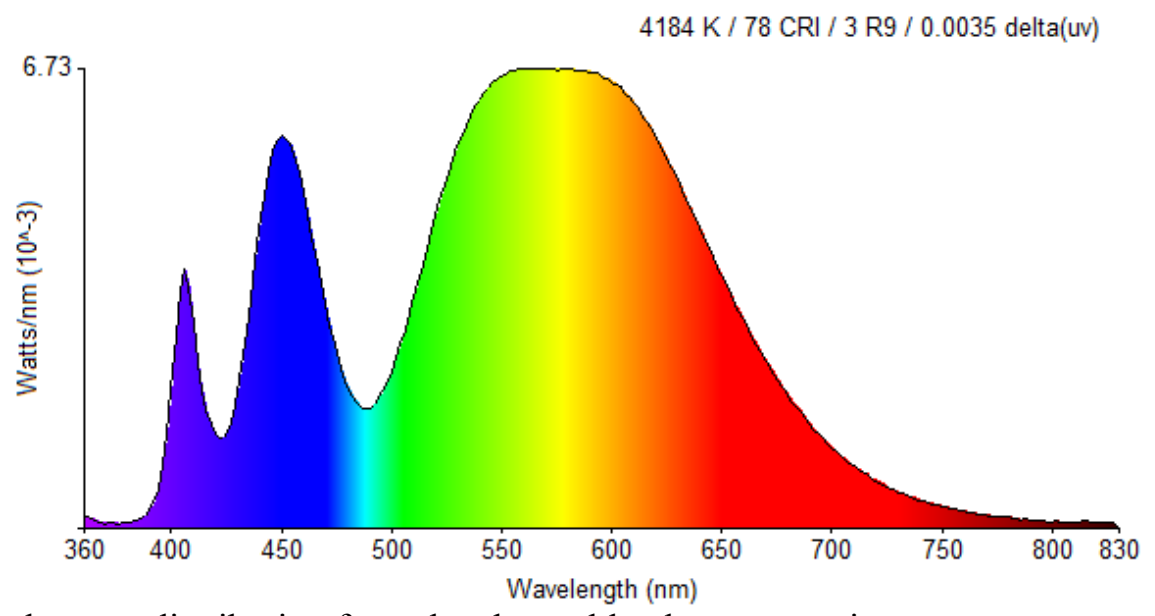

Fig. 32. Spectral power distribution from the closest blend to out requirements.

Table 8. Blend results (wt.\% of each phosphor) using $\mathrm{Lu}_{3} \mathrm{Al}_{5} \mathrm{O}_{12}: \mathrm{Ce}^{3+}$ as a yellow phosphor. SCAP $=$ $\mathrm{Sr}_{5}\left(\mathrm{PO}_{4}\right)_{3} \mathrm{Cl}: \mathrm{Eu}^{2+}, 2-5-8 \mathrm{SrSiN}=\mathrm{Sr}_{2-\mathrm{x}} \mathrm{Eu}_{\mathrm{x}} \mathrm{Si}_{5} \mathrm{~N}_{8}$, distance is amount from black body curve.

\begin{tabular}{|c|c|c|c|c|c|c|}
\hline SCAP & $\begin{array}{c}\text { Lu } \\
\text { garnet }\end{array}$ & $\begin{array}{c}\mathbf{2 - 5 - 8} \\
\text { SrSiN }\end{array}$ & CCT & Distance & CRI & LPW $_{\text {opt }}$ \\
\hline 73.4 & 25.0 & 1.7 & 3200 & $1.14 \mathrm{e}-3$ & 87 & 114.23 \\
\hline 60.5 & 37.0 & 2.5 & 3250 & $-1.59 \mathrm{e}-3$ & 89 & 121.70 \\
\hline 73.8 & 24.6 & 1.7 & 3050 & $1.58 \mathrm{e}-3$ & 87 & 118.07 \\
\hline
\end{tabular}




\begin{tabular}{|l|l|l|l|l|l|l|}
\hline 73.8 & 24.6 & 1.7 & 3000 & $2.46 \mathrm{e}-3$ & 86 & 112.23 \\
\hline 73.8 & 24.6 & 1.7 & 3050 & $2.63 \mathrm{e}-3$ & 87 & 105.80 \\
\hline 61.0 & 36.6 & 2.5 & 3400 & $-1.05 \mathrm{e}-3$ & 89 & 127.07 \\
\hline 61.0 & 36.6 & 2.5 & 3400 & $-4.40 \mathrm{e}-4$ & 89 & 121.45 \\
\hline 74.5 & 24.8 & 0.7 & 5300 & $2.26 \mathrm{e}-2$ & 81 & 143.51 \\
\hline 73.8 & 24.6 & 1.7 & 3050 & $1.42 \mathrm{e}-3$ & 87 & 120.11 \\
\hline 62.0 & 35.9 & 2.2 & 3677 & $-2.50 \mathrm{e}-4$ & 91 & 127.19 \\
\hline 62.8 & 35.2 & 2.1 & 3800 & $1.12 \mathrm{e}-3$ & 90 & 130.66 \\
\hline 63.5 & 34.3 & 2.3 & 3600 & $-7.04 \mathrm{e}-3$ & 91 & 118.63 \\
\hline 63.8 & 34.2 & 2.0 & 4000 & $-9.00 \mathrm{e}-4$ & 92 & 128.46 \\
\hline 63.8 & 34.2 & 2.0 & 4000 & $-1.27 \mathrm{e}-3$ & 91 & 139.36 \\
\hline 63.8 & 34.2 & 2.0 & 3900 & $-1.27 \mathrm{e}-3$ & 91 & 160.37 \\
\hline 63.9 & 34.3 & 1.8 & 4400 & $-7.20 \mathrm{e}-3$ & 93 & 142.68 \\
\hline 64.9 & 33.2 & 1.9 & 4400 & $-3.71 \mathrm{e}-3$ & 93 & 118.35 \\
\hline
\end{tabular}

Table 9. Blend results (wt.\% of each phosphor) with the addition of $\mathrm{CaMg}\left(\mathrm{SiO}_{4}\right) \mathrm{Cl}: \mathrm{Eu}$, which helped increase the CRI but did not improve the $\mathrm{lpw}_{\text {opt }}$ SCAP $=\mathrm{Sr}_{5}\left(\mathrm{PO}_{4}\right)_{3} \mathrm{Cl}: \mathrm{Eu}^{2+}, 2-5-8 \mathrm{SrSiN}=\mathrm{Sr}_{2-\mathrm{x}} \mathrm{Eu}_{\mathrm{x}} \mathrm{Si}_{5} \mathrm{~N}_{8}$, distance is amount from black body curve.

\begin{tabular}{|c|c|c|c|c|c|c|c|}
\hline SCAP & $\begin{array}{c}\text { Lu } \\
\text { garnet }\end{array}$ & $\mathbf{C a M g}\left(\mathbf{S i O}_{\mathbf{4}}\right) \mathbf{C I}$ & $\begin{array}{c}\mathbf{2 - 5 - 8} \\
\mathbf{S r S i N}\end{array}$ & $\mathbf{C C T}$ & Distance & CRI & LPW $_{\text {opt }}$ \\
\hline 69.6 & 27.9 & 2.6 & 15.3 & 4412 & $-2.87 \mathrm{e}-3$ & 96 & 154.49 \\
\hline 72.7 & 24.7 & 2.7 & 15.3 & 4468 & $-5.72 \mathrm{e}-3$ & 95 & 143.83 \\
\hline 72.7 & 24.4 & 3.0 & 17 & 4199 & $-1.04 \mathrm{e}-2$ & 93 & 140.63 \\
\hline 74.2 & 22.8 & 3.1 & 17 & 3826 & $-1.25 \mathrm{e}-2$ & 92 & 153.46 \\
\hline 78.4 & 18.8 & 2.9 & 15.3 & 4561 & $-1.18 \mathrm{e}-2$ & 93 & 153.42 \\
\hline
\end{tabular}

Table 10. Blend results (wt.\% of each phosphor) with the addition of a yellow silicate $\left(\left(\mathrm{Sr}_{\mathrm{x}} \mathrm{Ba}_{1-}\right.\right.$ $\left.\left.{ }_{2}\right)_{2} \mathrm{SiO}_{4}: \mathrm{Eu}^{2+}\right)$ to increase lumens. This helped however $\mathrm{lpw}_{\text {opt }}$ not high enough. $\mathrm{SCAP}=\mathrm{Sr}_{5}\left(\mathrm{PO}_{4}\right)_{3} \mathrm{Cl}: \mathrm{Eu}^{2+}$, Lu-garnet $=\mathrm{Lu}_{3} \mathrm{Al}_{5} \mathrm{O}_{12}: \mathrm{Ce}^{3+}, 2-5-8 \mathrm{SrSiN}=\mathrm{Sr}_{2-\mathrm{x}} \mathrm{Eu}_{\mathrm{x}} \mathrm{Si}_{5} \mathrm{~N}_{8}$, distance is amount from black body curve

\begin{tabular}{|c|c|c|c|c|c|c|c|c|}
\hline SCAP & $\begin{array}{c}\text { Lu } \\
\text { garnet }\end{array}$ & $\begin{array}{c}\mathbf{2 - 1 - 4} \\
\text { Silicate }\end{array}$ & $\begin{array}{c}\text { CaMg- } \\
\left(\mathbf{S i O}_{\mathbf{4}} \mathbf{)} \mathbf{C l}\right.\end{array}$ & $\begin{array}{c}\mathbf{2 - 5 - 8} \\
\mathbf{S r S i N}\end{array}$ & $\mathbf{C C T}$ & Distance & CRI & $\mathbf{L P W}_{\text {opt }}$ \\
\hline 57.3 & 28.6 & 10.3 & 2.1 & 1.8 & 3550 & $6.95 \mathrm{e}-3$ & 79 & 177.09 \\
\hline 59.6 & 27.1 & 9.7 & 1.9 & 1.7 & 3541 & $1.48 \mathrm{e}-2$ & 77 & 182.16 \\
\hline 59.9 & 26.9 & 9.6 & 1.9 & 1.7 & 3721 & $1.25 \mathrm{e}-2$ & 78 & 162.23 \\
\hline 60.5 & 24.2 & 12.1 & 2.2 & 1.0 & 4212 & $2.20 \mathrm{e}-2$ & 73 & 188.65 \\
\hline 61.1 & 24.4 & 12.2 & 1.2 & 1.0 & 4108 & $1.44 \mathrm{e}-2$ & 74 & 170.11 \\
\hline 63.8 & 23.0 & 10.2 & 2.0 & 1.0 & 4410 & $1.74 \mathrm{e}-2$ & 77 & 175.06 \\
\hline 68.8 & 18.4 & 9.4 & 1.2 & 2.1 & 3448 & $-5.67 \mathrm{e}-3$ & 83 & 153.17 \\
\hline 70.1 & 16.8 & 8.4 & 2.5 & 2.1 & 3623 & $-1.46 \mathrm{e}-3$ & 84 & 167.62 \\
\hline 70.8 & 17.0 & 8.8 & 2.0 & 1.4 & 4402 & $1.40 \mathrm{e}-3$ & 83 & 159.59 \\
\hline 71.0 & 17.0 & 8.8 & 1.7 & 1.4 & 4555 & $7.62 \mathrm{e}-4$ & 83 & 155.15 \\
\hline 70.3 & 16.9 & 9.8 & 1.7 & 1.3 & 4513 & $3.84 \mathrm{e}-3$ & 80 & 158.20 \\
\hline 71.3 & 16.3 & 8.1 & 2.4 & 1.9 & 3973 & $-8.40 \mathrm{e}-4$ & 85 & 163.61 \\
\hline
\end{tabular}




\begin{tabular}{l|l|l|l|l|l|l|l|l|}
71.2 & 16.2 & 8.1 & 2.4 & 2.1 & 3816 & $-3.09 \mathrm{e}-3$ & 85 & 160.06 \\
\hline
\end{tabular}

Table 11. Blend results (wt.\% of each phosphor) for a four phosphor blend. Both $\mathrm{lpw}_{\mathrm{opt}}$ and CRI decreased over the three phosphor blend. SCAP $=\mathrm{Sr}_{5}\left(\mathrm{PO}_{4}\right)_{3} \mathrm{Cl}: \mathrm{Eu}^{2+}, 2-1-4$ silicate $=\left(\mathrm{Sr}_{\mathrm{x}} \mathrm{Ba}_{1-\mathrm{x}}\right)_{2} \mathrm{SiO}_{4}: \mathrm{Eu}^{2+}$, 2-5-8 $\mathrm{SrSiN}=\mathrm{Sr}_{2-\mathrm{x}} \mathrm{Eu}_{\mathrm{x}} \mathrm{Si}_{5} \mathrm{~N}_{8}$, distance is amount from black body curve

\begin{tabular}{|c|c|c|c|c|c|c|c|}
\hline SCAP & $\begin{array}{c}\mathbf{2 - 1 - 4} \\
\text { Silicate }\end{array}$ & $\mathbf{C a M g ( S i O 4 ) C I}$ & $\begin{array}{c}\mathbf{2 - 5 - 8} \\
\text { SrSiN }\end{array}$ & $\mathbf{C C T}$ & Distance & CRI & LPW $_{\text {opt }}$ \\
\hline 73.7 & 19.8 & 5.3 & 1.2 & 4300 & $1.49 \mathrm{e}-3$ & 74 & 177.41 \\
\hline 73.7 & 19.2 & 5.3 & 1.8 & 4000 & $4.30 \mathrm{e}-3$ & 78 & 153.97 \\
\hline 80.6 & 11.3 & 5.6 & 2.4 & 3958 & $-1.19 \mathrm{e}-2$ & 90 & 154.12 \\
\hline 78.1 & 15.6 & 4.7 & 1.6 & 3990 & $-3.50 \mathrm{e}-3$ & 77 & 166.78 \\
\hline 81.6 & 11.4 & 4.9 & 2.1 & 4363 & $-2.79 \mathrm{e}-3$ & 90 & 155.06 \\
\hline 80.3 & 12.8 & 4.8 & 2.1 & 4011 & $-9.79 \mathrm{e}-3$ & 87 & 154.92 \\
\hline 78.1 & 15.6 & 4.7 & 1.6 & 2537 & $-1.19 \mathrm{e}-2$ & 79 & 149.07 \\
\hline 77.5 & 17.8 & 3.1 & 1.6 & 2537 & $-1.19 \mathrm{e}-2$ & 79 & 149.07 \\
\hline 77.5 & 17.8 & 3.1 & 1.6 & 3990 & $-3.47 \mathrm{e}-3$ & 77 & 166.78 \\
\hline 77.6 & 17.9 & 3.1 & 1.4 & 4115 & $-3.25 \mathrm{e}-3$ & 77 & 163.31 \\
\hline 77.0 & 18.5 & 3.1 & 1.4 & 4002 & $2.00 \mathrm{e}-4$ & 75 & 167.52 \\
\hline 82.2 & 14.7 & 2.1 & 0.9 & 3900 & $3.94 \mathrm{e}-3$ & 73 & 141.25 \\
\hline 82.2 & 14.7 & 2.1 & 0.9 & 3900 & $4.08 \mathrm{e}-3$ & 73 & 133.62 \\
\hline 82.2 & 14.7 & 2.1 & 0.9 & 3900 & $3.67 \mathrm{e}-3$ & 73 & 134.99 \\
\hline 75.7 & 20.4 & 2.7 & 1.2 & 4000 & $3.02 \mathrm{e}-3$ & 72 & 149.08 \\
\hline 75.7 & 20.4 & 2.7 & 1.2 & 4000 & $3.14 \mathrm{e}-3$ & 72 & 160.11 \\
\hline 75.7 & 20.4 & 2.7 & 1.2 & 4000 & $3.14 \mathrm{e}-3$ & 72 & 185.57 \\
\hline 74.8 & 20.1 & 2.7 & 2.4 & 3200 & $-5.30 \mathrm{e}-3$ & 74 & 166.11 \\
\hline 80.9 & 16.3 & 1.3 & 1.5 & 3000 & $2.55 \mathrm{e}-3$ & 69 & 141.54 \\
\hline 81.0 & 16.3 & 1.3 & 1.5 & 2950 & $2.81 \mathrm{e}-3$ & 68 & 133.20 \\
\hline 81.6 & 16.4 & 1.3 & 0.7 & 3644 & $9.78 \mathrm{e}-3$ & 67 & 153.85 \\
\hline 93.7 & 4.7 & 1.1 & 0.5 & 4000 & $3.48 \mathrm{e}-3$ & 80 & 88.82 \\
\hline
\end{tabular}

Table 12. Blend results (wt.\% of each phosphor) for a four phosphor blend. Using only the 2-1-4 silicates, and the 2-5-8 silicon nitride, we were able to achieve excellent results. SCAP $=$ $\mathrm{Sr}_{5}\left(\mathrm{PO}_{4}\right)_{3} \mathrm{Cl}: \mathrm{Eu}^{2+}, 2-1-4$ silicate $=\left(\mathrm{Sr}_{\mathrm{x}} \mathrm{Ba}_{1-\mathrm{x}}\right)_{2} \mathrm{SiO}_{4}: \mathrm{Eu}^{2+}, 2-5-8 \mathrm{SrSiN}=\mathrm{Sr}_{2-\mathrm{x}} \mathrm{Eu}_{\mathrm{x}} \mathrm{Si}_{5} \mathrm{~N}_{8}$, distance is amount from black body curve.

\begin{tabular}{|c|c|c|c|c|c|c|c|}
\hline SCAP & $\begin{array}{c}\mathbf{2 - 1 - 4} \\
\text { Silicate }\end{array}$ & $\begin{array}{c}\mathbf{2 - 1 - 4} \\
\text { Silicate }\end{array}$ & $\begin{array}{c}\mathbf{2 - 5 - 8} \\
\text { SrSiN }\end{array}$ & CCT & Distance & CRI & LPWopt \\
\hline 75.2 & 22.5 & & 2.3 & 4300 & $2.17 \mathrm{e}-2$ & 72 & 159.14 \\
\hline 81.3 & 16.3 & & 2.5 & 4000 & $5.59 \mathrm{e}-3$ & 79 & 154.88 \\
\hline 82.8 & 14.9 & & 2.3 & 4460 & $1.50 \mathrm{e}-3$ & 82 & 157.64 \\
\hline 81.4 & 14.7 & 1.6 & 2.3 & 4301 & $8.88 \mathrm{e}-4$ & 80 & 168.68 \\
\hline 80.1 & 14.4 & 3.2 & 2.2 & 4184 & $3.50 \mathrm{e}-3$ & 78 & 179.87 \\
\hline 80.5 & 14.5 & 2.7 & 2.3 & 3848 & $3.20 \mathrm{e}-3$ & 78 & 172.86 \\
\hline 80.5 & 14.5 & 2.7 & 2.3 & 4118 & $2.40 \mathrm{e}-3$ & 78 & 168.26 \\
\hline
\end{tabular}


Table 13. The high CRI blends (wt.\% of each phosphor); these all show lumen levels below what is required. $\mathrm{SCAP}=\mathrm{Sr}_{5}\left(\mathrm{PO}_{4}\right)_{3} \mathrm{Cl}: \mathrm{Eu}^{2+}$, Lu-garnet $=\mathrm{Lu}_{3} \mathrm{Al}_{5} \mathrm{O}_{12}: \mathrm{Ce}^{3+}, 2-1-4$ silicate $=\left(\mathrm{Sr}_{\mathrm{x}} \mathrm{Ba}_{1-\mathrm{x}}\right)_{2} \mathrm{SiO}_{4}: \mathrm{Eu}^{2+}, 2-$ 5-8 $\mathrm{SrSiN}=\mathrm{Sr}_{2-\mathrm{x}} \mathrm{Eu}_{\mathrm{x}} \mathrm{Si}_{5} \mathrm{~N}_{8}$, distance is amount from black body curve.

\begin{tabular}{|c|c|c|c|c|c|c|c|c|}
\hline SCAP & $\begin{array}{c}\text { Lu } \\
\text { garnet }\end{array}$ & $\begin{array}{c}\mathbf{2 - 1 - 4} \\
\text { Silicate }\end{array}$ & $\begin{array}{c}\text { CaMg- } \\
\mathbf{( S i O}_{\mathbf{4}} \mathbf{)} \mathbf{C l}\end{array}$ & $\begin{array}{c}\mathbf{2 - 5 - 8} \\
\mathbf{S r S i N}\end{array}$ & $\mathbf{C C T}$ & $\mathbf{D i s t a n c e}$ & $\mathbf{C R I}$ & $\mathbf{L P W}_{\text {opt }}$ \\
\hline 68.2 & 27.3 & & 2.5 & 2.1 & 4412 & $-2.87 \mathrm{e}-3$ & 96 & 154.49 \\
\hline 71.1 & 24.2 & & 2.6 & 2.2 & 4468 & $-5.72 \mathrm{e}-3$ & 95 & 143.83 \\
\hline 76.5 & 18.4 & & 2.8 & 2.3 & 4561 & $-1.18 \mathrm{e}-2$ & 93 & 153.42 \\
\hline 63.9 & 34.3 & & & 1.8 & 4400 & $-7.20 \mathrm{e}-3$ & 93 & 142.68 \\
\hline 70.9 & 23.8 & & 2.8 & 2.4 & 4199 & $-1.04 \mathrm{e}-2$ & 93 & 140.63 \\
\hline 64.9 & 33.2 & & & 1.9 & 4400 & $-3.71 \mathrm{e}-3$ & 93 & 118.35 \\
\hline 72.4 & 22.3 & & 2.9 & 2.5 & 3826 & $-1.25 \mathrm{e}-2$ & 92 & 153.46 \\
\hline 63.8 & 34.2 & & & 2.0 & 4000 & $-9.00 \mathrm{e}-4$ & 92 & 128.46 \\
\hline 63.8 & 34.2 & & & 2.0 & 3900 & $-1.27 \mathrm{e}-3$ & 91 & 160.37 \\
\hline 63.8 & 34.2 & & & 2.0 & 4000 & $-1.27 \mathrm{e}-3$ & 91 & 139.36 \\
\hline 62.0 & 35.9 & & & 2.1 & 3677 & $-2.50 \mathrm{e}-4$ & 91 & 127.19 \\
\hline 63.5 & 34.3 & & & 2.3 & 3600 & $-7.04 \mathrm{e}-3$ & 91 & 118.63 \\
\hline 81.6 & & 11.4 & 4.9 & 2.1 & 4363 & $-2.79 \mathrm{e}-3$ & 90 & 155.06 \\
\hline 80.6 & & 11.3 & 5.6 & 2.4 & 3958 & $-1.19 \mathrm{e}-3$ & 90 & 154.12 \\
\hline 500 & 280 & & & 16 & 3800 & $1.12 \mathrm{e}-3$ & 90 & 130.66 \\
\hline
\end{tabular}

Table 14. High lumen blends (wt.\% of each phosphor). All of these blends have CRI $\sim 80 . \mathrm{SCAP}=$ $\mathrm{Sr}_{5}\left(\mathrm{PO}_{4}\right)_{3} \mathrm{Cl}: \mathrm{Eu}^{2+}, 2-1-4$ silicate $=\left(\mathrm{Sr}_{\mathrm{x}} \mathrm{Ba}_{1-\mathrm{x}}\right)_{2} \mathrm{SiO}_{4}: \mathrm{Eu}^{2+}, 2-5-8 \mathrm{SrSiN}=\mathrm{Sr}_{2-\mathrm{x}} \mathrm{Eu}_{\mathrm{x}} \mathrm{Si}_{5} \mathrm{~N}_{8}$, distance is amount from black body curve.

\begin{tabular}{|c|c|c|c|c|c|c|c|c|c|}
\hline SCAP & $\begin{array}{c}2-1-4 \\
\text { Silicate } \\
\end{array}$ & $\begin{array}{c}\text { Lu } \\
\text { garnet }\end{array}$ & $\begin{array}{c}2-1-4 \\
\text { Silicate }\end{array}$ & $\begin{array}{c}\mathrm{CaMg-} \\
\left(\mathrm{SiO}_{4}\right) \mathrm{Cl} \\
\end{array}$ & $\begin{array}{c}2-5-8 \\
\text { SrSiN } \\
\end{array}$ & CCT & Distance & CRI & LPWopt \\
\hline 60.5 & & 24.2 & 12.1 & 2.2 & 1.0 & 4212 & $2.20 \mathrm{e}-2$ & 73 & 188.65 \\
\hline 75.7 & & & 20.4 & 2.7 & 1.2 & 4000 & $3.14 \mathrm{e}-3$ & 72 & 185.57 \\
\hline 59.6 & & 27.1 & 9.7 & 1.9 & 1.7 & 3541 & $1.48 \mathrm{e}-2$ & 77 & 182.16 \\
\hline 80.1 & 14.4 & & 3.2 & & 2.2 & 4184 & $3.50 \mathrm{e}-3$ & 78 & 179.87 \\
\hline 73.7 & & & 19.8 & 5.3 & 1.2 & 4300 & $1.49 \mathrm{e}-2$ & 74 & 177.41 \\
\hline 57.3 & & 28.6 & 10.3 & 2.1 & 1.8 & 3550 & $6.95 \mathrm{e}-3$ & 79 & 177.09 \\
\hline 63.8 & & 23.0 & 10.2 & 2.0 & 1.0 & 4410 & $1.74 \mathrm{e}-2$ & 77 & 175.06 \\
\hline
\end{tabular}

Task 6 - Fabricate LED white-emitting lamp

It is believed that a light source built using nUV LEDs will suffer from less droop than one made from standard blue LEDs. To test this behavior of nUV LEDs, three light sources were built. One light source has $5 \mathrm{nUV}$ dies topped with a hemispherical glass dome of $3 / 4$ " diameter, another light source was built with 5 OSLON blue packages and another light source with 5 blue Golden Dragon plus packages. Two of these light sources are shown in Fig. 33.

Each light source was placed inside an integrating sphere and was powered at $50 \mathrm{~mA}$ to $800 \mathrm{~mA}$ at $50 \mathrm{~mA}$ intervals. The measurement used an "instant-on" approach, where the light source was powered and the scan performed immediately, then the LED is turned off. The measured optical power for each light source is shown in Fig. 34(a) and the ratio of these optical 
powers compared to a Golden Dragon Plus light kernel is shown in Fig. 36(b). As shown in these figures, the nUV light source is more efficient than the OSLON and Golden Dragon Plus light sources at elevated currents. Drooping is reduced in the nUV dies compared to OSLON dies and the Golden Dragon Plus dies show the most current droop. In terms of output power, when driven at $800 \mathrm{~mA}$, the nUV LEDs are $30 \%$ more efficient than the GD+ packages and $15 \%$ more efficient than the OSLON packages.

In order to test the effect of binning of the LED chips, two white light solutions were produced, one at $4000 \mathrm{~K}$ $\mathrm{CCT}$, and the other at $3000 \mathrm{~K}$ CCT. The spectral power distribution from both solutions was measured, first using a 380nm light kernel, and then a $410 \mathrm{~nm}$ light kernel. The

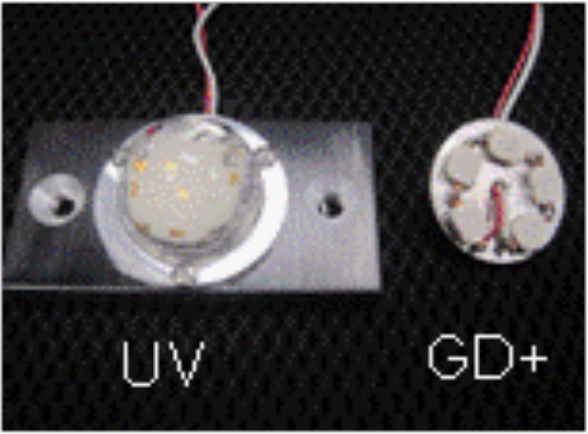

Fig. 33. Two light sources with five NUV dies (left) and five GD+(right) packages utilized in this study. CIE coordinates from the emission profiles were plotted and are shown in Fig. 35. The chromaticity coordinates for the $380 \mathrm{~nm}$ excitation and for the $410 \mathrm{~nm}$ excitation are within 2 MacAdam ellipses for both the $3000 \mathrm{~K}$ solution and the $4000 \mathrm{~K}$ solution. Thus, our binning requirements for nUV LEDs are much less stringent than that of standard blue LEDs. For blue LEDs we have a binning requirement of $+/-2.5 \mathrm{~nm}$, with near-UV LEDs we have a binning requirement of $+/-15 \mathrm{~nm}$.

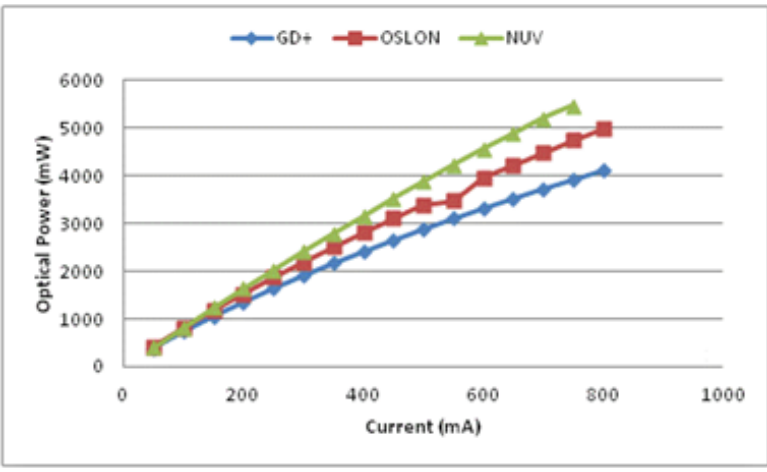

(a)

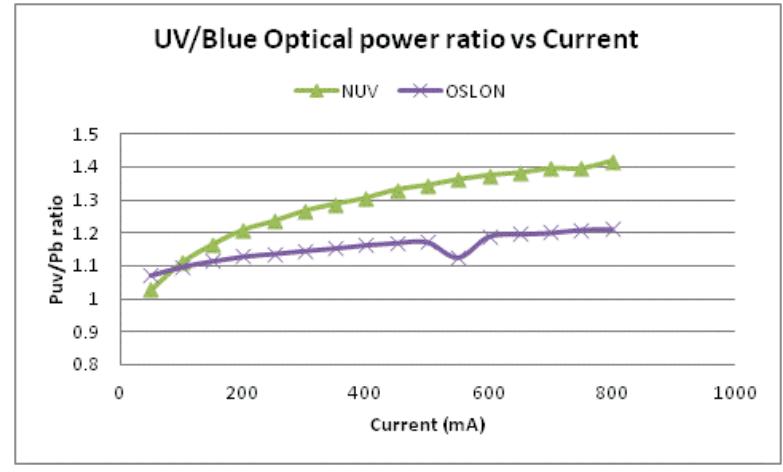

(b)

Fig. 34. (a) Measured optical power versus electrical current for 3 light sources, NUV, OSLON, and GD+ and (b) and the ratio of their respective optical power to the GD+ blue optical power.

The final form of the nUV lamp is shown in Fig. 36 that was used to test and optimize various blends to reach the target performance of $80 \mathrm{CRI}$ and $175 \mathrm{LPW}_{\text {opt,nUV }}$ at $4100 \mathrm{~K}$. The phosphor blend was applied in a remote configuration in the form of domes as shown as Fig. 36b. We had 24 blends with CCT between 3900K and 4200K, CRI between 72 and 91, and $\mathrm{LPW}_{\text {opt,nUV }}$ between 133 and 189. Hitting a target point by varying the blend composition could not be achieved using a linear interpolation scheme because of self-absorption from the individual phosphors and re-absorption by one phosphor from another, and the anti-correlation of CRI and efficacy at the targeted CCT. For example, we achieved high CRI blends of 86 and 93 with $137 \mathrm{LPW}_{\text {opt,nUV }}$ at $4118 \mathrm{~K}$, and $140 \mathrm{LPW}_{\text {opt,nUV }}$ at $4199 \mathrm{~K}$ respectively. The most efficacious

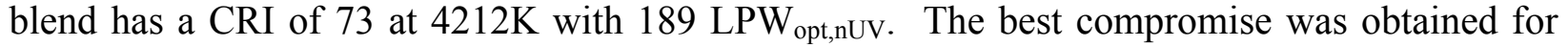
two blend compositions giving lamps with $\left(4184 \mathrm{~K}\right.$, CRI 78, $180 \mathrm{LPW}_{\text {opt,nuv}}$ ) and (4118 K, CRI 78, $168 \mathrm{LPW}_{\text {opt,nUV)}}$. 


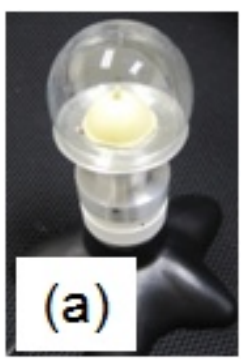

(a)

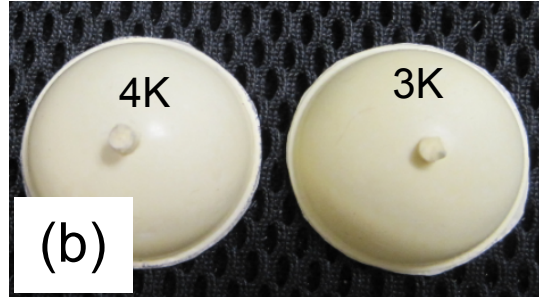

(b)

Fig. 36. Final lamp configuration (a) and sample phosphor domes (b) used for optimizing phosphor blends.

\subsection{CONCLUDING REMARKS}

From this work we have made several key observations relevant to designing solid state light sources using near-UV LED chips:

1) Reduced current droop allows the same light kernel to be used for both a $40 \mathrm{~W}$ and a $60 \mathrm{~W}$ replacement bulb. This can be done simply by increasing the drive current for the LEDs without the need to add extra LEDs to increase the light output.

2) We found silicates were the most promising phosphor for use with the near-UV LEDs. They produced some of the highest lumen output, with fairly high CRI values.

3) The blue phosphor used in the blend has the dominant effect on conversion efficiency since all of the phosphors in the blend will absorb the blue. If the efficiency of the blue phosphor used can be increased we can increase the overall package efficiency. The key to designing a more efficacious light source using nUV LEDs is to develop a very efficient blue emitting phosphor with a peak at $440 \mathrm{~nm}$ with a very narrow FWHM of $\sim 25 \mathrm{~nm}$ and $\mathrm{QE}>95$. Because of the required small Stokes shift of $>50 \mathrm{~nm}$, this is not going to be an easy task.

4) Another option to designing an efficient light source would be to find green, yellow, and red phosphors that absorb only the near-UV light, and are transparent in the visible. This choice would lead to white body color for the converter element instead of yellow. This is not possible for blue LEDs as the blue emission has to be absorbed by the phosphor blend, the blend will be intrinsically colored. This continues to be an issue with phosphor converted blue LEDs

\section{MILESTONES AND SUCCESS CRITERIA}

Task 1 - we have identified potential phosphor compositions $\left(20 \mathrm{Eu}^{2+}\right.$ and $\left.30 \mathrm{Ce}^{3+}\right)$, which are required for our new light source design. Task 2 - we have optimized synthesis conditions for the production of nanophosphor cores with QE $>94 \%$, which is required to reduce scattering, increasing extraction efficiency. Task 3 - we have successfully developed high QE ( 90\%) core/shell nanophosphors, which are required to improve the $\mathrm{QE}$ of the nanophosphor particles. Task 4 - Individual and blended phosphor coatings were prepared by EPD, which is required for the successful integration of the phosphor with the UV-LED. Task 5 - we have identified appropriate mixtures of 3-5 near-UV phosphors with high CCT and CRI, which is required for an optimal light source. Task 6 - we have fabricated a UV-LED with phosphors - success of all of 
the above tasks is required for the fabrication of a novel white-light source. Table 15 summarizes our success criteria.

Table 15. Milestones and success criteria

\begin{tabular}{|c|c|c|c|c|c|c|c|}
\hline Task & Description & Success metric & 1 & 2 & 3 & 4 & $\begin{array}{l}\text { Met } \\
\text { success } \\
\text { metric? }\end{array}$ \\
\hline 1 & $\begin{array}{l}\text { Identification of phosphors for } \\
\text { excitation in the spectral range of } 370- \\
410 \mathrm{~nm} \text { (OS, UCSD) }\end{array}$ & & & & & & YES \\
\hline 2 & $\begin{array}{l}\text { Synthesis and optimization of candidate } \\
\text { phosphors for quantum efficiency } \\
\text { greater than } 95 \% \text { (OS, UCSD) }\end{array}$ & $\mathrm{QE}>95 \%$ & $\bullet$ & & & & YES \\
\hline 3 & $\begin{array}{l}\text { Development of core/shell } \\
\text { nanophosphors (UCSD) }\end{array}$ & $\begin{array}{l}\text { QE same or better than bare } \\
\text { phosphor }\end{array}$ & $\bullet$ & $\bullet$ & $\bullet$ & $\bullet$ & YES \\
\hline 4 & $\begin{array}{l}\text { Successful development for integrating } \\
\text { the phosphor with the LED by } \\
\text { electrophoretic deposition (UCSD) }\end{array}$ & $\begin{array}{l}\text { Uniform EPD coverage, } \\
\text { controllable thickness for } \\
\text { both bare and core/shell } \\
\text { nanophosphors }\end{array}$ & $\bullet$ & $\bullet$ & $\bullet$ & • & YES \\
\hline 5 & $\begin{array}{l}\text { Development of phosphor blends for } \\
\text { white light generation (OS) }\end{array}$ & & $\bullet$ & $\bullet$ & $\bullet$ & $\bullet$ & YES \\
\hline 6 & $\begin{array}{l}\text { Fabrication of simple white light } \\
\text { sources using candidate phosphor } \\
\text { blends and LEDs with efficacy near } 140 \\
\text { LPW (OS) }\end{array}$ & & $\bullet$ & $\bullet$ & $\bullet$ & $\bullet$ & YES \\
\hline
\end{tabular}

\subsection{Comparison to MYPP plan}

A1.3 Down Converters Description: Explore new non-toxic, high-efficiency wavelength conversion materials for improved quantum yield and phosphor conversion efficiency for the purposes of creating warm white LEDs with a particular emphasis on improving spectral efficiency with high color quality and improved thermal stability.

As shown in Table 16, we were on target with the DOE MYPP.

\section{Deliverables}

Task 1 List of candidate phosphors for optimization including excitation, emission spectra and quantum efficiency (submitted in 2011 and in this report)

Task 2 List of optimized phosphors with excitation and emission spectra and quantum efficiency (submitted in 2012 and this report)

Task 3 A detailed description of the core/shell nanophosphors, with comparisons to bare phosphor powders (submitted in 2011, 2012 and this report)

Task 4 An analysis of the two phosphor integration schemes: remote phosphor or phosphor powders deposited directly on the LED (submitted in this report)

Task 5 Report of phosphor blends describing the blend composition and performance (submitted in 2012 and this report)

Task $6 \quad$ Final report on performance of the white light source 
Table 16. Comparison to DOE MYPP

\begin{tabular}{|c|c|c|c|}
\hline Metric(s) & 2010 Status(es) & 2012 Target(s) & Our progress \\
\hline $\begin{array}{l}\text { Quantum yield }\left(25^{\circ} \mathrm{C}\right) \text { across visible } \\
\text { spectrum }\end{array}$ & $95 \%$ & $95 \%$ & $95 \%$ \\
\hline $\begin{array}{l}\text { Quantum yield }\left(150^{\circ} \mathrm{C}\right) \text { across visible } \\
\text { spectrum }\end{array}$ & $70 \%$ & $85 \%$ & No measurement \\
\hline $\begin{array}{l}\text { Thermal stability across visible spectrum } \\
\text { Relative quantum yield at } 150^{\circ} \mathrm{C} \text { vs } 25^{\circ} \mathrm{C}\end{array}$ & $85 \%$ & $90 \%$ & No measurement \\
\hline Ave. conversion efficiency (pc-LEDs) & $58 \%$ & $72 \%$ & $\begin{array}{l}56 \% \text { watts } \\
78 \% \text { photons }\end{array}$ \\
\hline Spectral full width half max. (FWHM) & $150 \mathrm{~nm}(\mathrm{red})$ & $<50 \mathrm{~nm}(\mathrm{red})$ & $104 \mathrm{~nm}$ \\
\hline Color stability (pc-LEDs) & $\begin{array}{r}\text { Color shift } 0.012 \mathrm{u} \\
\text { 'v' over life }\end{array}$ & $\begin{array}{c}\text { Color shift }< \\
0.004 \mathrm{u} \text { ' } \mathrm{v} \text { ' } \\
\text { over life } \\
\end{array}$ & Not tested yet \\
\hline LER & $\sim 315 \mathrm{~nm}$ & TBD & 328 \\
\hline
\end{tabular}

\section{Publications and Presentations Resulting from this Work}

\section{Publications}

1. Han, J.K., J.B. Talbot, J. McKittrick, "Synthesis and photoluminescence properties of $\mathrm{Y}_{2} \mathrm{O}_{3}: \mathrm{Eu}^{3+} / \mathrm{SiO}_{2}$ nano phosphor core/shell particles," ECS Trans., 28, 183 (2010).

2. Han, J.K., G.A. Hirata, J. B. Talbot and J. McKittrick, "Luminescence enhancement of $\mathrm{Y}_{2} \mathrm{O}_{3}: \mathrm{Eu}^{3+}$ and $\mathrm{Y}_{2} \mathrm{SiO}_{5}: \mathrm{Tb}$, Ce core particles with $\mathrm{SiO}_{2}$ shells," Mater. Sci. \& Eng. B, $176436-441$ (2011).

3. Han, J.K., M. Hannah, G.A. Hirata, J.B. Talbot, K.C. Mishra, and J. McKittrick, "Structure dependent luminescence characterization of green-yellow emitting $\mathrm{Sr}_{2} \mathrm{SiO}_{4}: \mathrm{Eu}^{2+}$ phosphors for near UV LEDs ," J. Lumin. 132, 106-10 (2012).

4. Hannah, M.E., A. Piquette, M. Anc, J. McKittrick, J. Talbot, J.K. Han and K. Mishra, “A study of blue emitting phosphors, $\mathrm{ABPO}_{4}: \mathrm{Eu}^{2+}(\mathrm{A}=\mathrm{K}, \mathrm{Li}, \mathrm{Na} ; \mathrm{B}=\mathrm{Ca}, \mathrm{Sr}, \mathrm{Ba})$ for UV LEDs," ECS Trans., 41, 19-25 (2012).

5. Oviedo, M.J., O.E. Contreras, R. Vazquez-Duhalt, G.G. Carbajal Arizaga, G.A. Hirata and J. McKittrick, "Photoluminescence of europium-activated hydroxyapatite nanoparticles in body fluids," Sci. Adv. Mater., 4, 1-5 (2012).

6. McKittrick, J., J.K. Han, J.I. Choi and J.B. Talbot, "Effect of powder synthesis and processing on luminescence properties," in TMS Proceedings, Materials Processing and Interfaces, eds. K. Morsi, F.D.S. Marquis, J.L. Meyer and A. El-Desouky, John Wiley \& Sons, 1, 497-504 (2012). (invited)

7. Oviedo, M. J., O. Contreras, C.E. Rodriguez, Z.S. Macedo, G. A. Hirata and J. McKittrick' "Photo- and radioluminescence characteristics of bismuth germanate nanoparticles by sol-gel and pressure-assisted combustion synthesis," Opt. Mater., 34, 1116-1119 (2012).

8. Oviedo, M. J., J.K. Han, O. Contreras, Z.S. Macedo, G. A. Hirata and J. McKittrick, "Photoluminescence of bismuth germanate phosphors with silica-shell structure," Physics Procedia, 29, 91-96 (2012)

9. Han, J.K., M.E. Hannah, A. Piquette, J.B. Talbot, K.C. Mishra and J. McKittrick "Sol-gel synthesis of single phase, high quantum efficiency $\mathrm{LiCaPO}_{4}: \mathrm{Eu}^{2+}$ phosphors", J. Solid 
State Sci. Tech., 1, R37-R40 (2012).

10. Choi, J.I., E. Sluzky, M. Anc, A. Piquette, M.E. Hannah, K.C. Mishra, J. McKittrick and J.B. Talbot, "EPD of Phosphors for Display and Solid State Lighting Technologies," Key Eng. Mater., 507, 149-153 (2012).

11. Han, J. K., M. E. Hannah, A. Piquette, J. B. Talbot, K. C. Mishra, and J. McKittrick, "Nano- and submicron sized europium activated silicate phosphors prepared by a modified co-precipitation method." J. Solid State Sci. Technol., 1, R98-R102 (2012).

12. Han, J. K., M. E. Hannah, A. Piquette, J. Micone. G. A. Hirata, J. B. Talbot, K. C. Mishra, and J. McKittrick, "Europium-activated barium/strontium silicates for near-UV light emitting diode applications," J. Lumin., 133, 184-187 (2013).

13. Han, J.K., M.E. Hannah, A. Piquette, J.B. Talbot, K.C. Mishra and J. McKittrick, "Europium activated $\mathrm{KSrPO}_{4}-\left(\mathrm{Ba}, \mathrm{Sr}_{2} \mathrm{SiO}_{4}\right.$ solid solutions as efficient and color tunable phosphors for near-UV light emitting diode applications," J. Am. Ceram Soc., 96, 15261532 (2013).

14. McKittrick, J., J.K. Han, M. Hannah, A. Piquette, J.I. Choi, M. Anc, M. Galvez, H. Lüger, J.B Talbot and K.C. Mishra, "Phosphor selection, and development for near-UV LEDs,” ECS J. Solid State Sci. Technol., 2, R3119-R3131 (2013). (invited).

15. Aburto-Crespo, M., T. C. Medrano-Pesqueira, M.E. Álvarez-Ramos, G. A. Hirata and J. McKittrick, "Synthesis and characterization of $\left(\mathrm{Lu}_{1-\mathrm{x}-\mathrm{y}} \mathrm{Y}_{\mathrm{x}} \mathrm{Ce}_{\mathrm{y}}\right)_{2} \mathrm{SiO}_{5}$ powders with fast decay time," J. Lumin., 136, 86-89 (2013).

16. Han, J.K., J. I. Choi, A. Piquette, M. Hannah, M. Anc, M. Galvez, J. B Talbot and J. McKittrick, "Phosphor development and integration for near-UV LEDs," ECS J. Solid State Sci. Technol., 2, R3138-R3147 (2013).

17. Choi, J.I., M. Anc, A. Piquette, M.E. Hannah, K.C. Mishra, J. McKittrick, J.B. Talbot, "Electrophoretic deposition of phosphors for white solid state lighting using near UVemitting LEDs," ECS J. Solid State Sci. Tech., 2, R1-R7 (2013).

18. Han, J.K., A. Piqutte, M. E. Hannah, G. A. Hirata, J. B. Talbot, K. C. Mishra and J. McKittrick, "Analysis of $\left(\mathrm{Ba}, \mathrm{Ca}, \mathrm{Sr}_{3} \mathrm{MgSi}_{2} \mathrm{O}_{8}: \mathrm{Eu}^{2+}, \mathrm{Mn}^{2+}\right.$ phosphors for application in solid state lighting," J. Lumin., 148, 1-5 (2014).

19. McKittrick, J., L.E. Shea-Rohwer, "Review: Novel designs and materials for whiteemitting light emitting diodes," J. Am. Ceram. Soc. (accepted) (invited).

20. Choi, J. I., M. Anc, A. Piquette, M. E. Hannah, K. C. Mishra, J. B. Talbot and J. McKittrick, "Electrophoretic deposition of nano- and micron-sized $\mathrm{Ba}_{2} \mathrm{SiO}_{4}: \mathrm{Eu}^{2+}$ phosphor particles," J. Electrochem. Soc. (accepted)

21. Lee, J., J.K. Han, Y.J. Kim, J.B. Talbot, J. McKittrick, "Morphology and particle size dependent luminescence properties of $\mathrm{Y}_{2} \mathrm{O}_{3}: \mathrm{Eu}^{3+}$ phosphors prepared by various synthetic methods," (in preparation).

22. Han, J.K., M.E. Hannah, A. Piquette, J. Micone, J.B. Talbot, K.C. Mishra and J. McKittrick, "Particle morphology and luminescence properties of green-emitting $\mathrm{Ba}_{2} \mathrm{SiO}_{4}: \mathrm{Eu}^{2+}$ through the hydrothermal reaction route," (in preparation).

23. Han, J.K., A. Piquette, M. E. Hannah, G. A. Hirata, J. B. Talbot, K. C. Mishra and J. McKittrick, " Sol-gel synthesis of single phase, high quantum efficiency $\mathrm{LiCaPO}_{4}: \mathrm{Eu}^{2+}$ phosphors," (in preparation) 


\section{Invited, keynote presentations and plenary lectures}

1. J. McKittrick, J. Tao, G.A. Hirata and E.J. Bosze, "White-emitting phosphors for solid state lighting," $3^{\text {rd }}$ Joint Workshop between UCSD/Korea University, UCSD, Sept. 11, 2009.

2. J. McKittrick, J.B. Talbot and K. Mishra, "Phosphors for near UV-Emitting LEDs for efficacious generation of white light," Dept. of Energy, July 28, 2010, Pittsburgh, PA. (invited).

3. J. McKittrick, J.H. Tao, J.K. Han, M. Hannah, G.A. Hirata, J.B. Talbot and K.C. Mishra, "Novel materials for white-emitting LEDs," $1^{\text {st }}$ International Conference on New Trends in Luminescence and Phosphor Materials, Oct. 4-8, 2010, Hermosillo, Mexico (plenary).

4. J. McKittrick, J.K. Han, J.B. Talbot and K.C. Mishra, "Phosphors for near UV-Emitting LEDs for efficacious generation of white light," Department of Energy R\&D Workshop, Feb. 2, 2011, San Diego, CA.

5. J. McKittrick, "Synthesis and characterization of phosphors for near UV LED applications," International Conference on Luminescence and Applications, Feb. 12, 2012, Hyderabad, India (keynote).

6. J. McKittrick, J. Han, J.I. Choi, J.B. Talbot, "Effect of powder synthesis and processing on luminescence properties," The Minerals, Metals \& Materials Society Meeting, March 11-15, 2012, Orlando, FL. (invited).

7. J. McKittrick, "The challenges of fabricating nanocrystalline luminescent materials," $1^{\text {st }}$ International Symposium on Nanoscience and Nanomaterials, March 16, 2012, Ensenada, Baja California, Mexico (plenary).

8. J.B. Talbot, J.K. Han, J.I. Choi and J. McKittrick, "Development of efficient solid state lighting materials," $243^{\text {rd }}$ American Chemical Society National Meeting, March 28, 2012, San Diego, CA (invited)

9. J. McKittrick, J.K. Han, M. Hannah, J.I. Choi, A. Piquette, M. Anc, J.B. Talbot and K.C. Mishra, "Phosphors for near UV-emitting LEDs for efficacious generation of white light.” Department of Energy R\&D Workshop, Jan. 31-Feb. 2, 2013, Long Beach, CA.

10. J. McKittrick, Jinkyu Han, Jae Ik Choi and Jan B Talbot, "Rare Earth Activated Oxides for Solid State Lighting," 8th Pacific Rim International Conference on Advanced Materials and Processes, Aug. 8, 2013, Waikoloa, HI (keynote).

11. J. McKittrick, J.K. Han, J.I. Choi and J.B. Talbot, "Solid state lighting: Design and development of phosphors for near UV LEDs," American Chemical Society Annual Meeting, Sept. 9, 2013, Indianapolis, IN (invited).

12. J. McKittrick, J.K. Han, J.I. Choi, M.E. Hannah, A. Piquette, M. Anc, J.B. Talbot, K.C. Mishra, "Development of phosphors for white emitting near UV LEDs," $224^{\text {th }}$ Electrochemical Society Meeting, October 27 - November 1, 2013, San Francisco, CA (invited).

\section{Contributed presentations}

1. J.K. Han, J.B. Talbot and J. McKittrick, "Synthesis of nano core/shell phosphor particles with cores of the luminescent material," Materials Research Society Spring Meeting, San Francisco, CA, April 7, 2010.

2. J.K. Han, J.B. Talbot and J. McKittrick, "Nanophosphor core/shell luminescent properties," UCSD Jacobs School of Engineering Research Expo, April 15, 2010. 
3. J.K. Han, J.B. Talbot and J. McKittrick, "Synthesis and photoluminescence properties of $\mathrm{Y}_{2} \mathrm{O}_{3}: \mathrm{Eu}^{3+} / \mathrm{SiO}_{2}, \mathrm{Y}_{2} \mathrm{SiO}_{5}: \mathrm{Ce}, \mathrm{Tb} / \mathrm{SiO}_{2}$ nanophosphor core/shell particles," The $217^{\text {th }}$ Electrochemical Society Meeting, Vancouver, BC, Canada, April 25-29, 2010.

4. J.K. Han, G. Hirata, J. Talbot and J. McKittrick, "Core/shell nanophosphors for LED lighting," $7^{\text {th }}$ Pacific Rim International Conference on Advanced Materials and Processing, Aug. 5, 2010, Cairns, Australia.

5. J.K, Han, M. Hannah, G.A. Hirata, J.B. Talbot, K.C. Mishra and J. McKittrick, "Preparation and luminescence characterization of green/yellow-emitting $\mathrm{Sr}_{2} \mathrm{SiO}_{4}: \mathrm{Eu}^{2+}$ for near UV-LEDs," $1^{\text {st }}$ International Conference on New Trends in Luminescence and Phosphor Materials, Oct. 4-8, 2010, Hermosillo, MX.

6. J.K. Han, M. Hannah, G.A. Hirata, J.B. Talbot, K.C. Mishra and J. McKittrick, "Core/shell phosphors for excitation by near UV radiation," $1^{\text {st }}$ International Conference on New Trends in Luminescence and Phosphor Materials, Oct. 4-8, 2010, Hermosillo, Mexico.

7. D. Cervantes-Vásquez, J.K. Han, G.A. Hirata and J. McKittrick, "White light emission from rare earth activated yttrium silicate nanoparticles covered with silica," $1^{\text {st }}$

International Conference on New Trends in Luminescence and Phosphor Materials, Oct. 4-8, 2010, Hermosillo, Mexico.

8. J. McKittrick, J.H. Tao, J.K. Han, J.B. Talbot, and K.C. Mishra, "Luminescence properties of $\mathrm{Ga}_{1-\mathrm{x}} \mathrm{Al}_{\mathrm{x}} \mathrm{N}$ and $\mathrm{Ga}_{1-\mathrm{x}-\mathrm{y}} \mathrm{Al}_{\mathrm{x}} \mathrm{Dy}_{\mathrm{y}} \mathrm{N}$ powders," $1^{\text {st }}$ International Conference on New Trends in Luminescence and Phosphor Materials, Oct. 4-8, 2010, Hermosillo, Mexico.

9. J. Han, M. Hannah, J.B. Talbot, K.C. Mishra and J. McKittrick, "Phosphors for near UVemitting LEDs for efficacious generation of white light," Jacobs School of Engineering Research Expo, April 14, 2011, La Jolla, CA.

10. M. Aburto, J. K. Han G. A. Hirata and J. McKittrick, "Synthesis and characterization of $\left(\mathrm{Lu}_{1-\mathrm{x}-\mathrm{y}} \mathrm{Y}_{\mathrm{x}} \mathrm{Ce}_{\mathrm{y}}\right)_{2} \mathrm{SiO}_{5}$ and $\left(\mathrm{Lu}_{1-\mathrm{m}-\mathrm{n}} \mathrm{Y}_{\mathrm{m}} \mathrm{Pr}_{\mathrm{n}}\right)_{2} \mathrm{SiO}_{5}$ powders with fast decay time," $16^{\text {th }}$ International Conference on Luminescence, June 26-July 1, 2011, Ann Arbor, MI.

11. J. K. Han, M. Hannah, A. Piquette, J. Micone, G. A. Hirata, J. B. Talbot, K. C. Mishra and J. McKittrick, "Europium activated barium/strontium silicates for near-UV light emitting diode applications," $16^{\text {th }}$ International Conference on Luminescence, June 26July 1, 2011, Ann Arbor, MI.

12. M. J. Oviedo, J.K. Han, S. Castro, O. Contreras, Z.S. Macedo, G. A. Hirata and J. McKittrick, "Photoluminescence of bismuth germanate phosphors with silica-shell structure," $16^{\text {th }}$ International Conference on Luminescence, June 26-July 1, 2011, Ann Arbor, MI.

13. J. I. Choi, G. A. Hirata, J. B. Talbot, K. C. Mishra and J. McKittrick, "Silicon-based nitride red phosphors for white light emitting diodes (LEDs)," $220^{\text {th }}$ "Electrochemical Society Meeting, Oct. 9-11, 2011, Boston, MA.

14. J. K. Han, M. E. Hannah, J. B. Talbot, K. C. Mishra, and J. McKittrick, "High quantum efficiency of $\left(\mathrm{Ba}_{1-\mathrm{x}} \mathrm{Eu}_{\mathrm{x}}\right)_{2} \mathrm{SiO}_{4}$ sub-micron sized green emitting phosphors for near UVemitting LEDs," $220^{\text {th }}$ Electrochemical Society Meeting, Oct. 9-11, 2011, Boston, MA.

15. M.E. Hannah, A. Piquette, M. Anc, J. McKittrick, J. Talbot, J. K. Han, and K.C. Mishra, "A Study of Blue Emitting Phosphors, $\mathrm{ABPO}_{4}: \mathrm{Eu}^{2+}(\mathrm{A}=\mathrm{K}, \mathrm{Li}, \mathrm{Na}$; $\mathrm{B}=\mathrm{Ca}, \mathrm{Sr}, \mathrm{Ba})$ for UV LEDs," $220^{\text {th }}$ Electrochemical Society Meeting, Oct. 9-11, 2011, Boston, MA. 
16. G. A. Hirata, J. K. Han, M. E. Hannah, J. B. Talbot, K. C. Mishra, and J. McKittrick, "Synthesis and luminescence properties of full-color $(\mathrm{Ba}, \mathrm{Ca}, \mathrm{Sr})_{3} \mathrm{MgSi}_{2} \mathrm{O}_{8}: \mathrm{Eu}^{2+}, \mathrm{Mn}^{2+}$ phosphors for near UV-Emitting LEDs," $220^{\text {th }}$ Electrochemical Society Meeting, Oct. 911, 2011, Boston, MA.

17. J. B. Talbot, J. I. Choi, E. Sluzky. K. C. Mishra and J. McKittrick, "Electrophoretic deposition of phosphors for UV-emitting LEDs," $220^{\text {th }}$ Electrochemical Society Meeting, Oct. 9-11, 2011, Boston, MA.

18. J. McKittrick, J.K. Han, M. Hannah, J.I. Choi, A. Piquette, M. Anc, J.B. Talbot and K.C. Mishra, "Phosphors for near UV-emitting LEDs for efficacious generation of white light." Department of Energy R\&D Workshop, Jan. 31-Feb. 2, 2012, Atlanta, GA.

19. J.I. Choi, E. Sluzky, M. Anc, A. Piquette, M.E. Hannah, K.C. Mishra, J.B. Talbot and J. McKittrick, "Electrophoretic deposition of phosphors for white light emitting diodes," Jacobs School of Engineering Research Expo, April 12, 2012, La Jolla, CA.

20. J.K. Han, M. Hannah, A. Piquette, J.B. Talbot, K.C. Mishra and J. McKittrick, "Phosphors for near UV-emitting LEDs for efficacious generation of white light," Jacobs School of Engineering Research Expo, April 12, 2012, La Jolla, CA.

21. N.L.M. Garcia, Y.J. Kim, J. McKittrick and G.A. Hirata Flores, "Luminescent $\mathrm{Gd}_{2} \mathrm{O}_{3}$ :Eu nanospheres synthesized by spray pyrolysis," $5^{\text {th }}$ international Conference on Surfaces, Materials and Vacuum, Sept. 24-28, 2012, Tuxtla Gutiérrez, Chipas, Mexico.

22. J. K. Han, J. B. Talbot, and J. McKittrick, "Luminescence properties of $(\mathrm{Ba}, \mathrm{Sr})_{3} \mathrm{MgSi}_{2} \mathrm{O}_{8}: \mathrm{Eu}^{2+}, \mathrm{Mn}^{2+}$," IEEE Photonics Conference, Sept. 26, 2012, Burlingame, CA

23. J.I. Choi, J. McKittrick and J.B. Talbot, "White-emitting solid stat lighting by electrophoretic deposition of phosphors," IEEE Photonics Conference, Sept. 26, 2012, Burlingame, CA

24. J. K. Han, M. E. Hannah, A. Piquette, J. B. Talbot, K. C. Mishra, and J. McKittrick, "Single phase, highly efficient $\mathrm{Li}\left(\mathrm{Ca}_{0.99-\mathrm{x}} \mathrm{Sr}_{\mathrm{x}} \mathrm{Eu}_{0.01}\right) \mathrm{PO}_{4}$ blue emitting phosphors for near UV-emitting LEDs," $222^{\text {nd }}$ Meeting of the Electrochemical Society, October 7-12, 2012, Honolulu, Hawaii.

25. J. I. Choi, M. Anc, A. Piquette, M. E. Hannah, K. C. Mishra, J. B. Talbot and J. McKittrick, "Highly efficient phosphor-converted white light emitting diode (LED) by electrophoretic deposition," $222^{\text {nd }}$ Meeting of the Electrochemical Society, October 7-12, 2012, Honolulu, Hawaii.

26. J.I. Choi, A. Piquette, M.E. Hannah, K.C. Mishra, J.B. Talbot and J. McKittrick, "Synthesis of $\mathrm{Sr}_{2} \mathrm{Si}_{3} \mathrm{~N}_{8}: \mathrm{Eu}^{2+}$ red-emitting phosphors for near UV LEDs," $222^{\text {nd }}$ Meeting of the Electrochemical Society, October 7-12, 2012, Honolulu, Hawaii.

27. Y.J. Kim, J. K. Han, J. Talbot and J. McKittrick. "Morphology and particle size dependent luminescence property of $\mathrm{Y}_{2} \mathrm{O}_{3}$ :Eu phosphors prepared by various synthetic method," $222^{\text {nd }}$ Meeting of the Electrochemical Society, October 7-12, 2012, Honolulu, Hawaii.

28. J. K. Han, M. E. Hannah, A. Piquette, J. B. Talbot, K. C. Mishra, and J. McKittrick, "Luminescence properties and stability improvement by $\mathrm{SiO}_{2}$ coating on various promising phosphors for near UV-emitting LEDs," $222^{\text {nd }}$ Meeting of the Electrochemical Society, October 7-12, 2012, Honolulu, Hawaii. 
29. J.I. Choi, J.B. Talbot and J. McKittrick, "Electrophoretic deposition of phosphors for near UV LED solid state lighting,"Jacobs School of Engineering Research Expo, April 18, 2013, La Jolla, CA.

30. J.I. Choi, M.E. Hannah, A. Piquette, M. Anc, J.B. Talbot, K.C. Mishra, J. McKittrick, "Comparison of electrophoretic deposition of nano- and micron-sized $\mathrm{Ba}_{2} \mathrm{SiO}_{4}$ : $\mathrm{Eu}^{2+}$ phosphor particles," $224^{\text {th }}$ Electrochemical Society Meeting, October 27 - November 1 , 2013, San Francisco, CA.

31. J. Lee, J.K. Han, J.I. Choi, J.B. Talbot and J. McKittrick, "Effect of synthesis methods on the powder characteristics and luminescence properties of nanophosphors," $224^{\text {th }}$ Electrochemical Society Meeting, October 27 - November 1, 2013, San Francisco, CA.

32. J.K. Han, M.E. Hannah, A. Piquette, J.B. Talbot, K.C. Mishra, J. McKittrick, "Luminescence characteristics of color tunable $\mathrm{Eu}^{2+}$-activated $\mathrm{KSrPO}_{4}-(\mathrm{Ba}, \mathrm{Sr})_{2} \mathrm{SiO}_{4}$ phosphors for near UV light emitting diode applications," $224^{\text {th }}$ Electrochemical Society Meeting, October 27 - November 1, 2013, San Francisco, CA. 